$$
\text { Pontifícia Universidade } \text { C }_{\text {Atólica }} \text { Do Rio de JaneIRo }
$$

Julio Damian Suni Mamani

\title{
Quantificação por Microscopia Digital do Microconstituinte Austenita-Martensita em Aço de Baixa Liga
}

\section{Dissertação de Mestrado}

\begin{abstract}
Dissertação apresentada como requisito parcial para obtenção do grau de Mestre pelo Programa de Pós-graduação em Engenharia de Materiais e de Processos Químicos e Metalúrgicos do Departamento de Engenharia de Materiais da PUC-Rio.
\end{abstract}

Orientador: Prof. Sidnei Paciornik Co-orientadora: Profa. Ivani de Souza Bott 


$$
\text { Pontifícia Universidade } \text { C }_{\text {Atólica }} \text { Do Rio de Janeiro }
$$

Julio Damian Suni Mamani

\section{Quantificação por Microscopia Digital do Microconstituinte Austenita-Martensita em Aço de Baixa Liga}

Dissertação apresentada como requisito parcial para obtenção do grau de Mestre pelo Programa de Pós-Graduação em Engenharia de Materiais e de Processos Químicos e Metalúrgicos do Departamento de Engenharia de Materiais do Centro Técnico Científico da PUC-Rio. Aprovada pela Comissão Examinadora abaixo assinada.

Prof $^{\circ}$. Sidnei Paciornik

Orientador e Presisdente

Departamento de Engenharia de Materiais - PUC-Rio

Profa. Ivani de Souza Bott

Co-Orientadora

Departamento de Engenharia de Materiais - PUC-Rio

Prof $^{\circ}$. Luís Felipe Guimarães de Souza

CEFET/RJ

$\operatorname{Dr}^{\circ}$ Marcos Henrique de Pinho Maurício

Departamento de Engenharia de Materiais - PUC-Rio

Prof ${ }^{\circ}$. José Eugênio Leal

Coordenador Pós-Graduação do Centro Técnico Científico - PUC-Rio

Rio de Janeiro, 13 de Março de 2013 
Todos os direitos reservados. É proibida a reprodução total ou parcial do trabalho sem autorização da universidade, do autor e do orientador.

\section{Julio Damian Suni Mamani}

Possui graduação em Engenharia Metalúrgica - Universidade Nacional San Agustín Arequipa-Perú, 1990. Possui experiência na indústria siderúrgica, processo de fabricação de aço. No campo da fundição, processo de fabricação de bolas de aço para trituração de minerais, fabricação de peças fundidas para a mineração, cimento e outros.

Ficha Catalográfica

Suni Mamani, Julio Damian

Quantificação por microscopia digital do microconstituinte Austenita-Martensita em aço de baixa liga / Julio Damian Suni Mamani; orientador: Sidnei Paciornik ; coorientadora: Ivani de Souza Bott. - 2013.

112 f. ; $30 \mathrm{~cm}$

Dissertação (mestrado) - Pontifícia Universidade Católica do Rio de Janeiro, Departamento de Engenharia de Materiais, 2013.

Inclui bibliografia

1. Engenharia de materiais - Teses. 2. Aço microligado. 3. Microconstituinte AM. 4. Microscopia. 5. Análise de imagens. I. Paciornik, Sidnei. II. Bott, Ivani de Souza. III. Pontifícia Universidade Católica do Rio de Janeiro. Departamento de Engenharia de Materiais. IV. Título. 
A minha esposa Margarita, Meus filhos Cristhian, Renato e Lúcia por serem a motivação mais forte para meu constante progresso.

Aos meus pais Estefa, Damian, A meus irmãos Gerardo, Ruperto e Felipa. 


\section{Agradecimentos}

À Deus por me deixar viver esta maravilhosa experiência. Por estar comigo durante esse tempo, por proteger a mim e a todos dos perigos da vida, por cuidar de minha família, auxiliando-me a realizar um dos maiores sonhos de minha vida.

Ao meu Orientador: professor Sidnei Paciornik, a quem admiro profundamente, pela paciência, pelos ensinamentos, pela grande contribuição na realização do trabalho experimental e pela interpretação dos resultados. Sua orientação constante foi um ponto decisivo para o resultado deste trabalho.

À minha Co-orientadora: professora Ivani de Souza Bott, pela orientação, ensinamentos e confiança, em mim depositadas durante todo o mestrado.

Ao professor Marcos Henrique de Pinho Maurício, por suas valiosas sugestões, pelo tempo e colaboração na realização de aquisição de imagens no microscópio óptico e microscópio eletrônico de varredura. Por suas palavras de motivação e de ensinamentos em todas as etapas da dissertação.

Ao Dr. Otavio da Fonseca Martins Gomes do Centro de Tecnologia Mineral - CETEM/MCT por suas valiosas sugestões, tempo e colaboração na realização das análises e captura de imagens no Laboratório CETEM.

Agradecimento ao Heitor Nuss Guimarães, Supervisor do Laboratório de Metalografia e Tratamento Térmico da DEMA-PUC-RIO, pelo auxilio eficaz na contribuição nos testes de ataque químico e por suas valiosas sugestões, tempo, colaboração e amizade.

A minha amiga Patrícia Pontón por sua amizade verdadeira, paciência, seus conselhos e seu conhecimento compartilhado nos momentos mais críticos da minha vida.

Aos colegas da PUC-Rio: Margarita Habran, Rafael de Araújo, José L. Montalvo, Mariella Cortez, Leydi del Rocio, Antonio Merma, Jerson Alvarado, Jose Vallejos, Alex de la Cruz, Julian Santos, Leslie Lopez, Luis Poma pelos grandes momentos compartilhados e amizade verdadeira.

À minha Mãe Estefa, a qual não tenho palavras para agradecer tudo o que fez por mim, por me dar a vida, pelo seu grande coração, pela educação, valores e 
pela liberdade. Obrigado, obrigado e obrigado mil vezes. Que Deus a ajude a restaurar a saúde o mais brevemente possível.

Ao meu Pai Damian, agradeço por seu grande coração, seu exemplo. Sei que do céu, vela por mim e por minha família.

À minha esposa Margarita por sua paciência, compreensão e partilha de vida. Estar comigo sobretudo quando mais preciso dela.

A meus filhos Cristhian, Renato e Lúcia, por fazerem parte da minha vida, por serem o que são, pelo incentivo recebido.

À mãe Lúcia Melgar, à Raquel Flores, à Jose Chavez, por seu apoio incondicional e pelas palavras de motivação e de estímulo nos momentos mais críticos da vida.

Ao Conselho Nacional de Desenvolvimento Científico e Tecnológico CNPq pela bolsa concedida para a realização dos estudos de mestrado.

À Pontifícia Universidade Católica do Rio de Janeiro PUC-Rio, pelo auxilio concedido e pela bolsa de desempenho acadêmico. 


\section{Resumo}

Suni Mamani, Julio Damian; Paciornik, Sidnei (Orientador); Bott, Ivani de Souza (Co-orientadora). Quantificação por Microscopia Digital do Microconstituinte Austenita-Martensita em Aço de Baixa Liga. Rio de Janeiro, 2013. 112p. Dissertação de Mestrado - Departamento de Ciência dos Materiais e Metalurgia, Pontifícia Universidade Católica do Rio de Janeiro.

O objetivo deste trabalho foi desenvolver uma metodologia para quantificação, por microscopia, do microconstituinte Austenita-Martensita (AM) em um aço de alta resistência e baixa liga (ABRL) da classe API5LX80. Foram obtidas imagens de Microscopia Ótica (MO) em campo claro e Eletrônica de Varredura (MEV), nos modos de elétrons secundários (SE) e retroespalhados (BSE). As imagens foram quantificadas por Processamento e Análise Digital de Imagens (PADI) e os resultados dos dois tipos de microscopia foram comparados. O principal desafio foi discriminar AM em meio a uma microestrutura multifásica complexa, com frações variadas de ferrita, bainita e do próprio AM. Para revelar a presença de AM foram testadas diferentes sequências de ataques químicos e eletrolíticos. Os resultados demostraram que o ataque químico misto, acrescentando um passo Lepera modificado gerou uma melhora acentuada do contraste em imagens de MO e de MEV no modo BSE. Imagens de MEV no modo SE apresentaram problemas de borda devido à posição do detector de elétrons, o que impediu a correta discriminação das regiões de AM. No modo BSE, a tensão de aceleração foi reduzida para $5 \mathrm{kV}$, para reduzir a penetração do feixe de elétrons e aumentar o contraste devido à fina camada de AM. Estas imagens foram filtradas para reduzir ruído e segmentadas por limiar simples para quantificar o AM. Nas imagens coloridas de $\mathrm{MO}$, o $\mathrm{AM}$ foi segmentado por limiares nos espaços de cor RGB e HSB e em seguida foi quantificado. Utilizando Microscopia Co-Localizada (MCL) foram obtidas imagens de campos idênticos no MEV e no MO, permitindo comparar as técnicas. Mostrou-se que, no mesmo aumento, a microscopia ótica tende a subestimar a fração de AM quando comparada à microscopia eletrônica de varredura, no modo BSE.

\section{Palavras-chave}

Aço microligado; microconstituinte AM; microscopia; análise de imagens. 


\section{Abstract}

Suni Mamani, Julio Damian; Bott, Ivani de Souza; Paciornik, Sidnei. Quantification of Austenite-Martensite in Low Alloy Steel by Image Analysis. Rio de Janeiro, 2013. 112p. MSc. Dissertation - - Departamento de Ciência dos Materiais e Metalurgia, Pontifícia Universidade Católica do Rio de Janeiro.

This dissertation proposed the development of a quantification method, by microscopy, of the microconstituent Martensite-Austenite (MA) in a High Strength Low Alloy (HSLA) steel of the API5LX80 class. Images were obtained by Optical Microscopy (OM) and Scanning Electron Microscopy (SEM), in secondary electron (SE) and backscattered electron (BSE) modes. Digital Image Processing and Analysis (IA) was employed to process and quantify the acquired images and compare the results of the two types of microscopy. The main challenge was to discriminate the MA amidst a complex multiphase microstructure with varying fractions of ferrite, bainite and MA itself. To reveal the MA different chemical and electrolytic etching sequences were tested. The results showed that a mixed combination with an extra step of modified LePera etchant issued the best contrast for both OM and BSE mode SEM. SEM images in SE mode showed edge problems due to the location of the electron detector, what prevented the correct discrimination of MA regions. The accelerating voltage in the BSE mode was reduced to $5 \mathrm{kV}$ which in turn decreased beam penetration and increase contrast due to the thin MA layer. These images were filtered to reduce noise and segmented by a simple threshold to quantify MA. In the color OM images MA was segmented by thresholds in the RGB or HSB color spaces and subsequently quantified. Employing Co-Site Microscopy images of identical fields acquired by OM and SEM, a direct comparison of the techniques was allowed. It was show that, for the same magnification, optical microscopy tends to underestimate the MA fraction when compared to electron microscopy in BSE mode.

\section{Keywords}

Microalloyed steel; AM Phase; microscopy; image analysis. 


\section{Sumário}

1 Introdução 18

1.1. Objetivos 19

1.1.1. Objetivo Geral 19

1.1.2. Objetivos Específicos 19

$\begin{array}{ll}\text { 1.2. Justificativa } & 19\end{array}$

2 Revisão Bibliográfica $\quad 21$

2.1. Aços de alta resistência e baixa liga (ABRL) 21

2.2. Evolução dos aços ABRL 21

2.3. O microconstituinte austenita-martensita (AM) 24

2.3.1. Mecanismo de formação do microconstituinte AM 24

2.3.2. Morfologia e quantidade do microconstituinte AM 25

2.3.3. Efeitos das características do microconstituinte AM sobre as propriedades mecânicas 26

2.3.4. Evolução da quantificação do Microconstituinte Austenita-Martensita (AM)

2.3.5. Sobre a quantificação do microconstituinte AM 28

2.4. Métodos de ataque químico $\quad 29$

2.4.1. Ataque químico Lepera 29

2.4.2. Ataque químico Ikawa 30

2.4.3. Ataque químico Misto 30

2.5. Microscopia Digital 30

2.5.1. Aquisição Automática de Imagens 31

2.5.2. Microscopia Co-Localizada 32

2.6. Processamento e Análise Digital de Imagens 33

2.6.1. Aquisição e digitalização da imagem 34

$\begin{array}{ll}\text { 2.6.2. Pré-processamento } & 36\end{array}$

2.6.3. Segmentação $\quad 40$

2.6.4. Pós-Processamento, extração de atributos 41

3 Materiais e Métodos $\quad 43$

3.1. Materiais $\quad 43$

3.2. Metodologia 43

3.2.1. Ataque químico $\quad 44$

3.2.2. Aquisição de imagens $\quad 48$

3.2.3. Microscopia Co-Localizada $\quad 49$

4 Resultados e Discussão $\quad 57$

4.1. Otimização do ataque químico e das técnicas de microscopia 57

4.1.1. Microscopia Ótica $\quad 57$

4.1.2. Microscopia eletrônica de varredura 62

4.1.3. Resumo de resultados qualitativos em imagens de MO

4.1.4. Resumo dos resultados qualitativos em imagens de MEV 74

4.2. Processamento e análise digital de imagens $\quad 76$

4.2.1. Microscopia Ótica 76

4.2.2. Microscopia eletrônica de varredura $\quad 79$

4.3. Quantificação da Fase AM - MO e MEV 87 
4.3.1. Procedimento de Registro para Microscopia Co-localizada

5 Conclusões

6 Referências bibliográficas

103

7 Apêndice

1067 


\section{Lista de figuras}

Figura 2.1 Evolução dos aços para a fabricação de tubos de grandes diâmetros (7)

Figura 2.2 Relação entre composição química, processamento e mecanismos envolvidos (8)

Figura 2.3 Microestruturas típicas de AM observadas em MEV (14). (a) O microconstituinte AM na forma alongada (forma de bastões) para o tempo de resfriamento rápido $(22 \mathrm{~s})$ de $800^{\circ} \mathrm{C} \mathrm{a} 500^{\circ} \mathrm{C}$. (b) $\mathrm{O}$ microconstituinte $\mathrm{AM}$ na forma massiva, muda à medida que aumenta o tempo de resfriamento (70 s) de $800^{\circ} \mathrm{C}$ a $500^{\circ} \mathrm{C}$. (c) Decomposição do microconstituinte $\mathrm{AM}$ em agregados de ferrita e carbonetos, quando o tempo de resfriamento torna-se muito longo, como mostra-se na Figura 2.4

Figura 2.4 Relação entre o tempo de resfriamento e a fração de AM (14)

Figura 2.5 (a) Quantificação de AM com técnica de contagem de pontos(22).

(b) Quantificação por PADI

Figura 2.6 Técnica da captura de imagens

Figura 2.7 Sequencia padrão de PADI (26)

Figura 2.8 Representação imagem Digital

Figura 2.9 Histograma de uma imagem digital

Figura 2.10 Imagem modo RGB e suas componentes (31)

Figura 2.11 Correção dos defeitos de iluminação, (A) Imagem Original (B) Fundo calculado (C) Imagem corrigida

Figura 2.12 Correção dos defeitos de ruído (A) Imagem Original, (B) Imagem original, ou microconstituinte + defeitos de ruído, marcadas pela cor vermelha na imagem, (C) Imagem com redução de ruído na zona marcada de cor amarela

Figura 2.13 Interface do algoritmo SIFT no FIJI

Figura 2.14 Segmentação AM da Imagem MO (a) Imagem Original (b) Imagem Segmentada (c) Histograma da segmentação

Figura 2.15 Segmentação do AM na imagem MEV (a) Imagem original (b)

Imagem segmentada (c) Histograma da segmentação

Figura 3.1 MO. Pré-ataque Nital 2\% tempo $10 \mathrm{~s}$, aumento $1000 \mathrm{X}$

Figura 3.2 Verificação de padrão de calibração no microscópio ótico 
Figura 3.3 Verificação de padrão de calibração no microscópio eletrônico de

Figura 3.4 Identificação de amostras com identação de micro dureza

Figura 3.5 Representação esquemática de captura de imagens de microscopia Co-Localizada MO-MEV 52

Figura 3.6 Funções disponíveis no software FIJI (38)

Figura 3.7 Caixa de diálogo para especificar as medições por análise (38) 53

Figura 3.8 Interface de análise - análise de partículas (38) 54

Figura 3.9 Interface de "Set Scale”(38) 56

Figura 4.1 MO Tempo de ataque $10 \mathrm{~s}$, aumento $1000 \mathrm{X}$

Figura 4.2 . MO. Tempo de ataque $15 \mathrm{~s}$, aumento $1000 \mathrm{X}$

Figura 4.3 MO. Tempo de ataque $20 \mathrm{~s}$, aumento $1000 \mathrm{X}$

Figura 4.4 MO. Tempo de ataque $25 \mathrm{~s}$, aumento 1000X

Figura 4.5 MO. Tempo de ataque $30 \mathrm{~s}$, aumento 1000X

Figura 4.6 MO Ataque Misto (1) $20 \mathrm{~s}$, (2) $160 \mathrm{~s}$, aumento 1000X 60

Figura 4.7 MO Ataque Misto (1) $25 \mathrm{~s}$, (2) $160 \mathrm{~s}$, aumento 1000X 60

Figura 4.8 Ataque misto acrescentando um passo Lepera Modificado (Lepera Modificado: 20 s, Ikawa 2: 160 s, Lepera Modificado: 5 s). MO aumento $1000 \mathrm{X}$

Figura 4.9 Ataque misto acrescentando um passo Lepera Modificado (Lepera Modificado: 25 s, Ikawa 2: 160 s, Lepera Modificado: 5 s). MO aumento $1000 X$

Figura 4.10 MEV (SE) Ataque 1: $3 \mathrm{~s}$. Ataque 2: $30 \mathrm{~s}$ aumento 4000X

Figura 4.11 MEV (BSE) Ataque 1: 3 s. Ataque 2: 30 s, aumento 4000X 64

Figura 4.12 MEV (SE) Ataque 1: $30 \mathrm{~s}$. Ataque 2: $80 \mathrm{~s}$, aumento 4000X 65

Figura 4.13. MEV (BSE) Ataque 1: $30 \mathrm{~s}$. Ataque 2: $80 \mathrm{~s}$, aumento $4000 \mathrm{X} \quad 65$

Figura 4.14 MEV (SE) Ataque 1: Nital 2\% $10 \mathrm{~s}$. Ataque 2: $80 \mathrm{~s}$, aumento $1000 \mathrm{X}$

Figura 4.15 MEV (SE) Misto (1) $25 \mathrm{~s}$, (2) $80 \mathrm{~s}$, aumento 1500X 67

Figura 4.16 MEV (SE) Misto (1) $25 \mathrm{~s}$, (2) $120 \mathrm{~s}$, aumento 3000X 67

Figura 4.17 MEV (SE) Misto (1) 25 s, (2) 160 s, aumento 3000X 68

Figura 4.18 MEV (SE) Misto (1) $25 \mathrm{~s}$, (2) $200 \mathrm{~s}$, aumento 3000X 68

Figura 4.19 MEV (BSE) Misto (1) $25 \mathrm{~s}$, (2) $200 \mathrm{~s}, 20 \mathrm{kV}$, aumento 5000X 69 
Figura 4.20 MEV (BSE) Misto (1) $25 \mathrm{~s}$, (2) $200 \mathrm{~s}, 25 \mathrm{kV}$, aumento 2000X 70

Figura 4.21 MEV(BSE), 20kV, Aumento 900X 71

Figura 4.22 MEV(BSE), 15kV, Aumento 900X 71

Figura 4.23 MEV(BSE), 10kV, Aumento 900X 72

Figura 4.24 MEV(BSE), 5kV, Aumento 900X 72

$\begin{array}{ll}\text { Figura 4.25 MEV(SE) } & 73\end{array}$

Figura 4.26 (a) MO original (método misto acrescentando um passo Lepera modificado) as regiões claras AM (b) Histograma da imagem original 77

Figura 4.27 (a) MO segmentação. (b) Ampliação imagem segmentada 77

Figura 4.28 MO Bordas das imagens binárias superposta às imagens originais da Figura 4 27(b). (a) Faixa extração de atributos 0 - infinito. (b) Faixa $\begin{array}{ll}\text { extração de atributos 0.1-infinito } & 78\end{array}$

Figura 4.29 MEV (SE) Defeito das bordas do microconstituinte AM $\begin{array}{ll}\text { incompletas } & 80\end{array}$

Figura 4.30 MEV (SE) (a)Imagem posição inicial (b) Imagem com amostra girada $180^{\circ} \quad 80$

Figura 4.31 Alinhamento automático de imagens, utilização função SIFT (Scale Invariant Feature Transform)

Figura 4.32 Segmentação (a) Imagem posição inicial da amostra (b) Imagem com giro de $180^{\circ}$ da amostra

Figura 4.33 (a)combinação das imagens da Figura 4 32, (b) Preenchimento de área do microconstituinte AM 82

Figura 4.34 (a) Imagem Original, (b) Imagem segmentada e quantificação de atributos $\quad 83$

Figura 4.35 Imagem Original MEV (BSE). Tensão $5 \mathrm{kV}$

Figura 4.36 (a) MEV (BSE) Imagem original (b) Imagem ampliada com redução de ruído

Figura 4.37 (a) MEV (BSE) Imagem segmentada (b) Imagem ampliada da segmentação

Figura 4.38 MEV (BSE) Bordas das imagens binárias superposta às imagens originais (a) Faixa extração de atributos 0 - infinito. (b) Faixa extração de atributos 0.2 - infinito. (c) Faixa extração de atributos 0.4- infinito. (d) Faixa extração de atributos 0.6 - infinito 
Figura 4.39 Alinhamento de imagem MO com respeito à imagem MEV (BSE), aumento 1000X

Figura 4.40 Alinhamento de imagem MEV(BSE) com respeito à imagem MO, aumento 900X

Figura 4.41 Seleção de Limiarização no espaço RGB (Red=87, Green=129, Blue=133), Imagens MO

Figura 4.42 Histogramas para limiarização no espaço RGB (Red=87,

Green=129, Blue=133), Imagens MO. Imagem Figura 4.41.

Figura 4.43 Limiarização no espaço espaço RGB (Red=87, Green=129, Blue=133), Imagens MO

Figura 4.44 Comportamento dos tons de corte RGB em imagens MO

Figura 4.45 Comparação de quantidade de partículas AM + partículas

espúrias em imagens $\mathrm{MO}$

Figura 4.46 Ampliação do gráfico da quantidade de partículas de AM em imagens de MO

Figura 4.47 Variação da fração volumétrica de AM mantendo ou eliminando partículas espúrias pequenas em imagens $\mathrm{MO}$

Figura 4.48 Seleção limiarização binaria imagem MEV(BSE)

Figura 4.49 Histograma limiarização binaria imagem MEV(BSE).

Limiar $=165$

Figura a 4.50 Limiarização binaria imagem MEV(BSE). Limiar=165

Figura 4.51 Comportamento faixa de limiarização em imagens binarias MEV

Figura 4.52 Comportamento de partículas de AM + elementos espúrios em imagens MEV

Figura 4.53 Ampliação do gráfico da quantidade de partículas de AM em imagens de $\mathrm{MEV}$

Figura 4.54 Comportamento \% fração AM em imagens MEV

Figura 4.55 Comparação de quantidade de partículas em imagensMO-MEV 98

Figura 4.56 Comparação de \% fração de volumem AM em imagens 
Figura 4.57 (a) Bordas das imagens binárias superpostas na imagem original MO. (b) Visão ampliada do retângulo amarelo em (a). Partículas vermelhas não foram medidas. Compare a quantidade de partículas dentro dos círculos vermelhos com a Figura 4.58b

Figura 4.58 (a) Bordas das imagens binarias superpostas na imagem original MEV(BSE) (b) Visão ampliada do retângulo amarelo em (a). Partículas vermelhas não foram medidas. Compare a quantidade de partículas dentro dos círculos vermelhos com a Figura 4.57b 


\section{Lista de tabelas}

Tabela 3.1 Composição química (\% em peso do aço API5LX80)

Tabela 3.2 Métodos de Ataque para Revelação do Microconstituinte AM.(14)(18)(36)

Tabela 3.3 Ataque químico Lepera modificado $\quad 46$

Tabela 3.4 Ataque químico Ikawa 46

Tabela 3.5 Método de ataque químico misto 47

Tabela 3.6 Ataque misto acrescentando um passo Lepera Modificado 48

$\begin{array}{ll}\text { Tabela 3.7 Magnificações do MO - MEV } & 50\end{array}$

Tabela 4.1 - Resultados MO, ataque Lepera modificado 73

Tabela 4.2 Resultados MO, ataque misto 74

Tabela 4.3 - Resultados MO, misto acrescentando um passo Lepera $\begin{array}{ll}\text { modificado } & 74\end{array}$

Tabela 4.4 - Resultado do ataque Ikawa $\quad 74$

Tabela 4.5 - Resultado do ataque misto, MEV modo SE 75

Tabela 4.6 - Resultado do ataque misto, MEV modo BSE 75

Tabela 4.7 - Resultado ataque misto, acrescentando um passo Lepera modificado, MEV modo BSE 76

Tabela 4.8 Extração de atributos na quantificação do microconstituinte AM, $\begin{array}{ll}\text { no MO } & 78\end{array}$

Tabela 4.9 Resultados MEV(BSE), pós-processamento e extração de atributos 86 Tabela 4.10 Extração de atributos na quantificação do microconstituinte AM em MO

Tabela 4.11 Extração de atributos na quantificação do microconstituinte AM em MEV

Tabela 4.12 Resultados de Analise da Quantificação Co-localizada do microconstituinte AM. (MO - MEV) 


\section{Lista de abreviaturas}

$\begin{array}{ll}\text { AM } & \text { Austenita-Martensita } \\ \text { MO } & \text { Microscopia Ótica } \\ \text { MEV } & \text { Microscopia Eletrônica de Varredura } \\ \text { ABRL } & \text { Aços de alta resistência e baixa liga } \\ \text { PADI } & \text { Processamento e Análise Digital de Imagens } \\ \text { API } & \text { American Petroleum Institute } \\ \text { EDTA } & \text { Ácido etileno diamino tetracético } \\ \text { CE } & \text { Carbono equivalente } \\ \text { ZTA } & \text { Zona termicamente afetada } \\ \text { NaF } & \text { Fluoreto de sódio } \\ \text { SIFT } & \text { Scale Invariant Feature Transform } \\ \text { FIJI } & \text { Fiji is Just ImageJ } \\ \text { MET } & \text { Microscopia eletrônica de transmissão } \\ \text { HIS } & \text { Matiz, Brilho e Saturação } \\ \text { BSE } & \text { Elétrons retro espalhados } \\ \text { SE } & \text { Elétrons secundários }\end{array}$




\section{1 \\ Introdução}

Os aços de Alta Resistência e Baixa Liga (ARBL) são muito utilizados atualmente nos sistemas de transporte de gás natural e petróleo, pois aliam resistência e boa tenacidade [1]. Estudos realizados em aços API 5L X-80 mostraram que a fração volumétrica de AM aumenta na medida em que o carbono equivalente (CE) aumenta para um mesmo teor de carbono. No entanto, a resistência ao impacto é fortemente dependente da fração volumétrica, da morfologia e da conectividade entre as partículas do microconstituinte AM. Quando a morfologia de AM é massiva e interconectada resulta em baixa tenacidade [2] [3].

O presente trabalho visa desenvolver uma metodologia para caracterização microestrutural do microconstituinte autenita-martensita (AM) em aços de alta resistência e baixa liga (ABRL). Este microconstituinte tem forte influência sobre as propriedades mecânicas. No entanto, a análise quantitativa deste microconstituinte exige técnicas de preparação específicas para revelá-lo em meio a uma microestrutura multifásica complexa com frações variadas de ferrita, bainita, dentre outras fases. Ainda que algumas destas técnicas tenham sido relatadas na literatura, não se encontram trabalhos de quantificação automatizada do AM. Além disso, imagens de microscopia ótica (MO) e Microscopia Eletrônica de Varredura (MEV) raras vezes são comparadas.

No presente trabalho utilizou-se microscopia ótica de luz refletida (MO), microscopia eletrônica de varredura (MEV) e processamento digital de imagens para automatizar a identificação do microconstituinte AM, quantificar sua fração de área e comparar os resultados destas diversas técnicas. 


\section{1}

\section{Objetivos}

\subsection{1}

\section{Objetivo Geral}

Caracterizar o microconstituinte Austenita-Martensita (AM) em aços de alta resistência e baixa liga (ABRL) por Microscopia Digital, utilizando rotinas de Análise Digital de Imagens desenvolvidas para quantificar automaticamente o AM comparando os resultados das diversas técnicas.

\section{1 .2}

\section{Objetivos Específicos}

- Estabelecer uma metodologia de ataque químico para a revelação seletiva do microconstituinte Austenita-Martensita (AM).

- Definir o modo ótimo de captura de imagens por microscopia eletrônica de varredura e por microscopia ótica das melhores condições de metodologia de ataque químico, para o processamento digital de imagens.

- Comparar os resultados das diversas metodologias de ataque químico e da captura de imagens.

\section{2}

\section{Justificativa}

Muito embora estejam disponíveis na literatura metodologias de identificação do microconstituinte $\mathrm{AM}$, procedimentos sistemáticos estatisticamente confiáveis e reprodutíveis ainda não estão bem estabelecidos.

A dificuldade reside na discriminação do microconstituinte AM ser realizado por processamento digital de imagens em uma matriz onde a microestrutura é complexa e multifásica.

Portanto, o presente trabalho justifica-se por ser uma proposta de solução para este problema. Dessa forma, estabelece-se uma metodologia contendo a 
preparação de amostras para a microscopia e para a análise de imagens que permitam a quantificação automática da presença do microconstituinte AM. 


\section{Revisão Bibliográfica}

O presente capítulo aborda os principais aspectos e características do microconstituinte Autenita-Martensita (AM), em aços de alta resistência e baixa liga (ABRL), assim como o estado da arte em Processamento e Análise Digital de Imagens (PADI), com foco nos métodos desenvolvidos para a quantificação automática das microestruturas.

\section{1}

\section{Aços de alta resistência e baixa liga ( $A B R L)$}

São aços microligados de baixo conteúdo de carbono, contendo teores muito pequenos de elementos de liga como nióbio, titânio e/ou vanádio. A adição destes elementos de liga promove propriedades mecânicas superiores ao comparados com os aços ABRL e com os aços C-Mn convencionais.

A melhora nas propriedades mecânicas dá-se devido ao tamanho pequeno do grão e aos fenômenos de precipitação, associados à composição química e ao processo de fabricação. Este processo envolve laminação controlada com controle restrito da temperatura e da quantidade de deformação, seguida por resfriamento acelerado ao final da laminação, ou por um tratamento térmico de normalização [1] [4] [5] [6].

\section{2}

\section{Evolução dos aços ABRL}

A partir dos anos 40, as chapas de aço foram fabricadas para a produção de tubos API 5LX60, com teor de carbono relativamente alto $(0,20 \%)$, contendo também vanádio para aumentar a resistência mecânica. $O$ processo de laminação a quente, dessas chapas, tinha como objetivo somente obter as dimensões necessárias. Suas propriedades mecânicas foram definidas posteriormente, ao se aplicar tratamento térmico de normalização [1]. 
Com a mudança de critério de fabricação dos aços, o desenvolvimento dos aços de alta resistência e baixa liga, mostrou nas décadas de 1960 a 1980, um grande progresso na relação entre a microestrutura e as propriedades mecânicas [4].

Na década de 1960, pesquisadores ingleses começaram a estudar um novo conceito de material: os aços microligados de alta resistência e baixa liga (ABRL), contendo teores muito pequenos de nióbio, que apresentaram uma característica muito peculiar durante sua conformação a quente [1] [7].

No início dos anos 70, o aço API 5L grau X-70, contendo Nb, V e $0,12 \%$ de C, foi introduzido pela primeira vez na Alemanha com o objetivo da construção de dutos de transporte de gás. Isso foi possível com o desenvolvimento da técnica de laminação controlada. Desde então, o grau X-70 provou ser um material, confiável para a implantação de vários projetos de dutos. O material foi melhorado a partir da técnica de laminação controlada e, uma vez aprimorado, pode ser soldado sem problemas [8] [7].

Graças à experiência bem sucedida do aço X-70 e ao desenvolvimento do processo de laminação controlada, com resfriamento acelerado, o aço API 5L grau X-80 entrou em uso pela primeira vez em 1985, no Projeto MEGAL II, na Alemanha, com a construção de uma seção de $3,2 \mathrm{~km}$ de dutos feitos com este material. O processo de laminação controlada com resfriamento acelerado permitiu a produção de materiais com grau X-80, microligado com nióbio e vanádio, com a quantidade de carbono mais baixa e com boa soldabilidade [9].

Finalmente, em 1992, houve a primeira construção de dutos feitos inteiramente de aço X-80. Uma extensão de $250 \mathrm{~km}$ de linha dutoviária foi realizada na Alemanha, utilizando 145.000 toneladas de aço. $O$ fator que incentivou esta grande obra foi a redução da espessura dos tubos, necessária para a operação, com uma pressão de 100 bars. [7] [9].

Adições de elementos de liga como o molibdênio, o cobre e o níquel e o processamento da laminação controlada, seguida de resfriamento acelerado, possibilitaram o desenvolvimento dos aços API para os graus superiores como X100 e X-120 [5] (Figura 2.1, Figura 2.2).

Esses procedimentos de laminação controlada podem ser seguidos de resfriamento acelerado, ou não. No caso do aço em estudo API XLX80, o procedimento de fabricação não contemplou o resfriamento acelerado. 
Via de regra, o processo de laminação controlada, com ou sem resfriamento acelerado, dá origem a uma microestrutura multifásica com a presença de ferrita, bainita, bainita granular, agregados de ferrita, carbetos e microconstituinte Austenita-Martensita (AM). A presença deste microconstituinte é discutida na próxima seção.

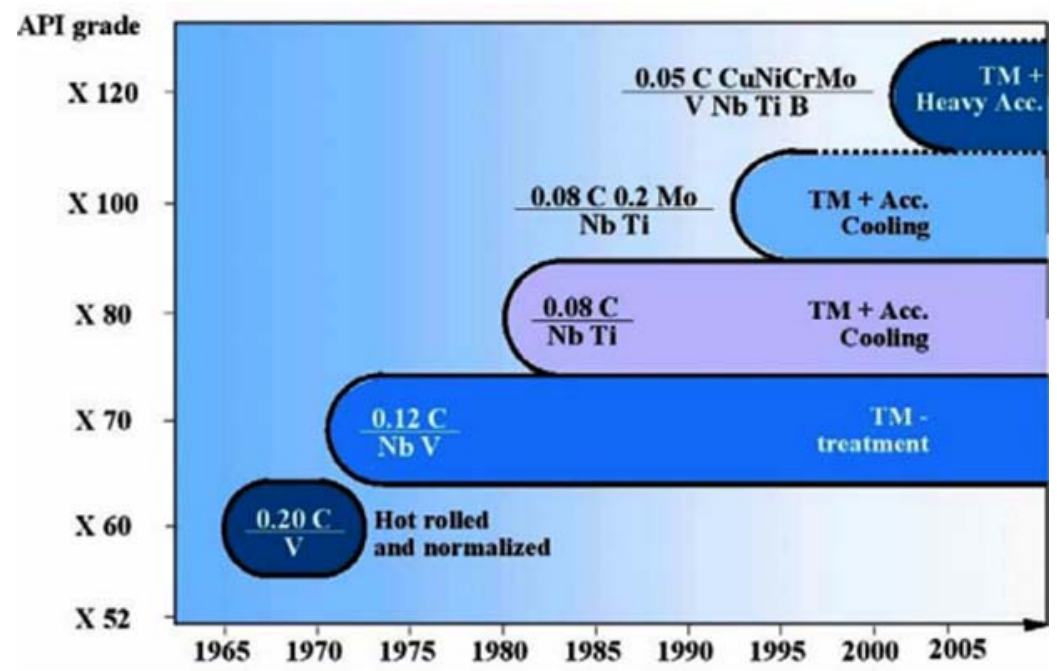

Figura 2.1 Evolução dos aços para a fabricação de tubos de grandes diâmetros [10].

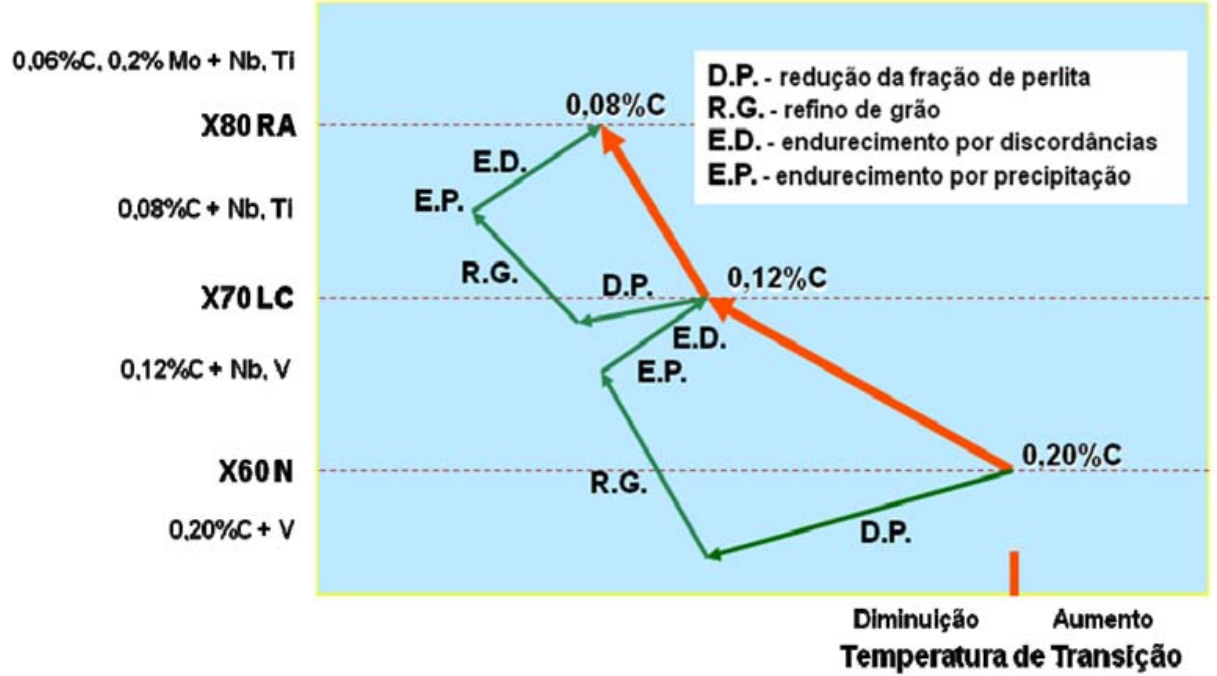

Figura 2.2 Relação entre composição química, processamento e mecanismos envolvidos [11]. 


\section{3}

\section{O microconstituinte austenita-martensita (AM)}

O presente trabalho tem como objetivo fazer uma breve revisão dos fatores que determinam a presença do microconstituinte, ou microfase austenitamartensita (AM) nos aços de baixa liga e sua quantificação por análise digital de imagens. Atenção especial será dada ao emprego dos métodos de ataque químico e de captura de imagens por microscopia ótica e microscopia eletrônica de varredura, com procedimentos e equipamentos essenciais à sua detecção e quantificação.

A presença do microconstituinte $\mathrm{AM}$ está geralmente associada à redução da tenacidade na zona termicamente afetada (ZTA), considerada zona frágil localizada (ZFL) e mostra-se importante em fenômenos relacionados à concentração de tensão e à fragilização por hidrogênio.

Assim sendo, é muito importante determinar uma metodologia de quantificação do microconstituinte AM [12] [13] [14].

\subsection{1}

\section{Mecanismo de formação do microconstituinte AM}

A austenita de baixo carbono transforma-se em ferrita para uma extensa faixa de taxas de resfriamento. Assim, a matriz ferrítica pode assumir várias morfologias e subestruturas, as quais estão em função da taxa de resfriamento da temperatura de formação e da composição química.

Para as taxas de resfriamento intermediárias os produtos de transformação podem ser descritos em termos dos seguintes estágios: a bainita lamelar se forma nos primeiros estágios de transformação e a austenita, enriquecida de carbono, forma pequenas ilhas que ficam aprisionadas pela matriz bainitica. Estas ilhas podem se transformar total, ou parcialmente, em martensita com alto carbono, em baixas temperaturas, durante o resfriamento contínuo [15].

A formação do microconstituinte Austenita-Martensita em chapas de aços bainiticos de baixo carbono laminados a quente é controlada pela composição do aço e pela taxa de resfriamento da chapa, após laminação a quente [16]. 


\subsection{2}

\section{Morfologia e quantidade do microconstituinte AM}

O microconstituinte AM é classificado morfologicamente em dois tipos: microconstituinte AM alongado e massivo, variando de acordo com o tempo de resfriamento entre $800^{\circ} \mathrm{C}$ e $500^{\circ} \mathrm{C}$, como mostrado na Figura 2.3.
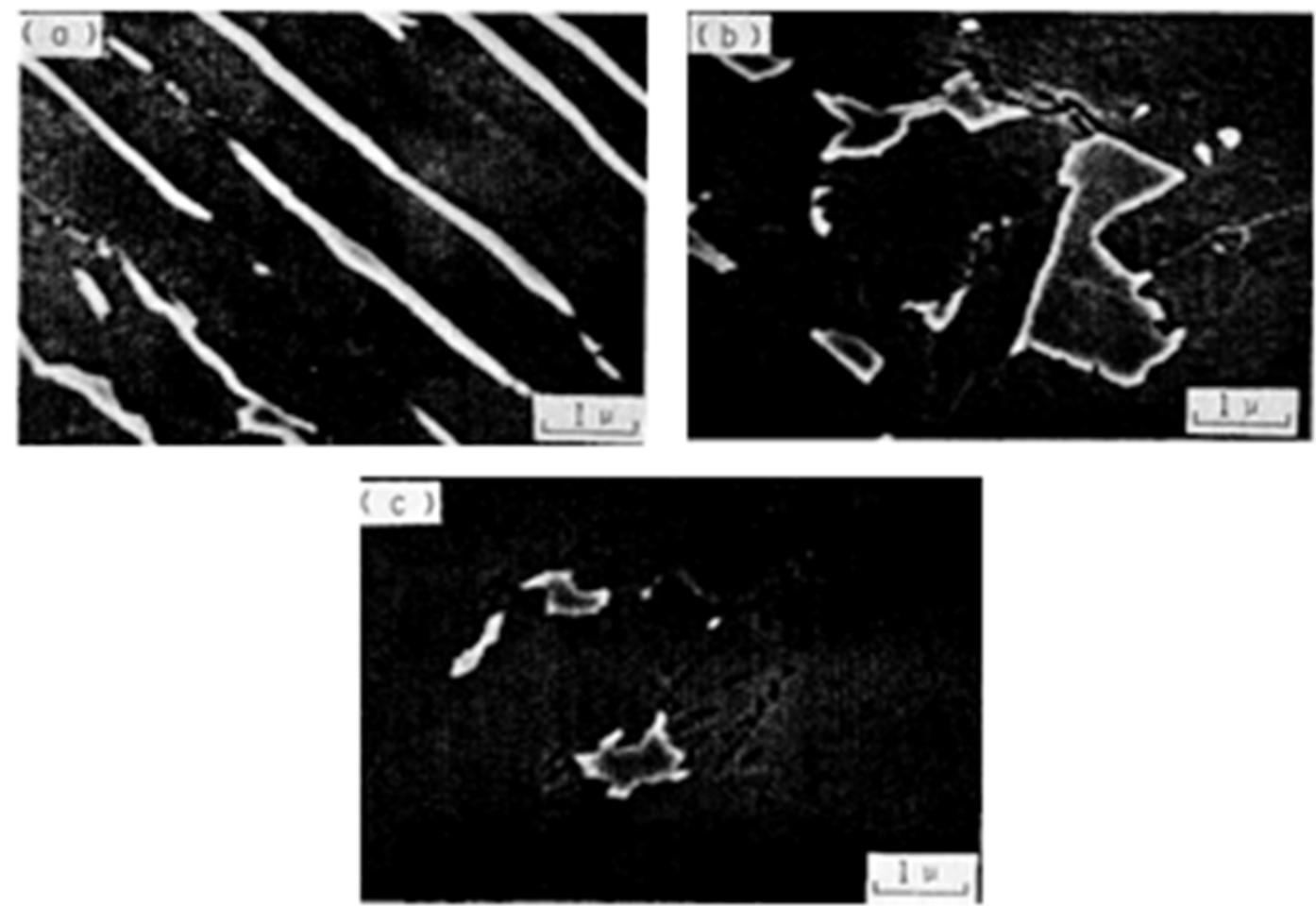

Figura 2.3 Microestruturas típicas de AM observadas em MEV [17]. (a) O microconstituinte AM na forma alongada para o tempo de resfriamento rápido (22 s) de $800^{\circ} \mathrm{C}$ a $500^{\circ} \mathrm{C}$. (b) $\mathrm{O}$ microconstituinte $\mathrm{AM}$ na forma massiva muda à medida que aumenta o tempo de resfriamento $\left(70 \mathrm{~s}\right.$ ) de $800^{\circ} \mathrm{C}$ a $500^{\circ} \mathrm{C}$. (c) Decomposição do microconstituinte AM em agregados de ferrita e carbonetos, quando o tempo de resfriamento torna-se muito longo, como mostra a Figura 2.4. 


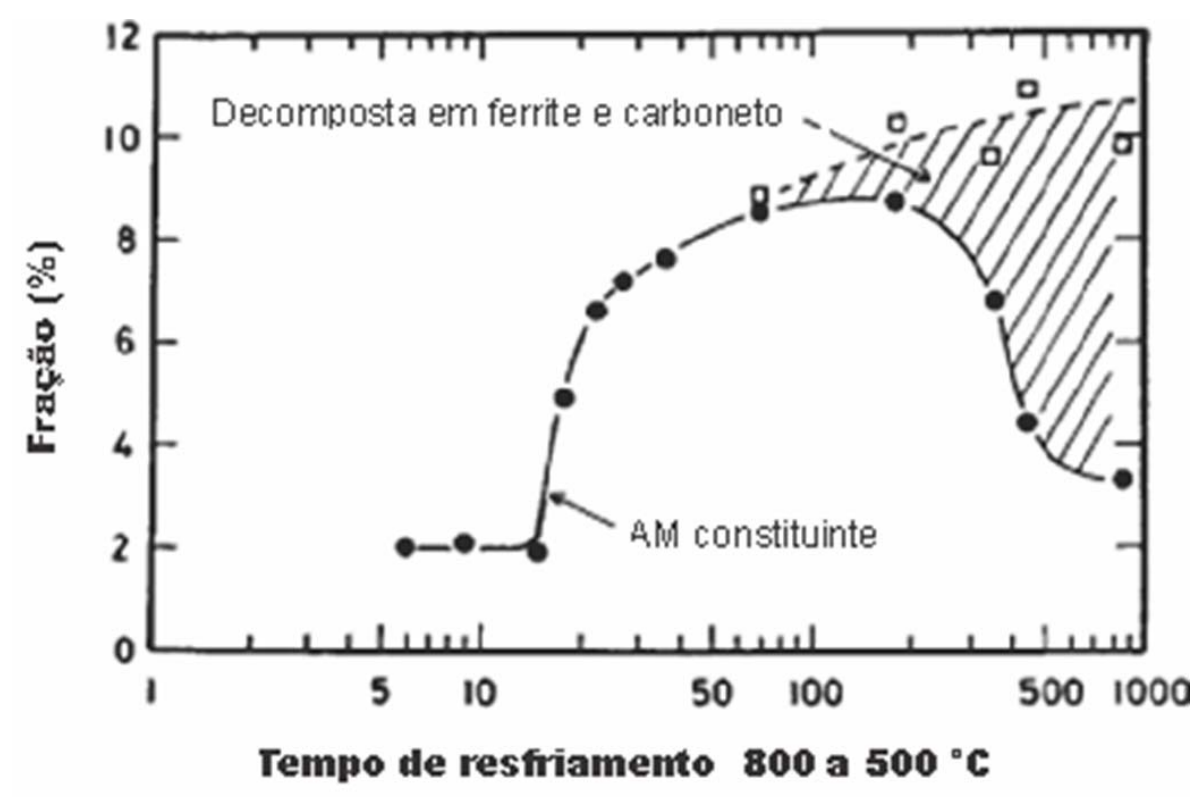

Figura 2.4 Relação entre o tempo de resfriamento e a fração de AM [17].

\subsection{3}

\section{Efeitos das características do microconstituinte AM sobre as propriedades mecânicas}

Estudos realizados em aços API 5L X-80 mostraram que a fração volumétrica de AM aumenta na medida em que o carbono equivalente (CE) aumenta para um mesmo teor de carbono. A fração volumétrica de AM aumenta com o teor de carbono e de carbono equivalente (CE) [18].

Outras pesquisas mostram que a presença de partículas isoladas de AM não tem efeito prejudicial sobre a resistência à temperatura ambiente. No entanto, a resistência ao impacto é fortemente dependente da fração volumétrica, da morfologia e da conectividade entre as partículas do microconstituinte AM. Quando a morfologia de AM é massiva e interconectada resulta em baixa tenacidade [2] [3]. 


\subsection{4}

Evolução da quantificação do Microconstituinte Austenita-Martensita (AM)

Le Pera trabalhou no aperfeiçoamento de contrastes utilizando vários ataques para a diferenciação das fases em microscopia ótica. $\mathrm{O}$ ataque com maior sucesso é o de Le Pera Modificado. Este é composto por duas soluções: o reagente I e o reagente II. Utilizam-se $30 \pm 2 \mathrm{ml}$ do reagente I (1\% de metabisulfito de sódio em água) e $30 \pm 2 \mathrm{ml}$ do reagente II (4g ácido pícrico em $100 \mathrm{ml}$ de etanol), que são colocados em diferentes béqueres. O tempo de ataque pode variar de $10 \mathrm{a}$ 20 segundos, dependendo da composição química do aço. $\mathrm{O}$ ataque é interrompido com álcool etílico, seguido de um jato de ar frio para a secagem da amostra. A amostra é pré-atacada com nital para delinear os contornos de grãos. Neste ataque, a ferrita aparece azul-esverdeada, a bainita aparece marrom e a austenita e a martensita aparecem brancas [19].

Ikawa et. al. [17] observaram o microconstituinte AM por Microscopia Eletrônica de Varredura (MEV) e Microscopia Eletrônica de Transmissão (TEM). No primeiro caso, foram utilizados dois passos do ataque eletrolítico a fim de distinguir o microconstituinte AM e os carbonetos.

O eletrólito para o primeiro ataque foi EDTA (ácido etileno diamino tetracético) $5 \mathrm{~g}$, fluoreto de sódio $(\mathrm{NaF}) 0,5 \mathrm{~g}$, água destilada $100 \mathrm{ml}$, com $3 \mathrm{~V}$ por 3 segundos. A ferrita é atacada, enquanto o AM e os carbonetos não são atacados.

O eletrólito para o segundo ataque foi o ácido pícrico $5 \mathrm{~g}$, hidróxido de sódio $(\mathrm{NaOH}) 25 \mathrm{~g}$, e a água destilada $100 \mathrm{ml}$ com 6V, por 30 segundos. Os carbonetos são preferencialmente atacados. Deste modo o microconstituinte AM foi identificado por MEV.

Alé et. al. [20] apresentaram uma nova forma de realizar o ataque metalográfico. Eles utilizaram o ataque Lepera Modificado e a solução 2 de Ikawa, o que permite a identificação do microconstituinte AM por Microscopia Ótica (MO) e (MEV). O estudo foi realizado na zona afetada termicamente (ZTA) de um aço C-Mn, com baixo teor de carbono, microligado com $\mathrm{Nb}$ e pequenas adições de $\mathrm{Cu}$ e $\mathrm{Ni}$.

Elisei et. al. [21] caracterizaram um aço multifásico com teor $0,08 \% \mathrm{C}$, $0,13 \% \mathrm{Si}$ e $1,55 \% \mathrm{Mn}$, com adições de molibdênio. Foram aplicadas diferentes 
proporções de soluções de metabissulfito e ácido pícrico, por exemplo, 12:7. Porém, notou-se que o ataque realçava demasiadamente na microestrutura as tonalidades em marrom, impossibilitando a diferenciação das fases presentes. A proporção ideal encontrada foi à mesma utilizada por Le Pera em seu trabalho original, ou seja, 1:1. A temperatura dos reagentes durante o ataque foi mantida próxima de $0 \quad{ }^{\circ} \mathrm{C}$. A análise realizada por $\mathrm{MO}$ permitiu caracterizar a microestrutura presente como multifásica, a bainita com a cor marrom escura, a ferrita em tom marrom claro e a austenita retida + martensita em cor branca.

\subsection{5}

\section{Sobre a quantificação do microconstituinte AM}

A quantificação de fração volumétrica do microconstituinte AM é tradicionalmente realizada através da técnica de contagem de pontos utilizando as imagens de microscopia ótica (MO) e de microscopia eletrônica de varredura (SEM), da norma ASTM E562-95, Figura 2.5.

Pereira et. al. [22] estudaram o aço microligado contendo $0,05 \% \mathrm{C}, 0,0021$ $\% \mathrm{~B},(\mathrm{API}-5 \mathrm{~L}-\mathrm{X} 80)$, onde o procedimento metalográfico utilizado foi o de LePera modificado na proporção do reagente 12:7, visando a identificação e a quantificação da ferrita, bainita e do microconstituinte AM por MO. A análise digital das fases presentes foi realizada sem a utilização de filtros para melhorar a qualidade da imagem. No entanto os autores não detalharam como foi feita a análise, nem identificaram o software de análise utilizado.

Atualmente a microscopia digital é uma ferramenta valiosa na quantificação das características de muitos materiais na indústria metalúrgica, biomédica, dentre outras. No caso dos aços com microestrutura multifásica e da identificação automatizada do microconstituinte $\mathrm{AM}$, o problema não é trivial. O microconstituinte AM pode ser revelado através de ataques para observação em MO. A Figura 2.5 compara duas metodologias de quantificação: (a) grade para a contagem de pontos, técnica tradicional, (b) identificação por PADI e contagem automática. 

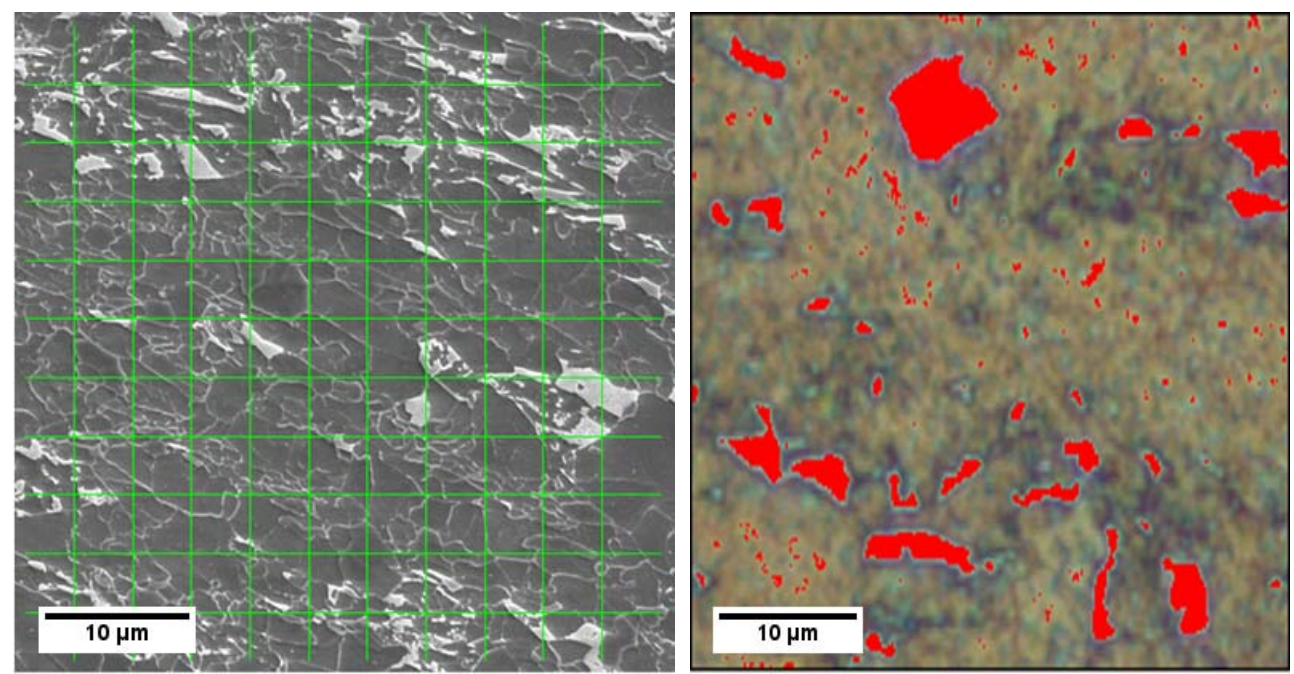

Figura 2.5 (a) Quantificação de AM com técnica de contagem de pontos (MEV) [23]. (b) Quantificação por PADI (MO)

\section{4}

\section{Métodos de ataque químico}

As técnicas mais utilizadas são as que usam o processo de corrosão controlada geradas pelas diferenças de potencial eletroquímico que ocorrem devido à presença de áreas com diferentes composições químicas.

Observa-se o seguinte procedimento: quando uma liga composta de duas ou mais fases está sendo atacada, o reagente é escolhido de modo seletivo. O resultado é usualmente um ataque parcial e o desgaste de uma das fases, enquanto a outra permanece sem ser afetada. Quando estas fases são observadas, gera-se no microscópio um efeito de sombras. As partes não afetadas aparecem em cores brilhantes, ou distintas, enquanto as outras aparecem escuras e em planos distintos.

\subsection{1}

\section{Ataque químico Lepera}

Neste caso, pode-se afirmar que uma reação química cria um filme na superfície da amostra [19]. A espessura deste filme é função da composição química do material. A cor observada é o resultado da interferência da luz 
refletida nas superfícies inferior e superior do filme, e, portanto, o efeito dependerá da espessura do filme.

Le Pera [19] utilizou o método Lepera modificado, em proporção de 1:1 explicado na seção 0 .

\subsection{2}

\section{Ataque químico Ikawa}

Ikawa et. al. [17] propuseram o método de ataque eletrolítico para obter micrografias através de MEV. Seção 0.

\subsection{3}

\section{Ataque químico Misto}

Alé R. M. et. al.[20] utilizaram uma técnica metalográfica a qual permite a identificação rápida e precisa do Microconstituinte AM por Microscopia Ótica (MO) e Microscopia Eletrônica de Varredura (MEV). O estudo foi conduzido na zona termicamente afetada (ZTA) de um aço micro-ligado ao $\mathrm{Nb}$ com pequenas adições de $\mathrm{Cu}$ e $\mathrm{Ni}$, e em um aço C-Mn, com baixo teor de carbono.

Foram utilizados os métodos Lepera modificado e a solução 2 Ikawa. O alto contraste obtido entre os microconstituintes AM e os carbonetos proporciona outra vantagem sobre os procedimentos tradicionais e pode ser utilizada para a análise automatizada por microscopia eletrônica de varredura (MEV), sendo esta superior a microscopia ótica para visualização deste microconstituinte. No caso dos aços com microestrutura multifásica e da identificação automatizada do microconstituinte $\mathrm{AM}$, não é fácil detectar a sua presença.

\section{5}

\section{Microscopia Digital}

A integração entre o microscópio e o computador, oferecendo aquisição digital de imagens, automação do microscópio e a análise digital de imagens levaram à criação de uma nova área, hoje denominada de Microscopia Digital. Esta área apresenta possibilidades realmente novas no que diz respeito à 
caracterização de materiais. Em alguns casos, a existência de sistemas totalmente controlados por software, com ambiente de programação permite uma automação completa dos procedimentos de caracterização [24] [25].

\subsection{1}

\section{Aquisição Automática de Imagens}

A aquisição de imagens de forma automática, com procedimentos de autoajuste (foco ótimo e varredura da amostra são cada vez mais comuns na microscopia digital). Evita a ocorrência de erros por fadiga do operador, como a repetição e a sobreposição de campos.

\subsubsection{1}

\section{Autofoco}

O autofoco é um procedimento essencial em qualquer processo que envolva a aquisição automática de imagens e passou a ser facilmente implementável através das técnicas de PADI [26].

As técnicas de autofoco por processamento e análise digital tanto para microscópios óticos como para microscópios eletrônicos de varredura, geralmente se baseiam na aquisição sucessiva de imagens de um mesmo campo, ou na porção de campo, variando-se a posição no eixo z. Em cada imagem capturada, uma determinada característica é medida, com contraste, de modo que o processo evolui buscando a maximização desta característica, até chegar ao ponto de foco ótimo associado [25] [27].

\subsubsection{2}

\section{Varredura automática da amostra}

Geralmente a varredura da amostra, com a aquisição automática de imagens, é integrada nas rotinas de correção e de auto-ajuste do microscópio, constituindose uma vantagem adicional do método.

Este procedimento de varredura da amostra e da aquisição de imagens da forma automática calcula as posições $(\mathrm{x}, \mathrm{y})$ dos campos, de modo a distribuí-los 
uniformemente na superfície da amostra. O procedimento consiste em mover a platina no plano $(\mathrm{x}, \mathrm{y})$ e, a cada posição calculada, capturar uma imagem. Para que isto faça sentido, a amostra deve estar em foco em cada coordenada $(\mathrm{x}, \mathrm{y})$.

Neste trabalho, foi realizado o procedimento automático de captura onde cada campo está à uma distância de $500 \mu \mathrm{m}$ do anterior, distribuídos uniformemente em uma região como se mostra na Figura 2.6.

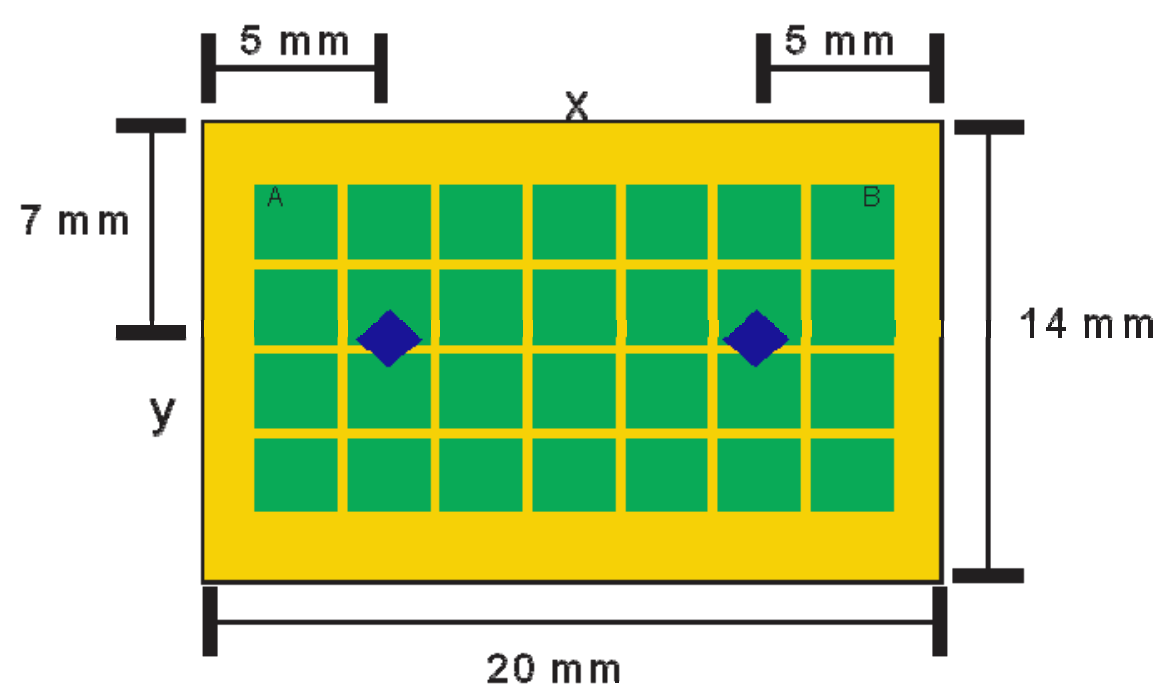

Figura 2.6 Técnica da captura de imagens.

\subsection{2}

\section{Microscopia Co-Localizada}

A microscopia Co-Localizada é uma técnica que combina imagens obtidas de diferentes modos em um dado microscópio, ou imagens obtidas em microscópios diferentes, para obter informação mais completa sobre um campo específico, ou um conjunto de campos de uma amostra. Podem-se combinar informações com diferentes significados físicos e se ampliar o contraste entre as fases no MEV. Por exemplo, na microscopia ótica, as imagens obtidas nos diferentes modos de contraste (campo claro, campo escuro, DIC) podem ser combinadas a fim de se revelarem determinadas características micro-estruturais [27] [28] [29].

Soto, et al. [30] desenvolveu uma forma de microscopia co-localizada no microscópio ótico de luz refletida a partir da realização de ataques químicos sucessivos da mesma amostra. O método inicia com a aquisição de imagens de 
diversos campos da amostragem. Em seguida, a amostra é retirada da platina, sofre um ataque químico e, após limpeza, retorna ao microscópio para a obtenção de imagens dos mesmos campos. No trabalho em questão, a microscopia Colocalizada foi responsável pela identificação e discriminação das fases minerais inicialmente indistintas em amostras de minério de cobre.

No presente trabalho foi utilizada uma metodologia de Microscopia Colocalizada que combina imagens de Microscopia Óptica de Luz Refletida (MO) e de Microscopia Eletrônica de Varredura (MEV) para quantificar o microconstituinte AM e comparar os resultados entre os dois microscópios.

Quando se utiliza diferentes microscópios é preciso levar em conta a necessidade de localizar o mesmo campo nos diferentes equipamentos. Em geral, ao mudar de um microscópio para outro ocorrem três tipos de desalinhamento: translação, rotação e ampliação.

A ampliação pode ser calibrada usando-se imagens de uma micro régua de referência (veja-se Seção 0) e ajustando-se o aumento de um dos microscópios para se equiparar ao outro. Como o microscópio ótico têm aumentos fixos devido às lentes objetivas, o MEV oferece aumento variável e torna-se mais fácil ajustar o aumento no MEV, através do MO [27].

Com a finalidade de se alinhar os pontos, translação e rotação podem ser parcialmente ajustadas. Usam-se marcas de referência localizadas nos dois microscópios deslocando-se e/ou, girando-se o porta-a mostras. Para este caso, costuma-se utilizar as identações de microdureza Víckers, de forma bem definida pois são de fácil de identificação. No entanto, este ajuste é sempre imperfeito exigindo uma etapa posterior de alinhamento digital das imagens. Esta etapa será descrita na seção 0 .

\section{6}

\section{Processamento e Análise Digital de Imagens}

A área de processamento de imagens vem sendo objeto de crescente interesse por permitir grande número de aplicações em duas categorias nitidamente distintas: (i) o aprimoramento de imagens digitais com um conjunto de técnicas que utilizam operações matemáticas para alterar os valores de intensidade dos pixels, corrigindo os defeitos de aquisição e/ou realçando detalhes 
de interesse; e (ii) a extração e tratamento de dados quantitativos a partir de imagens digitais [26] [31].

A Figura 2.7 apresenta a sequência padrão de PADI, dividida em três blocos básicos: Aquisição, PDI e ADI. Nos lados aparecem setas que indicam o nível semântico dos dados sobre os quais se trabalha [27].

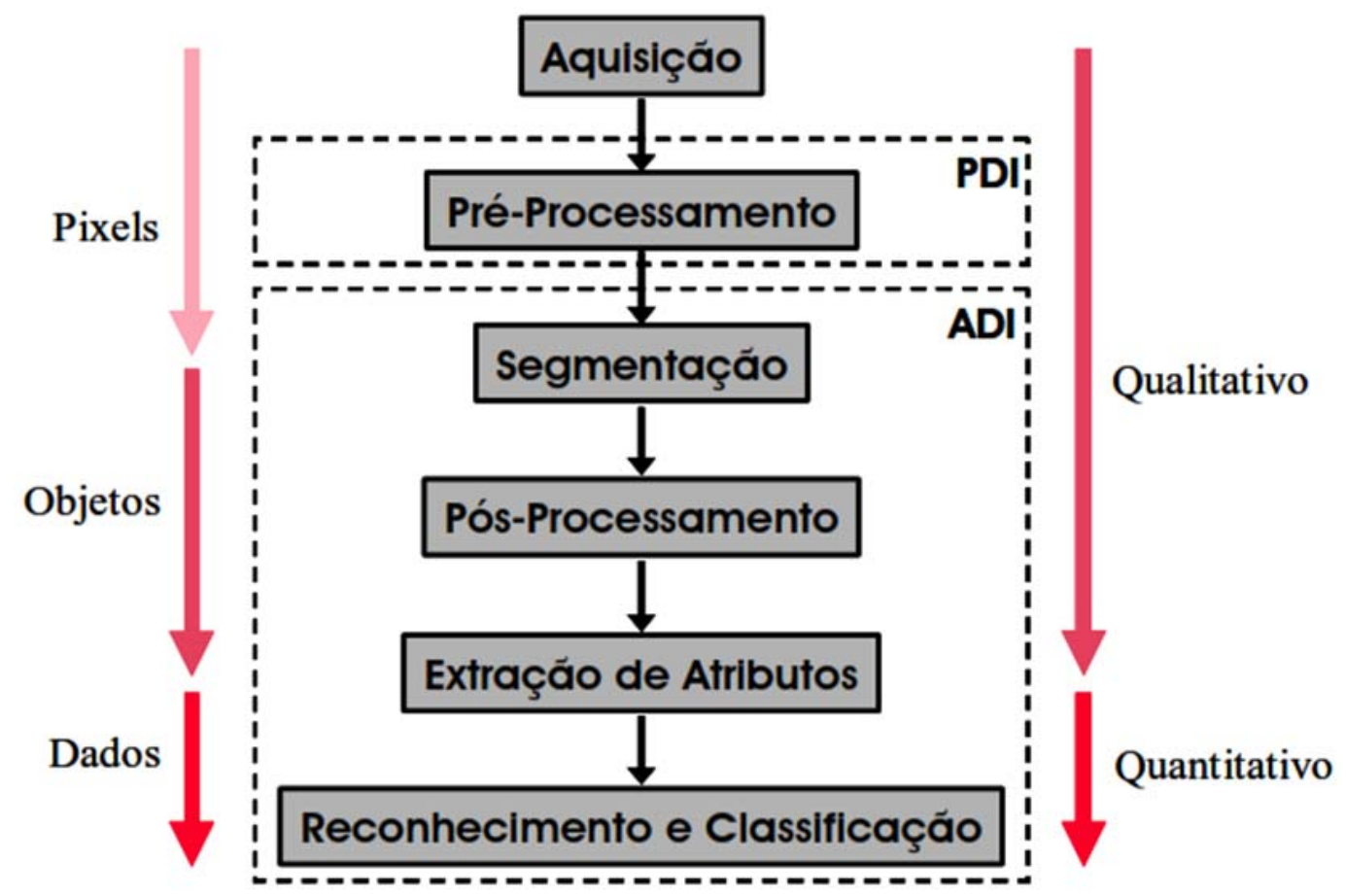

Figura 2.7 Sequencia padrão de PADI [27].

As etapas da sequência padrão serão explicadas, assim como as rotinas que foram usadas no presente trabalho.

\subsection{1}

\section{Aquisição e digitalização da imagem}

Uma imagem digital é uma matriz onde cada um de seus elementos é um número que representa a cor, ou a intensidade do pixel de posição correspondente na imagem real. Assim, esta matriz é uma representação que reproduz digitalmente uma imagem ponto a ponto, ou seja, pixel a pixel.

A quantização mais comumente encontrada em imagens digitais “monocromáticas" é 256 níveis de cinza, ou 8 bits $\left(2^{8}=256\right)$. A representação digital deste tipo de imagem pode variar bastante, mas, em geral, estas imagens 
são representadas por matrizes de números inteiros que variam de 0 (preto) a 255 (branco) [22] como se mostra na Figura 2.8.

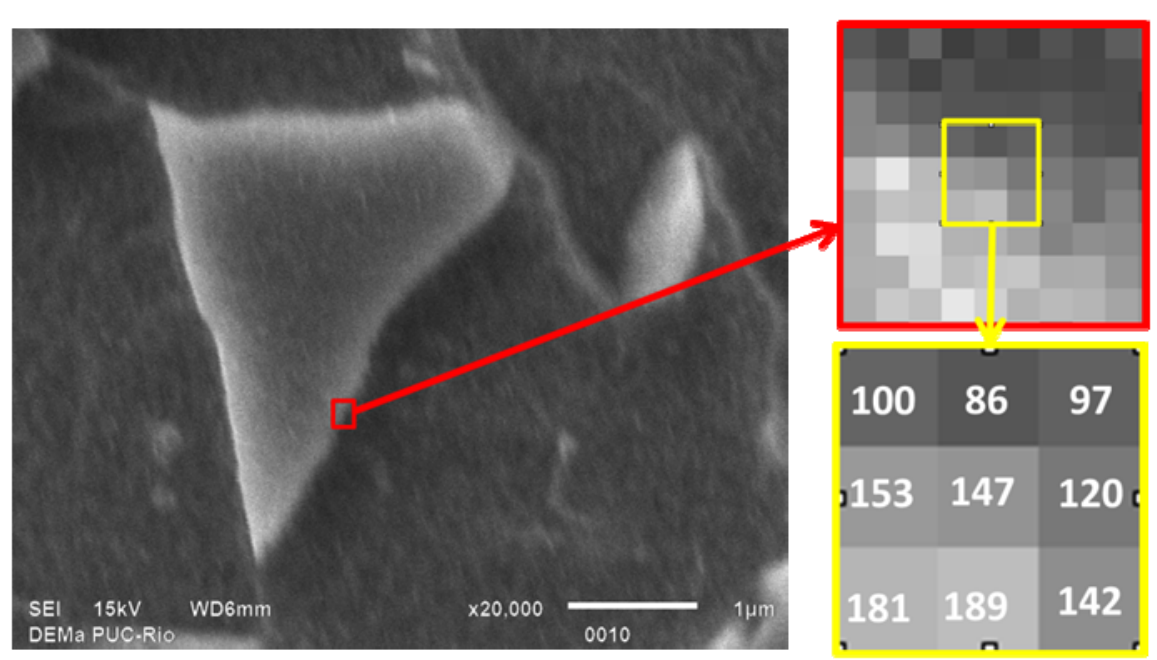

Figura 2.8 Representação imagem Digital

Uma das características mais importantes para a análise de uma imagem digital é o histograma de tonalidades. Este gráfico fornece uma visão estatística sobre a distribuição das intensidades dos pixels, sobre o contraste e o brilho da imagem. Além disso, o histograma é bastante utilizado na etapa de segmentação, principalmente em técnicas que se utilizam da similaridade entre os pixels, como mostrado na Figura 2.9, onde os pixels mais claros correspondem à fase AM, formando o lado direito do histograma.
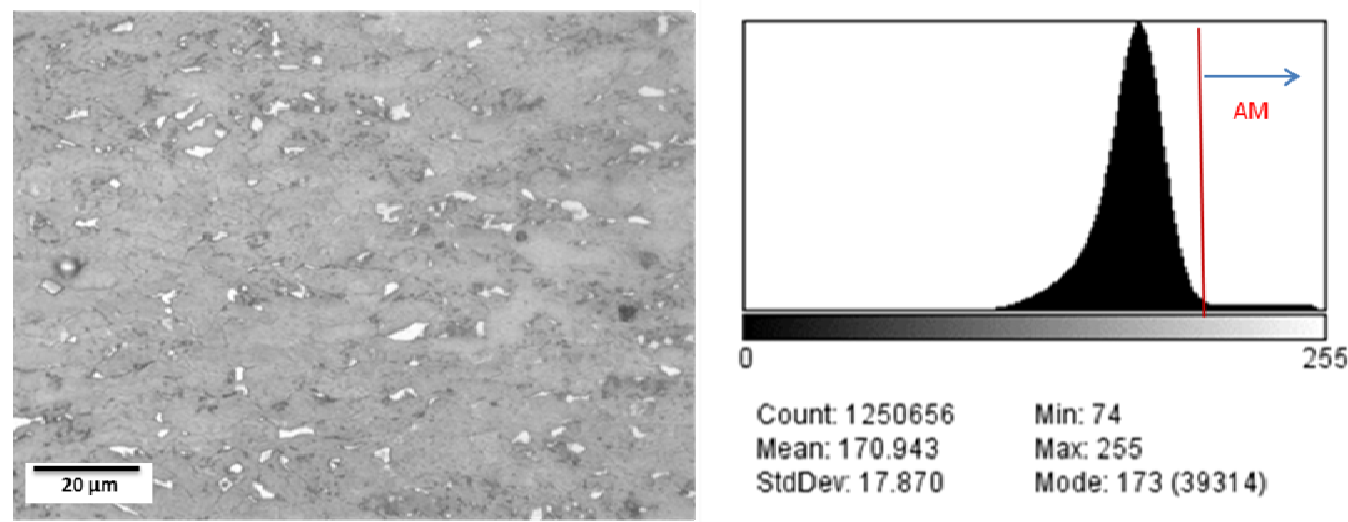

Count: 1250656

Mean: 170.943

Min: 74

StdDev: 17.870

Max: 255

Mode: 173 (39314)

Figura 2.9 Histograma de uma imagem digital 
No microscópio ótico é possível obter imagens coloridas. Neste caso, a imagem é representada pelas componentes primárias $R, G$ e B. Para cada componente é calculado o histograma correspondente. A Figura 2.10 mostra um exemplo de imagem RGB (red, green, blue) e cada uma de suas componentes.
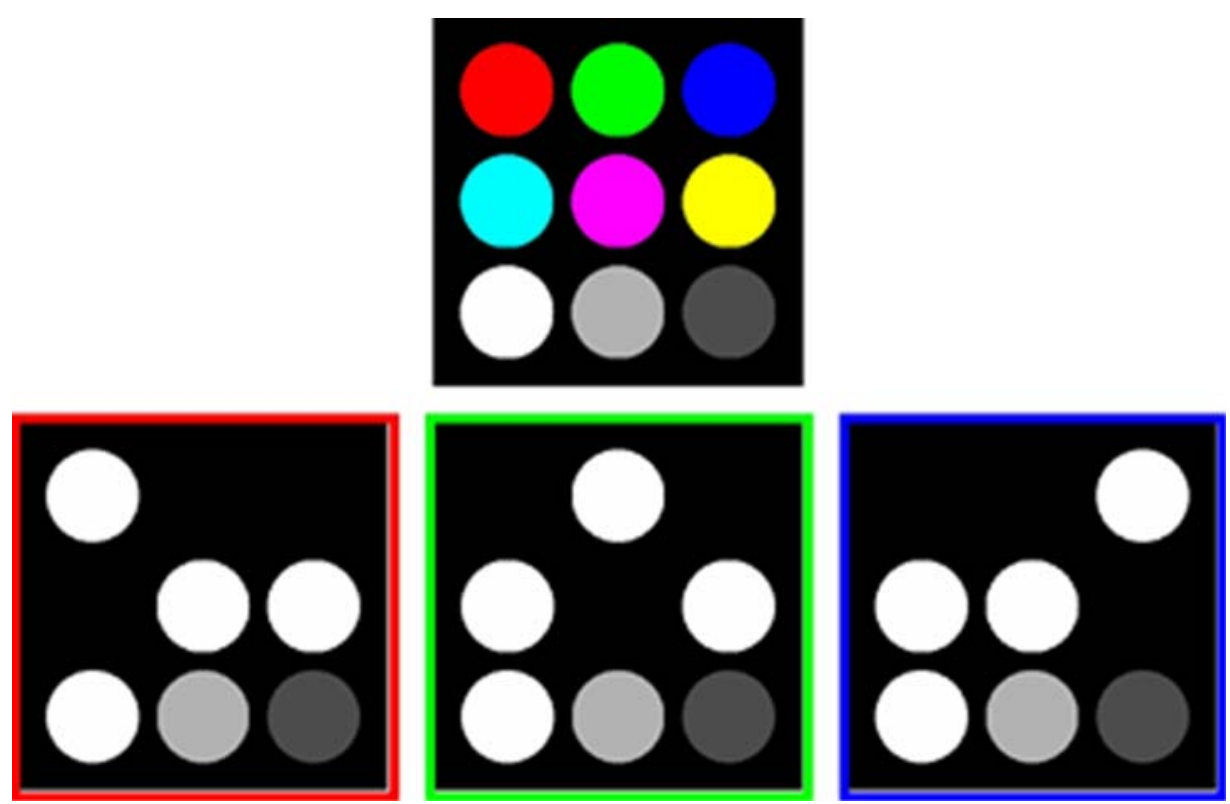

Figura 2.10 Imagem modo RGB e suas componentes [32].

\subsection{2}

\section{Pré-processamento}

É a etapa da correção dos defeitos oriundos da aquisição de imagens realçando detalhes de interesse, de modo a facilitar sua visualização, ou segmentação.

Uma das operações mais comuns do pré-processamento, particularmente importante para o tratamento de imagens de microscopia óptica, é a correção de fundo ou dos defeitos típicos como: inclinação da amostra, sujeira no sistema ótico do microscópio, etc. Uma solução estimativa que envolve fundo irregular é via filtro passa-baixa e subtração. O método consiste na obtenção da imagem do fundo e posterior subtração desta imagem da original. A imagem do fundo é calculada apagando-se a imagem original através da aplicação, repetidas vezes, de um filtro passa-baixa. Então, subtrai-se esta imagem calculada do fundo, da imagem original, obtendo-se a imagem corrigida, figura 2.11 [24]. 

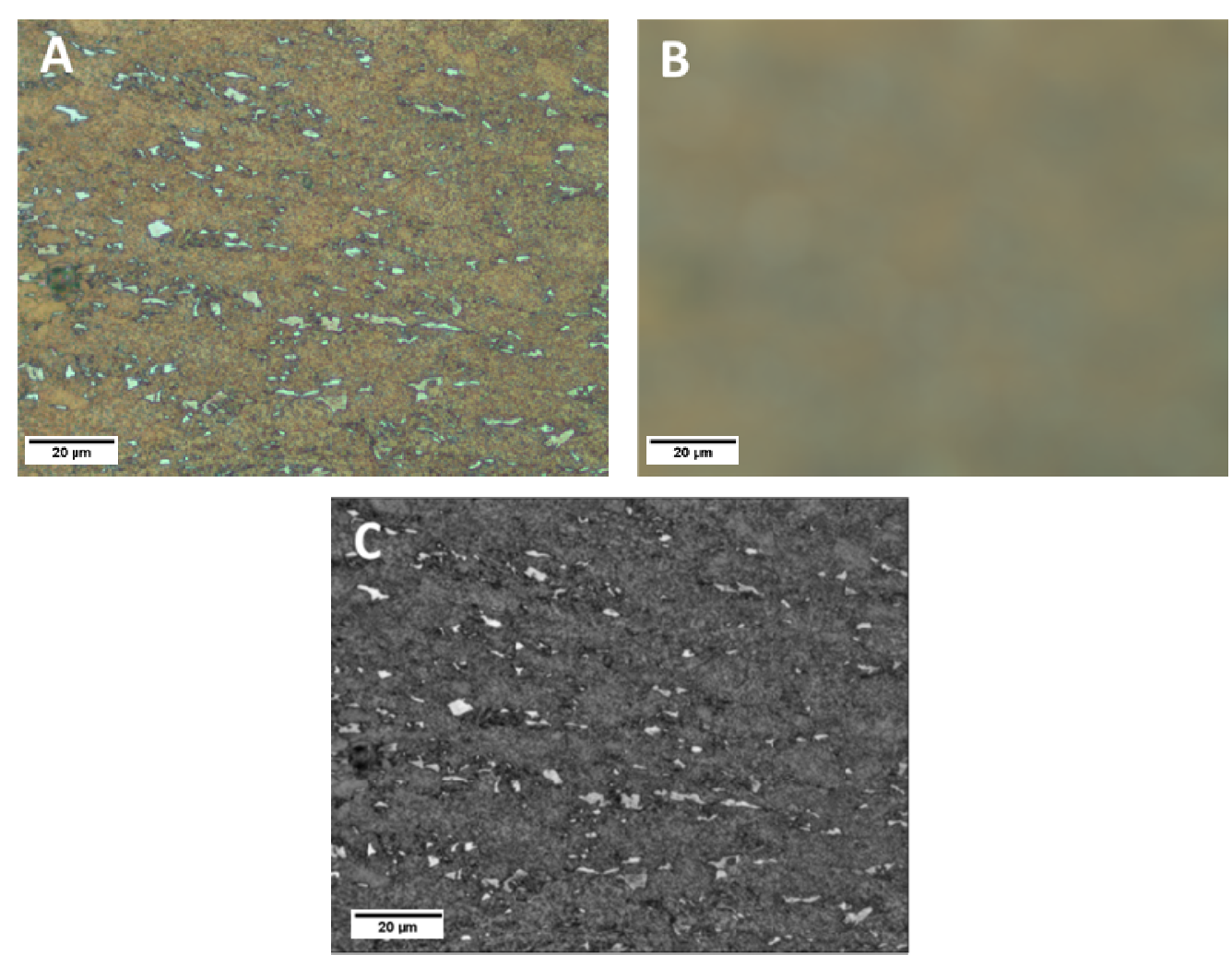

Figura 2.11 Correção dos defeitos de iluminação, (A) Imagem Original (B) Fundo calculado (C) Imagem corrigida

Em imagens de microscopia eletrônica de varredura é comum ocorrer ruído aleatório na aquisição. Este interfere na segmentação das partículas de interesse.

A técnica frequentemente empregada para mitigar o defeito de ruído é a aplicação de filtros passa-baixa que reduzem as frequências altas correspondentes ao ruído. No entanto, os filtros mais simples, além de reduzirem o ruído, também borram a imagem, especialmente as bordas dos objetos de interesse. O filtro sigma é um filtro passa-baixa "inteligente" que reduz o ruído apenas em regiões já razoavelmente uniformes, ou seja, nas quais não existem bordas de objetos [32].

A Figura 2.12 mostra uma imagem de MEV (A) imagem original, (B) A imagem original ou as zonas claras foram marcadas com cor vermelha que correspondem ao microconstituinte $\mathrm{AM}+$ ruído da imagem original e (C), resultado da aplicação do filtro sigma no interior na zona marcada pela cor amarela. Note-se que, após a aplicação do filtro sigma melhora-se a imagem, mas ainda ficam algumas partículas que não foram eliminadas nesta etapa. As mesmas serão tratadas na etapa de pós-processamento, ou da extração de atributos. 

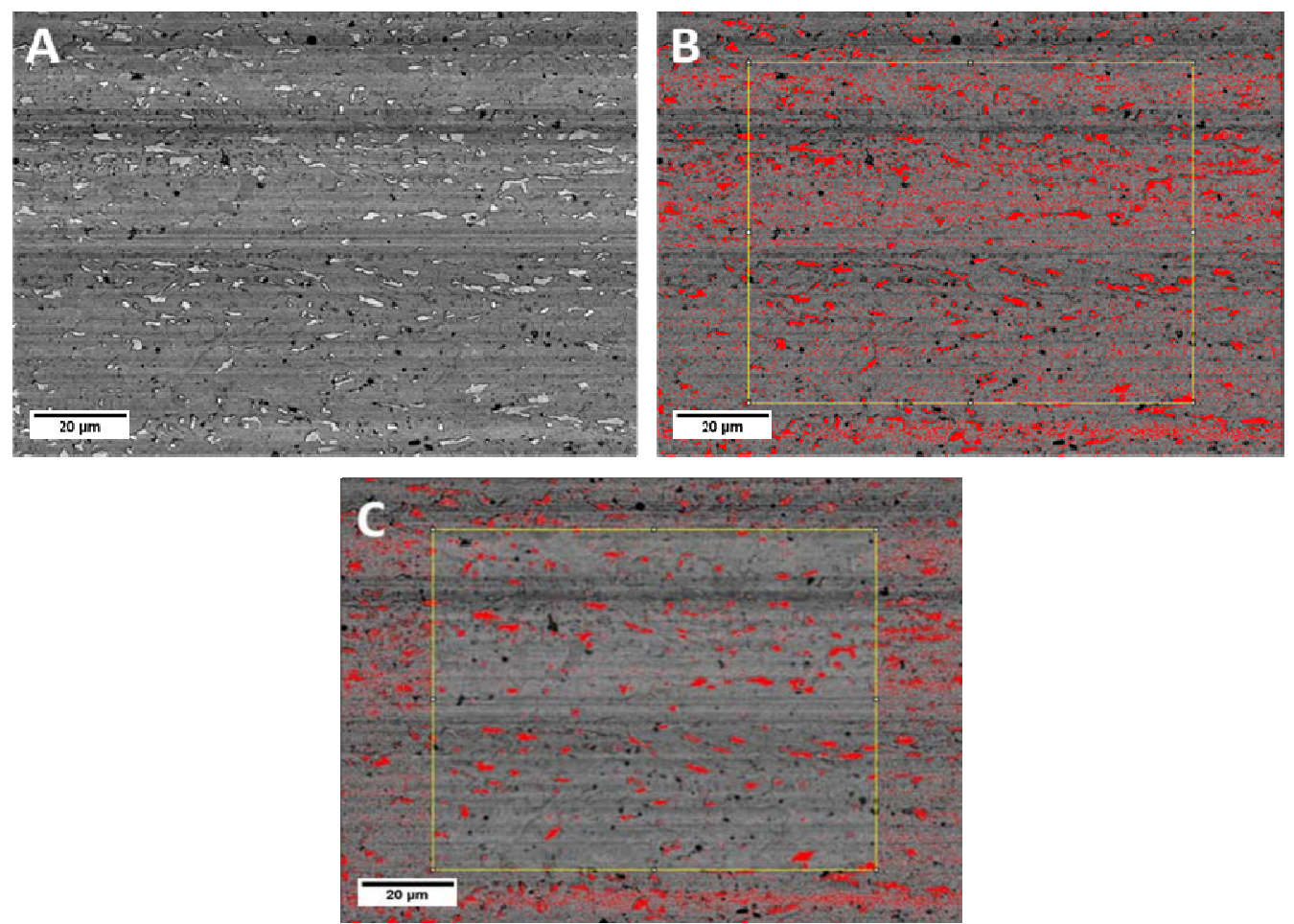

Figura 2.12 Correção dos defeitos de ruído (A) Imagem Original, (B) Imagem original, ou microconstituinte + defeitos de ruído, marcadas pela cor vermelha na imagem, (C) Imagem com redução de ruído na zona marcada de cor amarela

\subsubsection{1}

\section{Alinhamento das imagens}

Existem inúmeras técnicas de alinhamento semi-automático, ou automático. As técnicas semi-automáticas utilizam alguma referência oferecida pelo operador, tal como pontos, ou linhas em posições equivalentes nas duas imagens, para realizar o ajuste fino. As técnicas automáticas buscam localizar o ponto equivalente (pontos homólogos) nas duas imagens, sem interferência do operador [33].

Uma das mais poderosas técnicas automáticas é transformada de Características Invariantes por Escala (SIFT -Scale Invariant Feature Transform) [34]. Esta técnica usa um algoritmo sofisticado e robusto que identifica pontos homólogos em imagens com características distintas (tons de cinza, coloridas, MO, MEV, etc,). Uma vez identificados estes pontos, uma imagem pode ser corrigida para se ajustar à outra, a partir dos diferentes modelos que podem envolver translação, rotação, aumento e distorções. 
As características invariantes por escala permitem identificar os pontos homólogos entre as imagens que sofreram vários tipos de distorção, translação e rotação. Inclusive podem ser usadas, para pares de imagens obtidas em condições muito diferentes, como por exemplo, em microscópios de diversos tipos é possível registrar precisamente as imagens [32].

No presente trabalho utilizou-se a implementação da SIFT e do alinhamento automático disponível no software FIJI (Figura 2.13). A mesma está dividida basicamente em três partes, a do detector de pontos, a do descritor de características e a da transformação esperada entre as imagens. O detector SIFT é baseado nos cálculos da diferença de Gaussianas e o descritor SIFT utiliza histogramas de gradientes orientados para descrever a vizinhança local dos pontos de interesse [35]. A transformação pode envolver apenas translação, corpo rígido (translação + rotação), similaridade (que inclui também mudança de escala isotrópica), ou uma transformação afim (que pode envolver distorções).

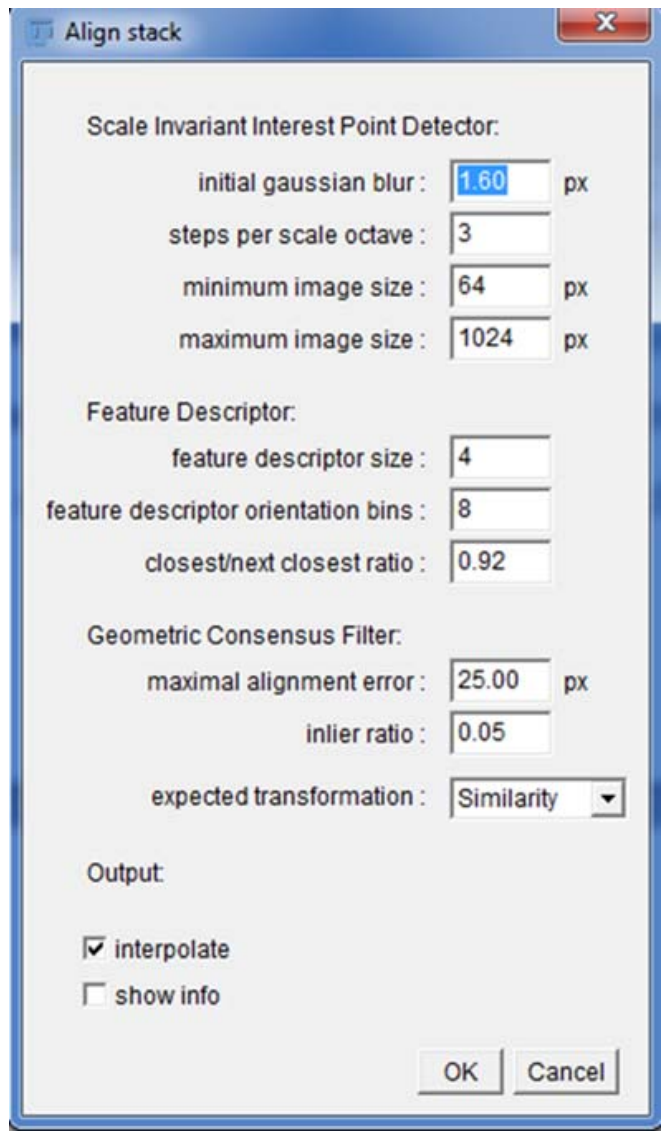

Figura 2.13 Interface do algoritmo SIFT no FIJI 


\subsection{3}

\section{Segmentação}

A segmentação particiona a imagem em regiões e distingue estas regiões como objetos independentes uns dos outros e do fundo. O resultado da segmentação são imagens com objetos, cuja representação é geralmente feita por regiões de pixels contíguos de mesmo valor (p. ex. uma imagem binária onde os objetos são regiões contíguas de pixels brancos em um fundo preto, ou viceversa).

Existem na literatura diversos métodos de segmentação baseados em diferentes princípios (limiarização de histograma, detecção de bordas, textura, morfologia matemática, etc.). Cada qual mais adequado a uma aplicação específica. Assim, categoricamente, não existe um método ideal e genérico de segmentação que seja sempre o melhor [27] [36].

A segmentação é um processo muito complexo, pois tenta traduzir para o computador um processo cognitivo e extremamente sofisticado. Além de ser a parte mais difícil do processo, é também a mais delicada, porque todas as medidas futuras serão realizadas sobre as regiões identificadas nesta etapa.
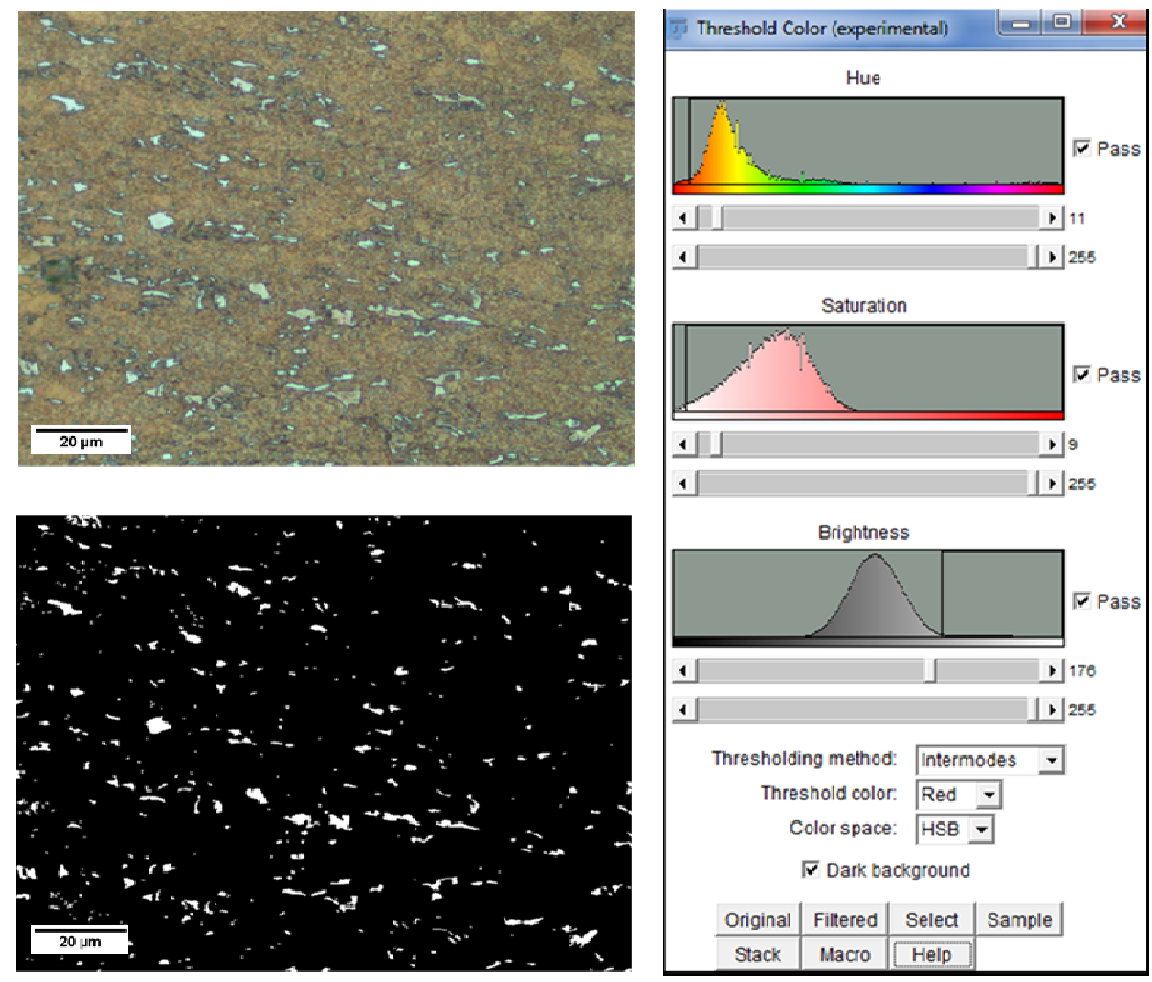

Figura 2.14 Segmentação AM da Imagem MO (a) Imagem Original (b) Imagem Segmentada (c) Histograma da segmentação 
Neste trabalho, o enfoque principal da segmentação está baseado no thresholding (limiarização, ou segmentação por faixa tonal).

As imagens coloridas do microscópio óptico foram segmentadas por limiarização no espaço HIS (Hue, Intensity, Saturation - Matiz, Brilho e Saturação), Figura 2.14. As imagens de MEV foram segmentadas por limiarização simples de intensidade. A Figura 2.15, mostra as regiões de AM como partículas brancas em fundo escuro.
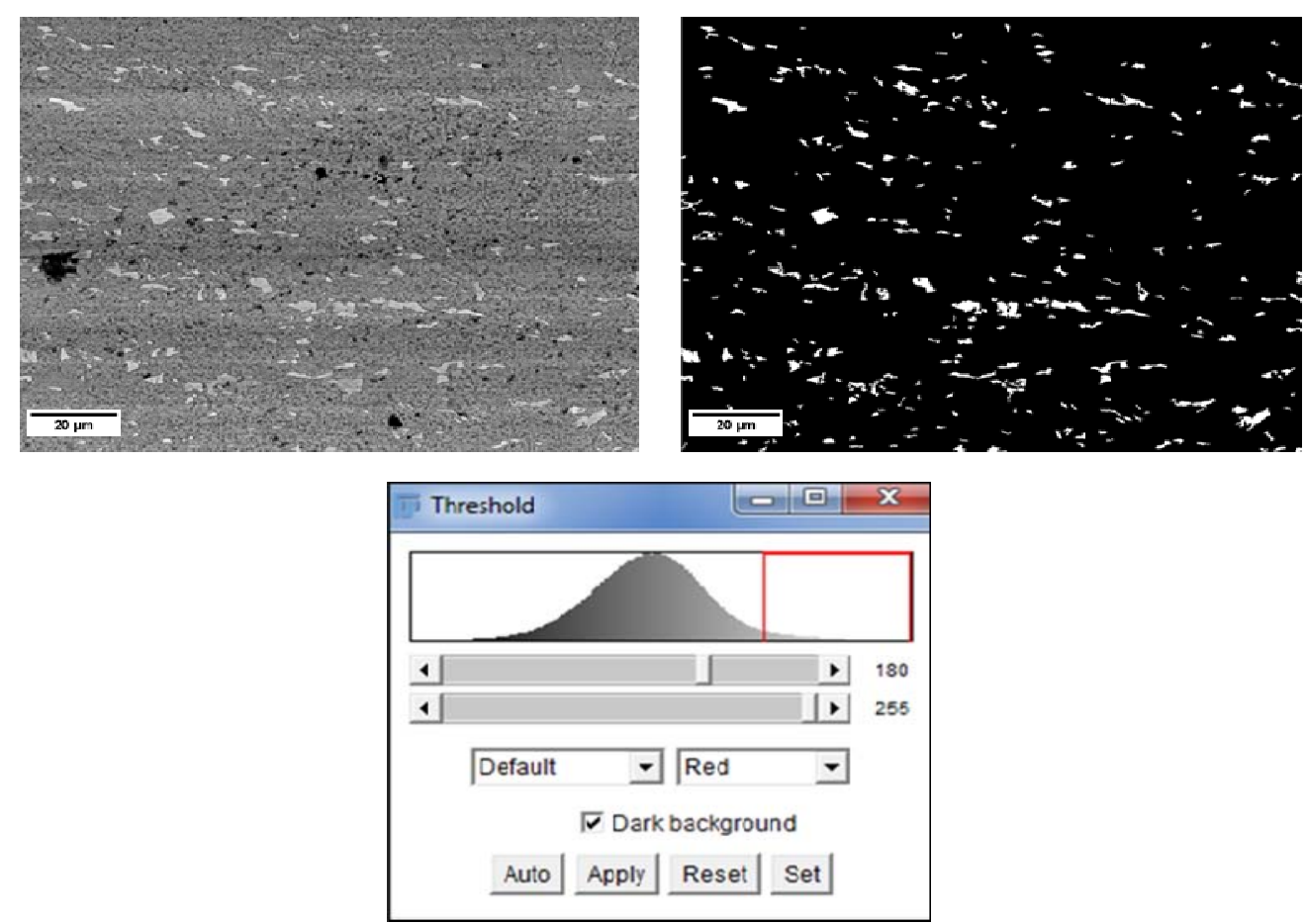

Figura 2.15 Segmentação do AM na imagem MEV (a) Imagem original (b) Imagem segmentada (c) Histograma da segmentação

\subsection{4}

\section{Pós-Processamento, extração de atributos}

Muitas vezes o resultado da segmentação não é adequado, sendo necessária uma etapa de pós-processamento antes da realização de medidas nos objetos.

No presente trabalho observaram-se pequenas partículas espúrias que foram segmentadas junto com o microconstituinte AM em imagens de MO e de MEV. Assim, a única etapa de pós-processamento utilizada, envolveu a eliminação de objetos por tamanho. 
Existem basicamente duas classes de medida: (i) medidas de campo, que são as medidas que se referem à imagem como um todo; e (ii) medidas de região, que se referem aos objetos independentes [26].

Neste trabalho foram usadas as medidas de campo para calcular a área percentual de cada fase em uma imagem binária, usando-se a seguinte equação:

$$
\% f V=\frac{\sum A F}{A T} \times 100
$$

onde:

\%f V \% de fração de volumem do microconstituinte AM;

$\sum \mathrm{AF}$ somatória de área total do microconstituinte AM na imagem;

AT é a área total da imagem varrida. 


\section{3}

\section{Materiais e Métodos}

Este capítulo apresenta as etapas experimentais e os materiais usados neste trabalho, assim como os equipamentos e as técnicas envolvidas.

\section{1}

\section{Materiais}

O aço em estudo é um aço microligado, tubos da classe API5LX80 (metal de base), pertencente ao sistema $\mathrm{Nb}-\mathrm{Cr}$, produzido por laminação controlada, sem resfriamento acelerado, cuja composição química está especificada na Tabela 3.1.

Tabela 3.1 Composição química (\% em peso do aço API5LX80).

\begin{tabular}{cccccccc}
\hline $\mathbf{C}$ & $\mathbf{S i}$ & $\mathbf{M n}$ & $\mathbf{P}$ & $\mathbf{S}$ & $\mathbf{C r}$ & $\mathbf{N i}$ & Mo \\
\hline 0,04 & 0,18 & 1,85 & 0,024 & 0,004 & 0,32 & 0,02 & 0,03 \\
$\mathbf{A l}$ & $\mathbf{C u}$ & $\mathbf{T i}$ & $\mathbf{N b}$ & $\mathbf{V}$ & $\mathbf{C a}$ & $\mathbf{N}$ & $\mathbf{C e q}$ \\
\hline 0,033 & 0,01 & 0,016 & 0,073 & 0,005 & 0,001 & 0,004 & 0,421 \\
\hline
\end{tabular}

As amostras foram usinadas em corpos de prova com dimensões $20 \mathrm{x} 14 \mathrm{x}$ $10 \mathrm{~mm}$, lixadas, polidas seguindo o método de preparação metalográfica tradicional, com posterior ataque químico para revelar o microconstituinte de interesse.

\section{2}

\section{Metodologia}

O presente trabalho envolve fundamentalmente três grupos de metodologias experimentais relacionadas: Ataque químico, aquisição de imagens por MO e MEV, Processamento e Análise Digital de Imagens (PADI). 


\subsection{1}

\section{Ataque químico}

Foram utilizados diferentes métodos, compostos de dois ou mais passos de pré-ataque ou de ataque, às vezes utilizando ataque eletrolítico. As condições estão listadas na Tabela 3.2 .

Tabela 3.2 Métodos de Ataque para Revelação do Microconstituinte AM. [17] [19] [37] [38].

\begin{tabular}{|c|c|c|c|}
\hline & LeperaModificado & Ikawa & Misto \\
\hline $\begin{array}{l}\text { Pré- } \\
\text { ataque }\end{array}$ & Nital 2\% & & Nital 2\% \\
\hline Ataque 1 & $\begin{array}{l}\text { Reagente I: } \\
1 \mathrm{~g} \text { de metasulfito de } \\
\text { sódio diluído em } 100 \\
\mathrm{ml} \text { de água } \\
\text { Reagente II: } \\
4 \mathrm{~g} \text { ácido pícrico } \\
\text { diluído em } 100 \mathrm{ml} \text { de } \\
\text { etanol. } \\
\text { Proporção 1:1 }\end{array}$ & $\begin{array}{l}4 \mathrm{~g} \text { EDTA + } 0.5 \mathrm{~g} \\
\mathrm{NaF}_{2}+100 \mathrm{ml} \text { água } \\
\text { destilada. Ataque } \\
\text { eletrolítico (3 V, } 3 \text { - } \\
30 \mathrm{~s}) .\end{array}$ & Lepera Modificado \\
\hline Ataque 2 & & $\begin{array}{l}5 \mathrm{~g} \text { ácido pícrico + } \\
25 \mathrm{~g} \mathrm{NaOH}+100 \mathrm{ml} \\
\text { de água destilada. } \\
\text { Ataque eletrolítico (6 } \\
\text { V, } 30-200 \mathrm{~s}) .\end{array}$ & Ataque 2 Ikawa \\
\hline
\end{tabular}

\subsubsection{1}

\section{Ataque químico Lepera Modificado}

É usado para observação em MO e permite discriminar a fase bainita da fase ferrita, enquanto o microconstituinte AM aparece com coloração clara [19] [39], como explicado na seção 2.3.4.

Mostra-se extremamente sensível a diversos fatores, tais como: tempo de ataque, proporção dos reagentes I e II, tipo de microestrutura, procedimento de preparação das amostras e temperatura na qual se realiza o ataque. Os reagentes I 
e II foram misturados no momento da realização do ataque químico para evitar redução na reatividade química.

O pré-ataque com Nital $2 \%$, com tempo de $10 \mathrm{~s}$, foi aplicado em todos os casos para revelar o contorno de grão, (Figura 3.1).

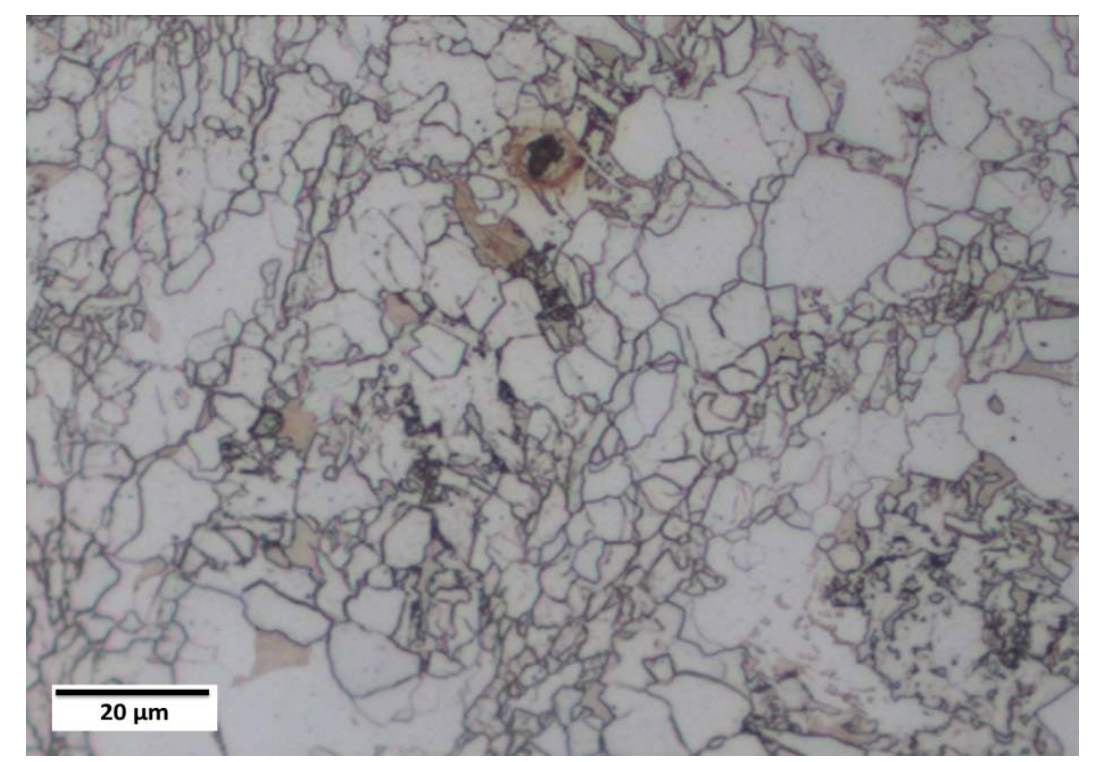

Figura 3.1 MO. Pré-ataque Nital 2\% tempo 10 s, aumento 1000X.

A temperatura de realização do ataque químico foi mantida em $4^{\circ} \mathrm{C}$ a $5^{\circ} \mathrm{C}$ e o polimento final foi realizado próximo ao momento do ataque químico.

A proporção de mistura do reagente foi a mesma utilizada por Lepera em seu trabalho original, $1: 1$.

As amostras foram testadas variando o tempo de ataque químico, com o objetivo de determinar o tempo ótimo para revelar o microconstituinte AM. A sequência do ataque químico é apresentada na Tabela 3.3 e os resultados aparecem na seção 4.1.1.1. 
Tabela 3.3 Ataque químico Lepera modificado.

\begin{tabular}{c|c|c}
\hline \multirow{2}{*}{ Estágios } & 1 & 2 \\
\cline { 2 - 3 } & Pré-ataque Nital 2\% & Lepera Modificado \\
\hline \multirow{3}{*}{ Tempos de ataque (s) } & 10 & 10 \\
& 10 & 15 \\
& 10 & 20 \\
& 10 & 25 \\
& 10 & 30 \\
\hline
\end{tabular}

\subsubsection{2}

\section{Ataque eletrolítico Ikawa}

$\mathrm{O}$ ataque Ikawa é usado para observação em MEV. $\mathrm{O}$ ataque 1 revela os contornos de grão da ferrita e o ataque 2 retira preferencialmente carbonetos deixando o microconstituinte AM em alto relevo [17]. A sequência do ataque químico realizado foi como segue:

- Ataque Ikawa método original.

- Ataque Ikawa variando tempos de ataque 1 e ataque 2.

- Ataque Ikawa substituindo ataque 1, por nital 2\%.

Os parâmetros são apresentados na Tabela 3.4 e os resultados são mostrados na seção 4.1.2.1.

Tabela 3.4 Ataque químico Ikawa.

\begin{tabular}{l|c|c}
\hline \multicolumn{1}{c|}{ Estágios } & $\begin{array}{c}\text { Ataque 1 } \\
\text { Tempos (s) }\end{array}$ & $\begin{array}{c}\text { Ataque 2 } \\
\text { Tempos (s) }\end{array}$ \\
\hline Ataque Ikawa método original & 3 & 30 \\
Variação tempos de ataque 1 e 2 & 30 & 80 \\
Subsituição do ataque 1 & Nital 2\% (10 s) & 80 \\
\hline
\end{tabular}

Voltagem utilizada: ataque 1 - $3 \mathrm{~V}$, ataque 2 - 6V 


\subsubsection{3}

\section{Ataque Misto}

$\mathrm{O}$ ataque misto se baseia no trabalho de Alé R. M., et. al. [20] e utiliza o método Lepera modificado completo, seguido do segundo ataque de Ikawa, como explicado na seção 2.4.3.

Foram testados diferentes tempos, conforme se demonstram na Tabela 3.5. Os resultados são apresentados na seção 4.1.1.2 (MO) e seção 4.1.2.2 (MEV).

Tabela 3.5 Método de ataque químico misto.

\begin{tabular}{c|c|c|c|c}
\hline \multirow{2}{*}{ Estágios } & $\begin{array}{c}1 \\
\text { Pré-ataque } \\
\text { Nital 2\% }\end{array}$ & $\begin{array}{c}2 \\
\text { Lepera } \\
\text { modificado }\end{array}$ & $\begin{array}{c}3 \\
\text { Ikawa ataque }\end{array}$ & Observações \\
\hline \multirow{3}{*}{ Tempo (s) } & 10 & 20 & 80 & Variação de tempo \\
& 10 & 20 & 120 & ataque: Ikawa ataque \\
& 10 & 20 & 160 & 2 \\
\hline \multirow{3}{*}{ Tempo (s) } & 10 & 20 & 200 & Variação de tempo \\
& 10 & 20 & 160 & $\begin{array}{c}\text { ataque: Lepera } \\
\text { modificado }\end{array}$ \\
\hline
\end{tabular}

\subsubsection{4}

\section{Ataque misto acrescentando um passo Lepera Modificado}

O ataque químico proposto se baseia na utilização do método misto, acrescentando um passo a mais: o ataque Lepera modificado na última etapa.

A finalidade foi aumentar a refletância de luz do AM para otimizar o contraste em imagens de MO.

As condições estão listadas na Tabela 3.6 e os resultados são apresentados na seção 4.1.1.3. 
Tabela 3.6 Ataque misto acrescentando um passo Lepera Modificado.

\begin{tabular}{c|c|c|c|c|c}
\hline \multirow{2}{*}{ Estágios } & $\begin{array}{c}1 \\
\text { Pré-ataque } \\
\text { Nital 2\% }\end{array}$ & $\begin{array}{c}2 \\
\text { Lepera } \\
\text { mod. }\end{array}$ & $\begin{array}{c}3 \\
\text { Ikawa } \\
\text { ataque 2 }\end{array}$ & $\begin{array}{c}4 \\
\text { Lepera } \\
\text { mod. }\end{array}$ & Observações \\
\hline \multirow{2}{*}{ Tempos (s) } & 10 & 20 & 160 & 5 & Voltagem utilizada \\
& 10 & 25 & 160 & 5 & Ataque 2 Ikawa: 6V \\
\hline
\end{tabular}

\section{2 .2}

\section{Aquisição de imagens}

\subsubsection{1}

\section{Aquisição de imagens ao microscópio ótico (MO)}

O microscópio ótico utilizado neste trabalho foi um equipamento Zeis AxioImager M2m, motorizado, com câmera digital Axiocam HR MRc5. Utilizouse uma lente Epiplan de 100X no modo de reflexão em campo claro.

A resolução digital da câmera utilizada de 1292 x 968 pixels, chega-se a uma escala de $0,109 \mu \mathrm{m} /$ pixel.

Como os ataques têm por objetivo gerar cores que facilitem a discriminação entre as fases presentes, as imagens foram capturadas no modo RGB (Red-GreenBlue) com 8 bits por canal. Para garantir a estabilidade das cores, usou-se controle digital do brilho da lâmpada do microscópio.

Foram capturadas imagens das amostras com diferentes ataques químicos:

- Ataque Lepera modificado conforme Tabela 3.3, seção 3.2.1.1.

- Ataque misto conforme Tabela 3.5, seção 3.2.1.3.

- Ataque misto acrescentando um passo Lepera Modificado conforme Tbela 3.6, seção 3.2.1.4.

Os resultados são apresentados: ataque Lepera modificado na seção 4.1.1.1 ataque misto seção 4.1.1.2 e ataque misto acrescentando um passo Lepera modificado na seção 4.1.1.3. 


\subsubsection{2}

\section{Aquisição de imagens ao microscópio eletrônico de varredura (MEV)}

A aquisição de imagens ao microscópio eletrônico de varredura foi realizada com um equipamento JEOL 65. As imagens foram capturadas nos modos de elétrons secundários (SE) e de elétrons retroespalhados (BSE). No caso de SE os parâmetros utilizados foram: tensão de aceleração de $20,25,30 \mathrm{kV}$, distância de trabalho $10 \mathrm{~mm}$. No caso de BSE os parâmetros utilizados foram: tensão de aceleração variável $5 \mathrm{kV}$ a $30 \mathrm{kV}$.

As imagens foram capturadas com resolução de 1280 x 960 pixels e quantização de 8 bits (256 tons de cinza).

Foram capturadas imagens das amostras com os seguintes ataques químicos:

- Ataque Ikawa conforme Tabela 3.4, seção 3.2.1.2.

- Ataque misto conforme Tabela 3.5, seção 3.2.1.3.

- Ataque misto acrescentando um passo Lepera Modificado conforme Tabela 3.6, seção 3.2.1.4.

\section{2 .3}

Microscopia Co-Localizada

No presente trabalho foi aplicada a técnica de microscopia Co-localizada, descrita na seção 2.5.2, visando comparar as imagens de campos equivalentes obtidas por MO e MEV. As imagens para as etapas de alinhamento manual e digital foram preparadas de acordo com os passos descritos nas seções a seguir.

\subsubsection{1}

\section{Calibração de Aumento MO-MEV}

Para a calibração foi utilizado o padrão "MRS-3, s/n R16-170 magnification standard", mostrado na Figura 3.2 no MO e na Figura 3.3 no MEV. Uma mesma distância em $\mu \mathrm{m}$ e em pixels foi medida em ambas as imagens. O aumento do MEV foi ajustado para que o tamanho do pixel fosse igual ao da imagem de MO. 


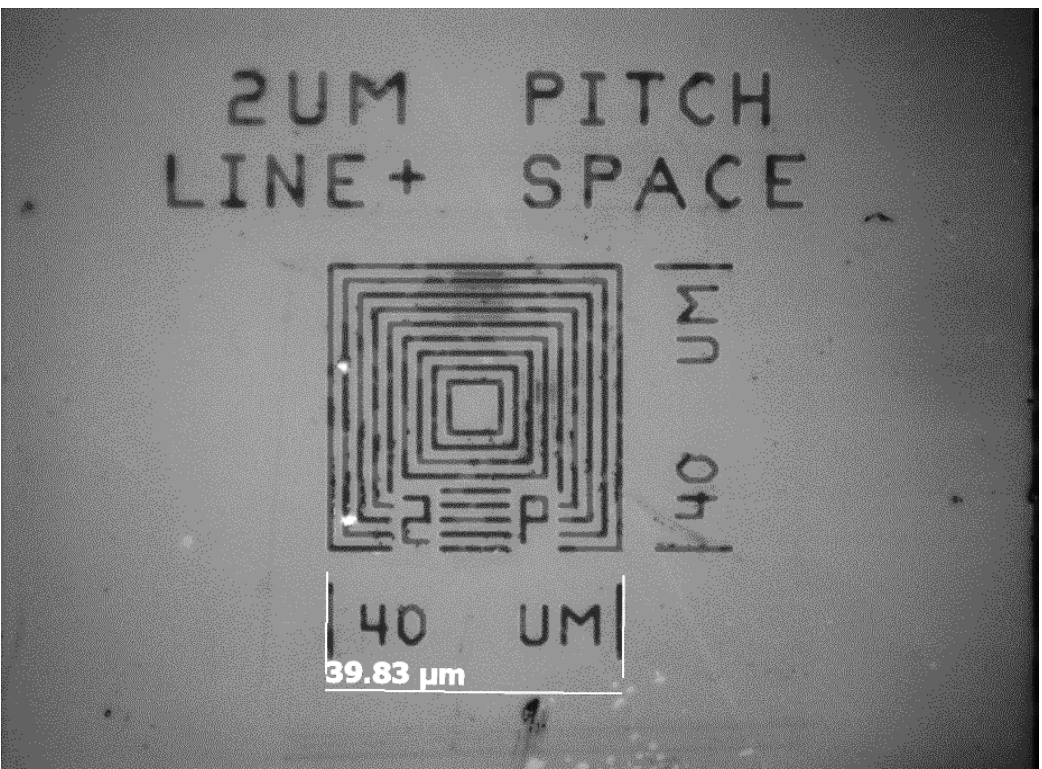

Figura 3.2 Verificação de padrão de calibração no microscópio ótico.

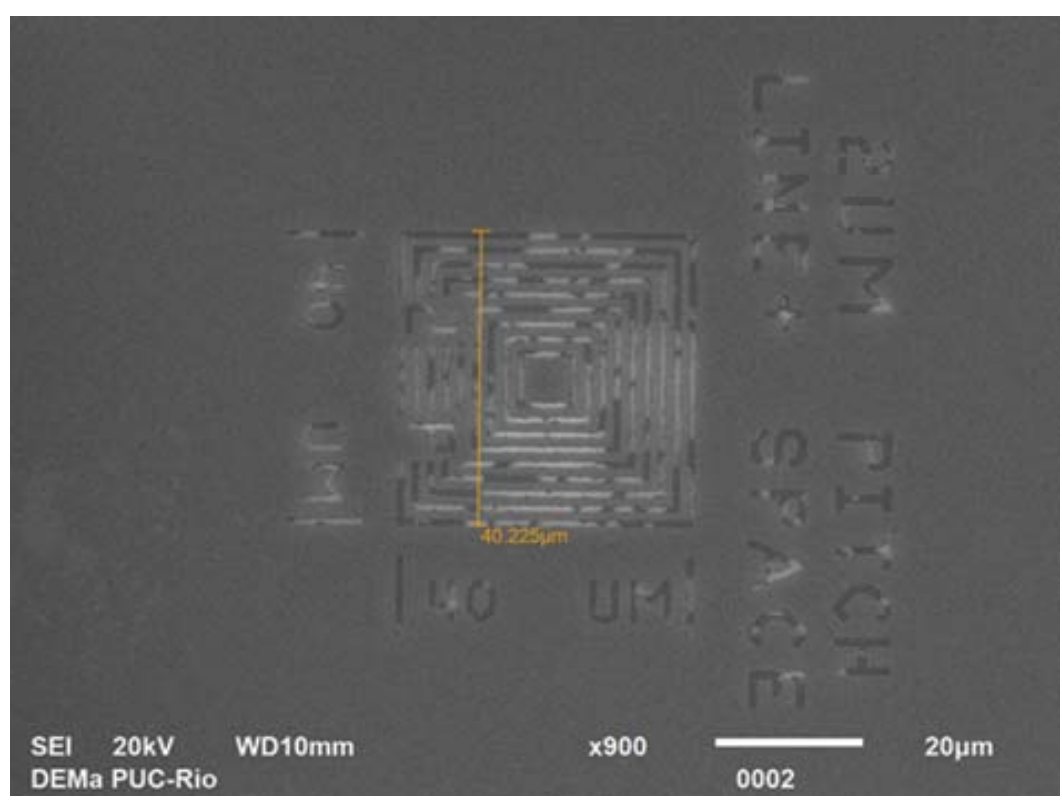

Figura 3.3 Verificação de padrão de calibração no microscópio eletrônico de varredura.

Tabela 3.7 Aumentos do MO - MEV.

\begin{tabular}{c|cc|c}
\hline \multirow{2}{*}{$\begin{array}{c}\text { Tamanho de } \\
(\mu \mathrm{m}) / \text { Pixel }\end{array}$} & \multicolumn{2}{|c|}{ Microscópio Ótico } & $\begin{array}{c}\text { Microscópio Eletrônico de } \\
\text { Varredura }\end{array}$ \\
\cline { 2 - 4 } & $\begin{array}{c}\text { Lente Objetiva } \\
(\mathrm{X})\end{array}$ & $\begin{array}{c}\text { Aumento no } \\
(\mathrm{MO})\end{array}$ & Aumento no MEV \\
\hline 0,109 & $100 \mathrm{X}$ & 1000 & - \\
\hline 0,110 & - & & 900 \\
\hline
\end{tabular}


Operacionalmente não foi possível conseguir no MEV exatamente a calibração desejada já que a variação de aumento no MEV utilizada tem um passo mínimo de 50X. Ainda assim foi possível atingir uma resolução de 0,109 $\mu \mathrm{m} /$ pixel para o MO para a lente objetiva de 100X (aumento total aproximado de 1000 ) e $0,110 \mu \mathrm{m} /$ pixel no MEV (aumento nominal de 900X). Assim, a diferença de resolução entre os dois microscópios foi de apenas $0.001 \mu \mathrm{m} /$ pixel.

\subsubsection{2}

\section{Pontos de referência nas amostras}

Uma das limitações para fazer microscopia Co-Localizada é a perda de registro de translação e rotação, quando a amostra é trocada de microscópio. Deste modo identações de dureza Vickers foram utilizadas como referência para um primeiro alinhamento, conforme mostrado na Figura 3.4.

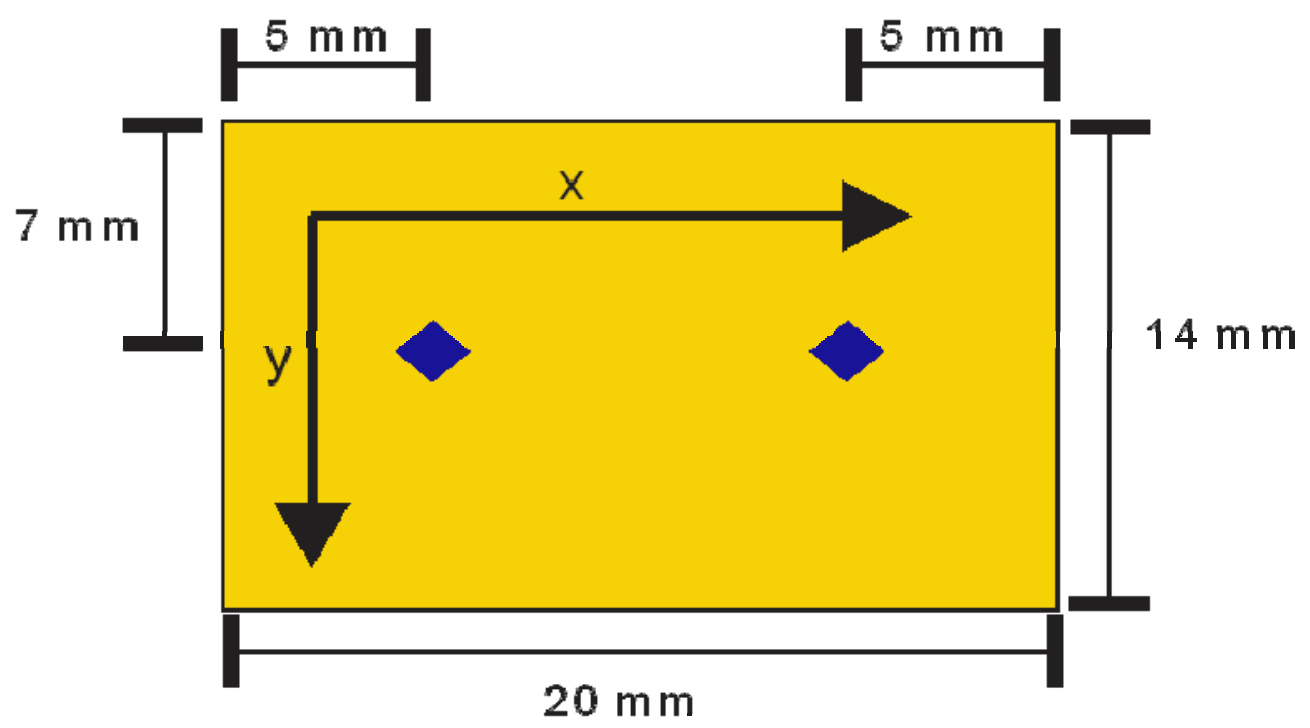

Figura 3.4 Identificação de amostras com identação de micro dureza.

Finalmente as imagens foram alinhadas, através do processamento de imagens, com a Função SIFT (Scale Invariant Feature Transform), transformada de características invariantes por escala, que realizam alinhamento automático entre imagens [32]. 


\subsubsection{3}

\section{Quantificação do Microconstituinte AM}

Uma vez estabelecido o procedimento para o alinhamento preciso entre os campos correspondentes em MO e MEV, buscou-se quantificar o microconstituinte AM em ambos os microscópios e comparar os resultados. Foram capturados 30 campos no MO, conforme mostrado na Figura 3.5. Em seguida a amostra foi levada ao MEV, já ajustada para o aumento correto. Passouse então, ao alinhamento inicial utilizando as marcas de dureza e 30 campos similares foram capturados. Cada um destes campos foi alinhado com seu correspondente de MO, utilizando a função SIFT. Finalmente, cada campo foi processado e analisado para medir a fração de área de $\mathrm{AM}$ e os resultados foram comparados.

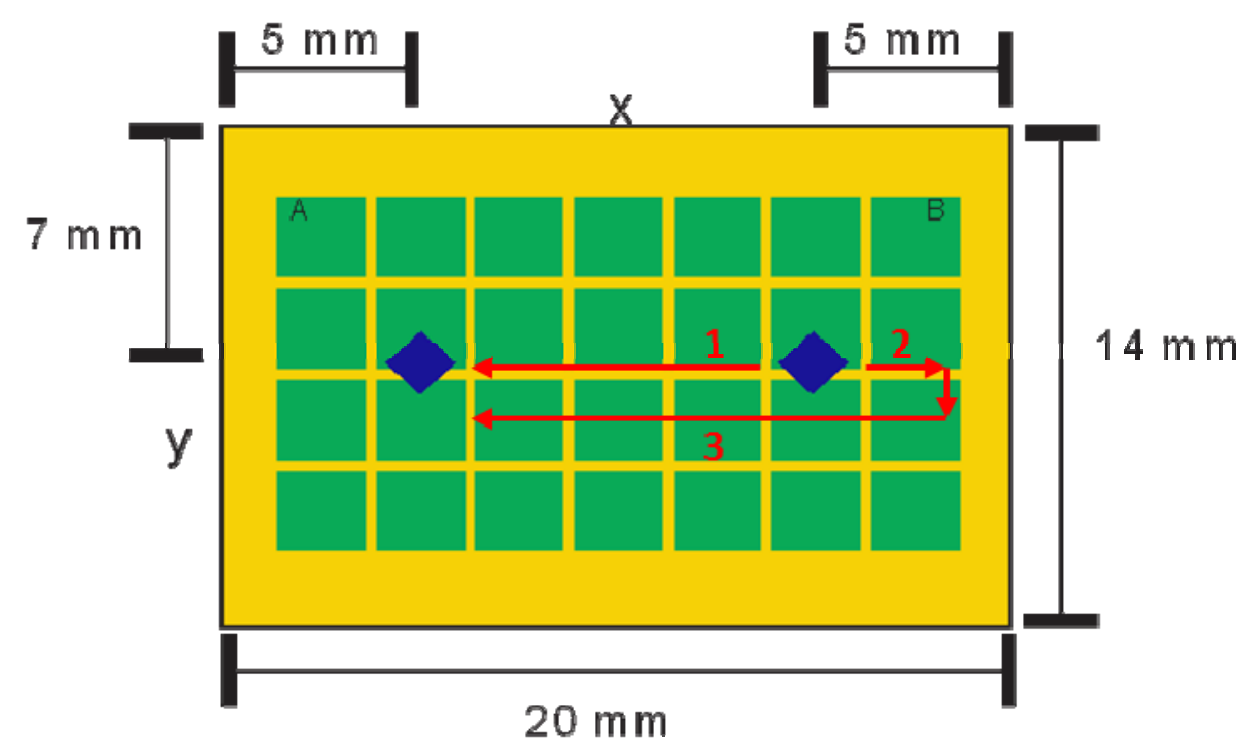

Figura 3.5 Representação esquemática de captura de imagens de microscopia CoLocalizada MO-MEV.

Neste trabalho as imagens foram processadas e analisadas à fração volumétrica AM com as funções disponíveis no software FIJI. Mostram-se os comandos do menu "Analize", na Figura 3.6, que serão utilizados na etapa de extração de atributos, medição e análise. 


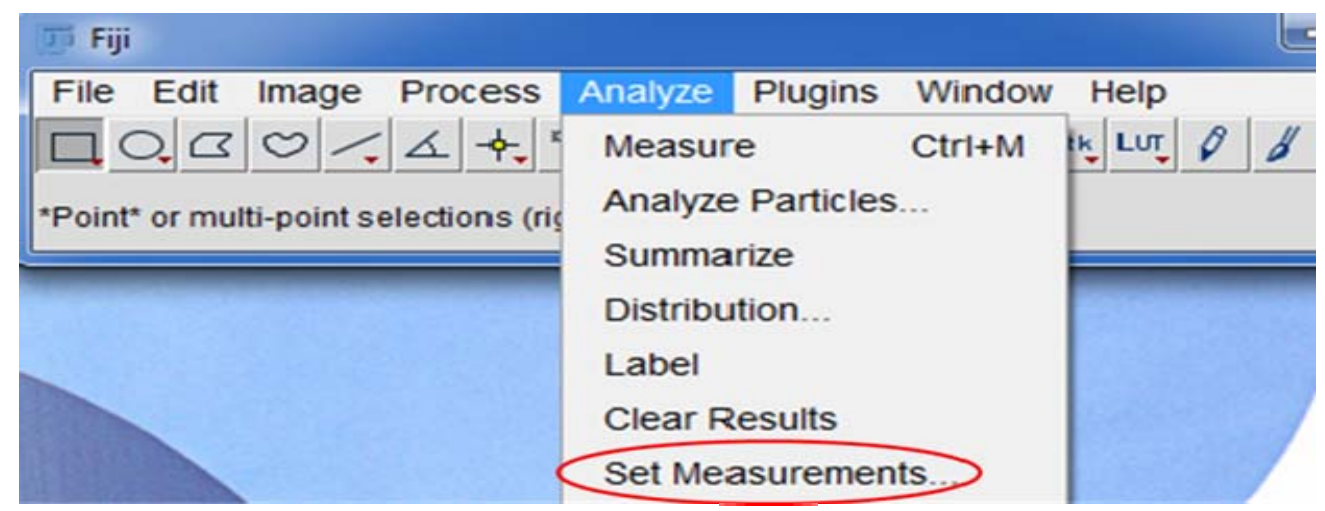

Figura 3.6 Funções disponíveis no software FIJI (40).

Comandos do menu "Analyze - Set Measurements". Esta caixa de diálogo justifica-se por especificar quais são as medições de análise e de registro, Figura 3.7.

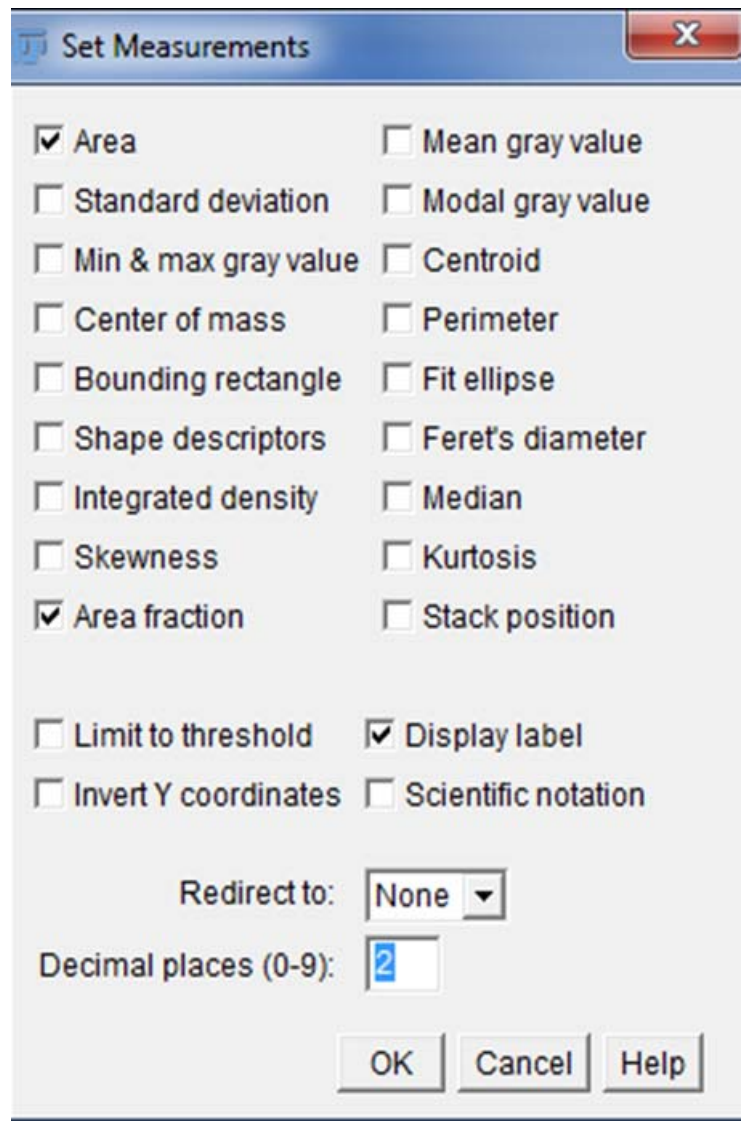

Figura 3.7 Caixa de diálogo para especificar as medições por análise [40].

“Área”. Mostra o resultado de área da seleção em pixels em quadrados, ou em unidades quadradas como foram definidas na escala da calibração.

“Área fraction”. É útil para verificar as imagens de limiar definido. É a percentagem de pixels de interesse na imagem, seguindo a equação (1). 
"Redirect to". É a imagem selecionada a partir deste menu. Será usada a janela como destino para os cálculos feitos por análise estatística.

Comandos do menu "Analise - Analise Partículas". Está descrito na interface de usuário. Este menu contém comandos relacionados às medidas estatísticas sobre o perfil dos dados de imagem e o histograma de plotagem e plugins relacionados à análise da imagem.

O comando realiza as medidas de objetos em imagens binárias, ou limiarizada, "Image Adjust Threshold or Color Threshold". A análise é efetuada sobre a seleção da área existente, ou da imagem inteira, caso nenhuma seleção esteja presente, como se mostra na Figura 3.8.

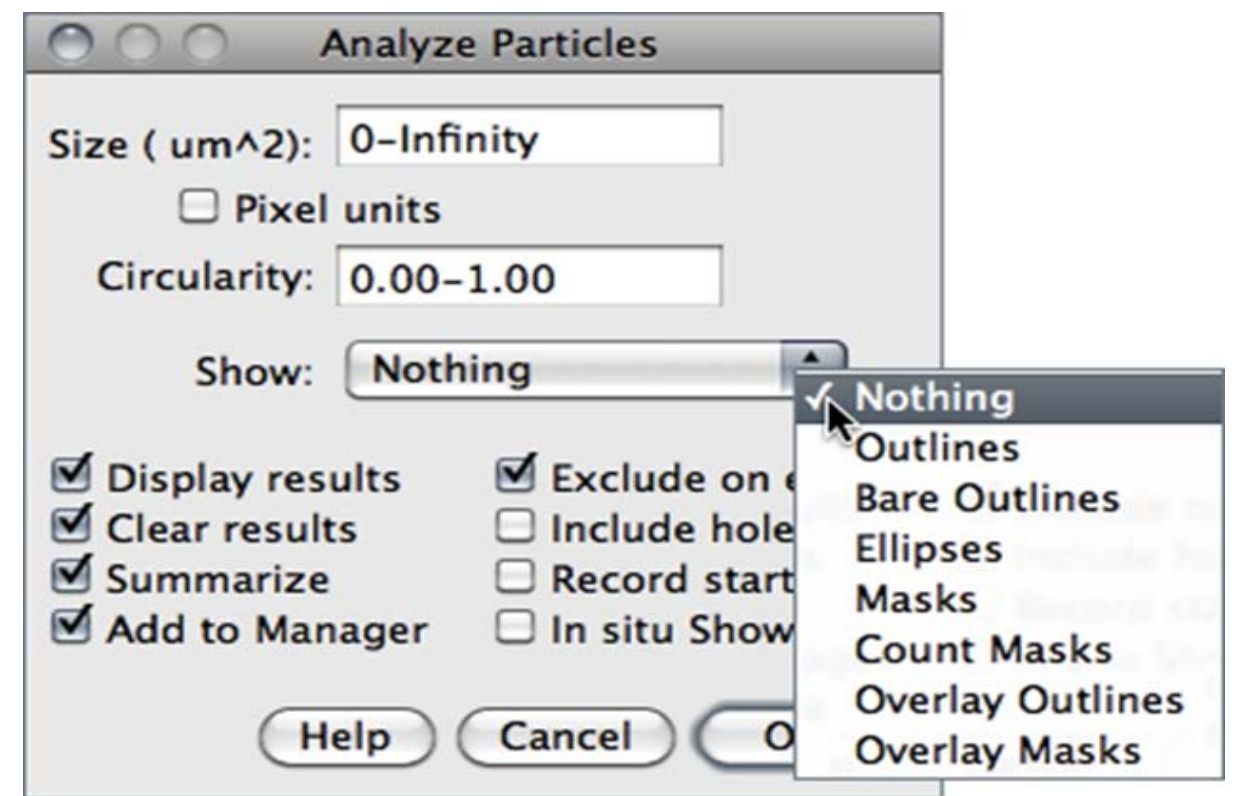

Figura 3.8 Interface de análise - análise de partículas [40].

"Size (um^2)". Tamanho de Partículas (área); Os valores fora do intervalo especificados neste campo são ignorados. Os valores podem ser no intervalo 0 'Infinity'.

"Circularity". Partículas com valores de tamanho de circularidade fora do intervalo especificado neste campo são também ignorados. Os valores podem ser no intervalo $0-1$, onde " 0 " (polígono infinitamente alongado), "1" círculo perfeito).

"Show". Especifica qual imagem deve exibir depois da análise (ver opções de exibição de Analisador de Partículas). 
"Clear Results". Se estiver marcada, qualquer medida anterior listada na Tabela de Resultados será apagada.

"Summarize". Mostra uma tabela com resumo separado. A contagem de partículas, a área total de partículas, o tamanho médio de partícula da área, a fração de área é média de todos os parâmetros listados na caixa de diálogo.

"Add to Manager". As partículas medidas serão adicionadas ao administrador da região de interesse (ROI).

"Exclude on Edges". As partículas que tocam a borda da imagem (ou seleção) serão ignoradas.

"Include Holes". Os buracos interiores serão incluídos.

“In situ Show”. A imagem original será substituída pela máscara binária especificada.

Para as imagens espaciais em escala "Set Scale", Figura 3.9, os valores são expressos em unidades físicas, em quadrados de tamanho, ou em pixels, se as unidades de pixel estiverem marcadas.

"Set Scale". Este diálogo é para definir a escala espacial da imagem ativa assim que os resultados da medição forem apresentados em unidades calibradas, tais como $\mathrm{mm}, \mu \mathrm{m}$ ou outros.

Antes de se utilizar este comando, utiliza-se a ferramenta de seleção de linha reta para fazer uma seleção de linha, correspondente a uma distância conhecida.

Após isso é importante abrir o diálogo conjunto escale, digitar a distância conhecida e a unidade de medida e em seguida, clicar em "OK".

FIJI terá preenchido automaticamente a distância em pixels campo, com base no comprimento da linha de seleção. Quando o campo global está marcado, a escala definida nesta caixa de diálogo é usada para todas as imagens abertas durante a sessão atual. 
Set Scale

Distance in pixels: 1280

Known distance: 141.9

Pixel aspect ratio: $\quad 1.0$

Unit of length: um

Click to Remove Scale

V Global

Scale: 9.020 pixels/um

OK Cancel Help

Figura 3.9 Interface de "Set Scale" [40]. 
4

Resultados e Discussão

4.1

Otimização do ataque químico e das técnicas de microscopia

\subsection{1}

\section{Microscopia Ótica}

\subsubsection{1}

Ataque químico Lepera Modificado

Os resultados das imagens obtidas, de acordo com a Tabela 3.3, são apresentados nas Figura 4.1 a Figura 4.4. É possível notar que o contraste ótimo ocorre para tempos entre 20 e $25 \mathrm{~s}$. Para tempos menores o microconstituinte fica mal revelado, enquanto para os tempos maiores (Figura 4.5) surgem na superfície, manchas azuladas, que prejudicam a análise.

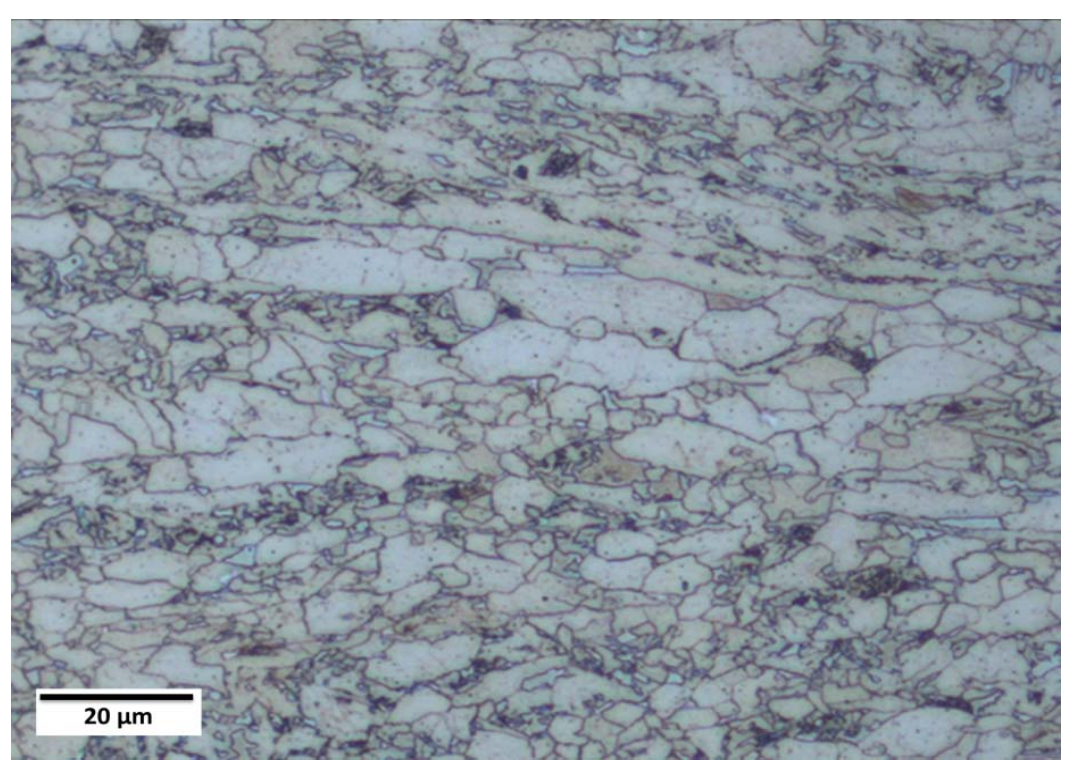

Figura 4.1 MO Tempo de ataque $10 \mathrm{~s}$, aumento 1000X. 


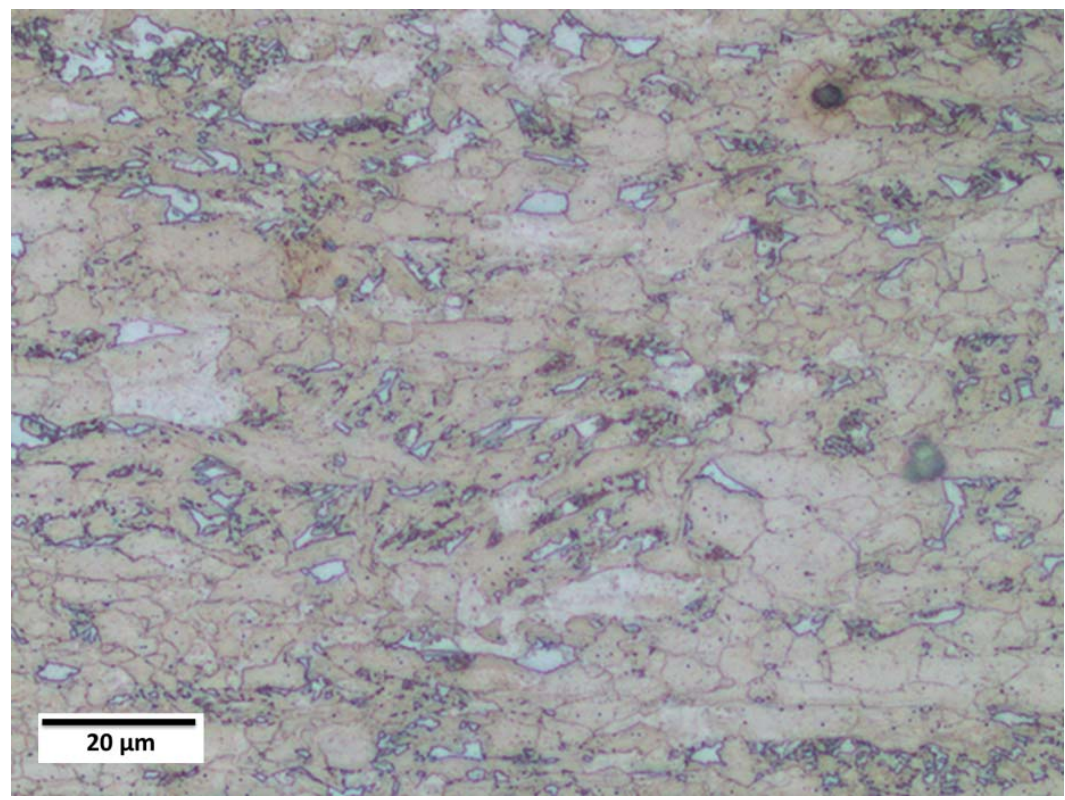

Figura 4.2 . MO. Tempo de ataque $15 \mathrm{~s}$, aumento 1000X.

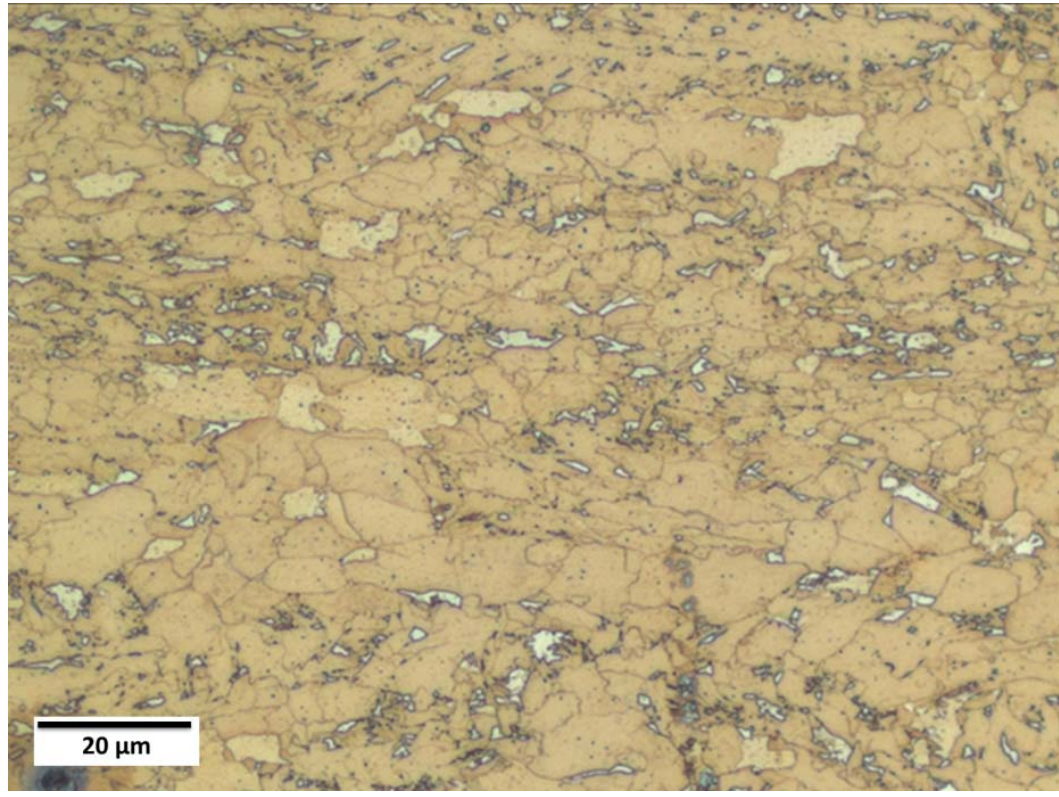

Figura 4.3 MO. Tempo de ataque $20 \mathrm{~s}$, aumento 1000X. 


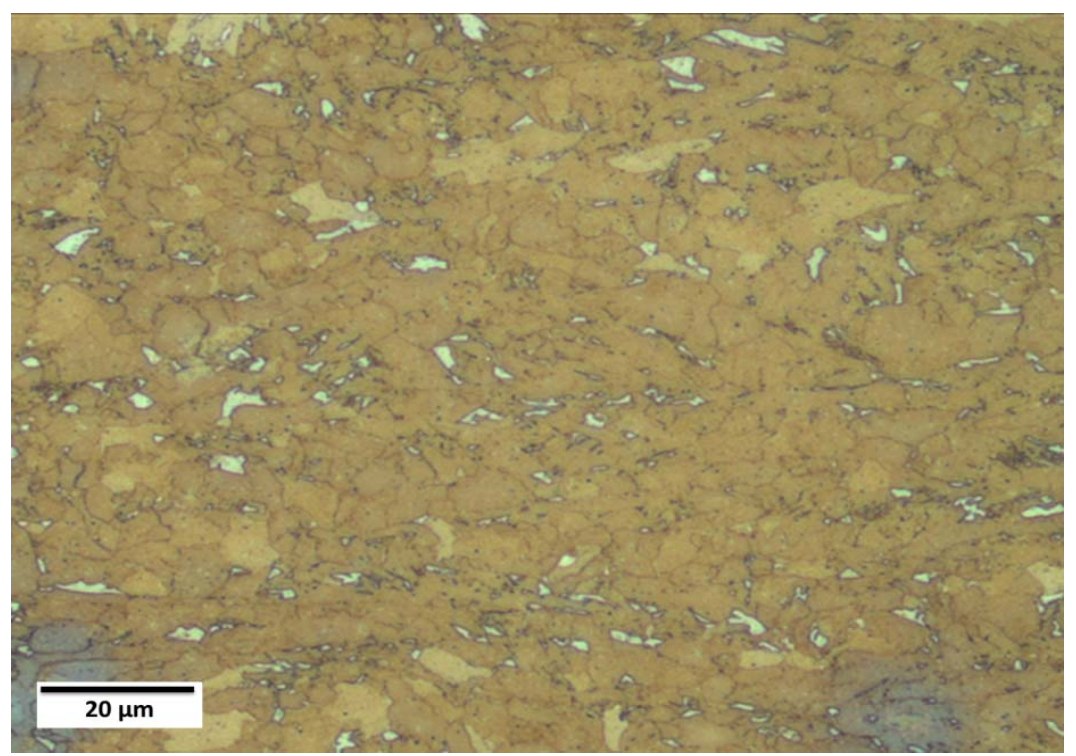

Figura 4.4 MO. Tempo de ataque $25 \mathrm{~s}$, aumento 1000X.

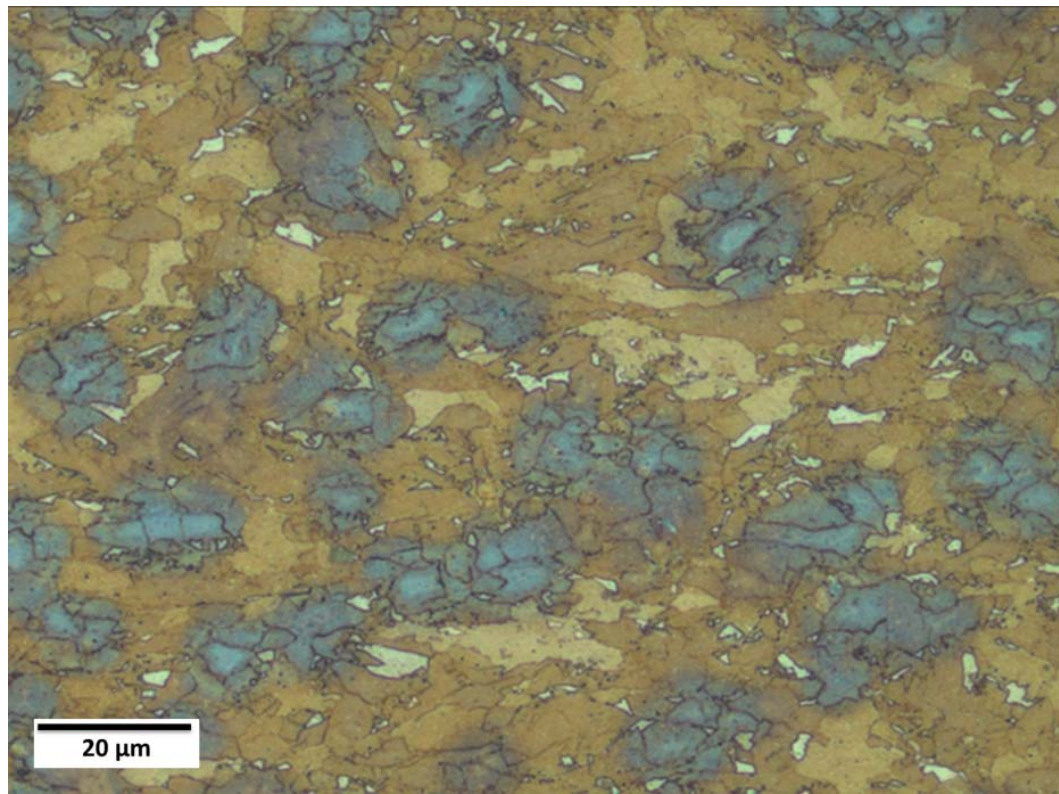

Figura 4.5 MO. Tempo de ataque $30 \mathrm{~s}$, aumento 1000X.

\subsubsection{2}

\section{Ataque Misto}

Mistura de dois métodos, Lepera modificado e ataque 2 de Ikawa, de acordo com Tabela 3.5 na seção 3.2.1.3. As imagens foram capturadas com MO e MEV.

As imagens capturadas com este método mostraram resultados muito mais consistentes, com uma melhora no contraste das imagens (Figura 4.6, Figura 4.7). Os tempos para o ataque Lepera modificado mostraram uma faixa ótima de $20 \mathrm{~s}$ a 
$25 \mathrm{~s}$. Além disto, este método tem a vantagem da captura de imagens em ambos os microscópios, no caso do MEV foram capturadas no modo elétron secundários (SE), Figura 4.17, seção 4.1.2.2.

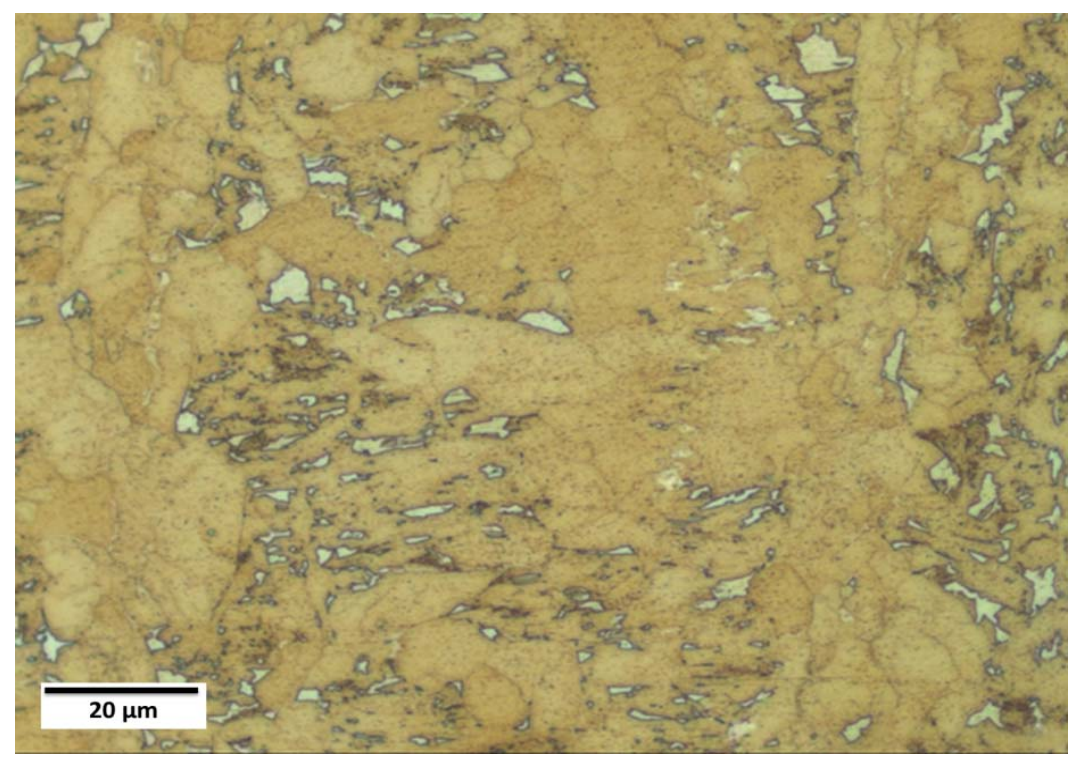

Figura 4.6 MO Ataque Misto (1) $20 \mathrm{~s}$, (2) $160 \mathrm{~s}$, aumento 1000X.

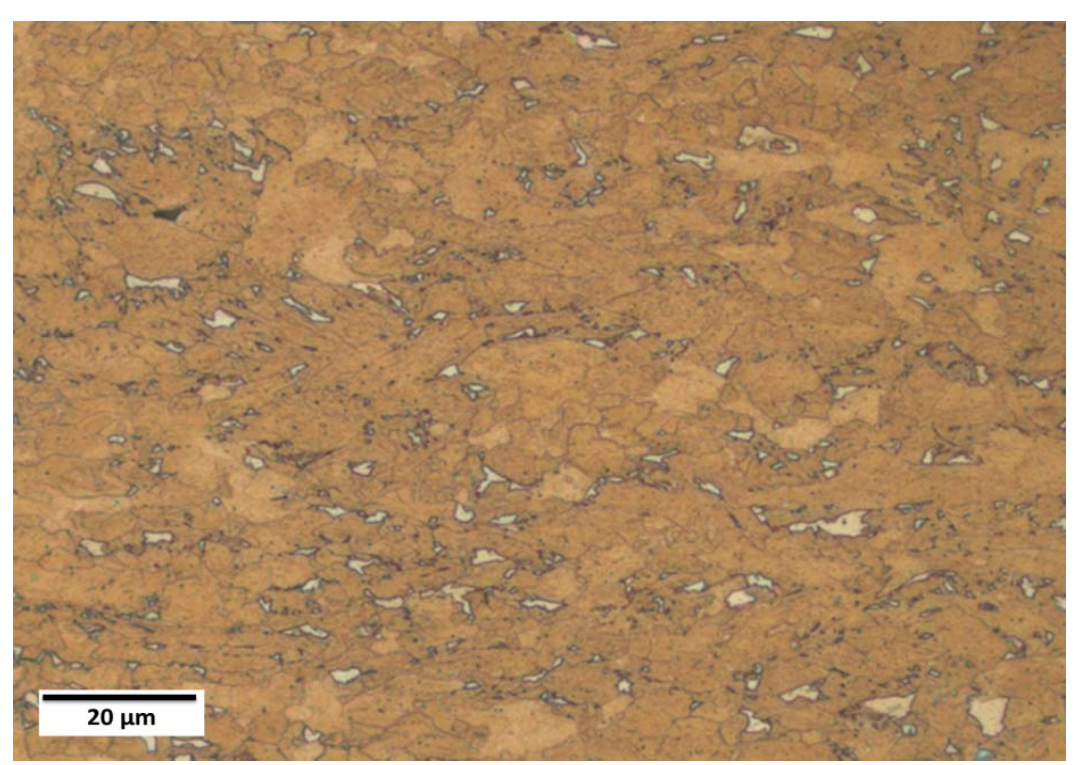

Figura 4.7 MO Ataque Misto (1) $25 \mathrm{~s}$, (2) $160 \mathrm{~s}$, aumento 1000X. 


\subsubsection{3}

\section{Ataque misto acrescentando um passo Lepera Modificado}

$\mathrm{O}$ ataque químico proposto se baseia na utilização do método misto acrescentando um passo a mais do ataque Lepera modificado na última etapa. A Tabela 3.6, na seção 3.2.1.4, apresenta a sequência proposta. Figura 4.8 e Figura 4.9 .
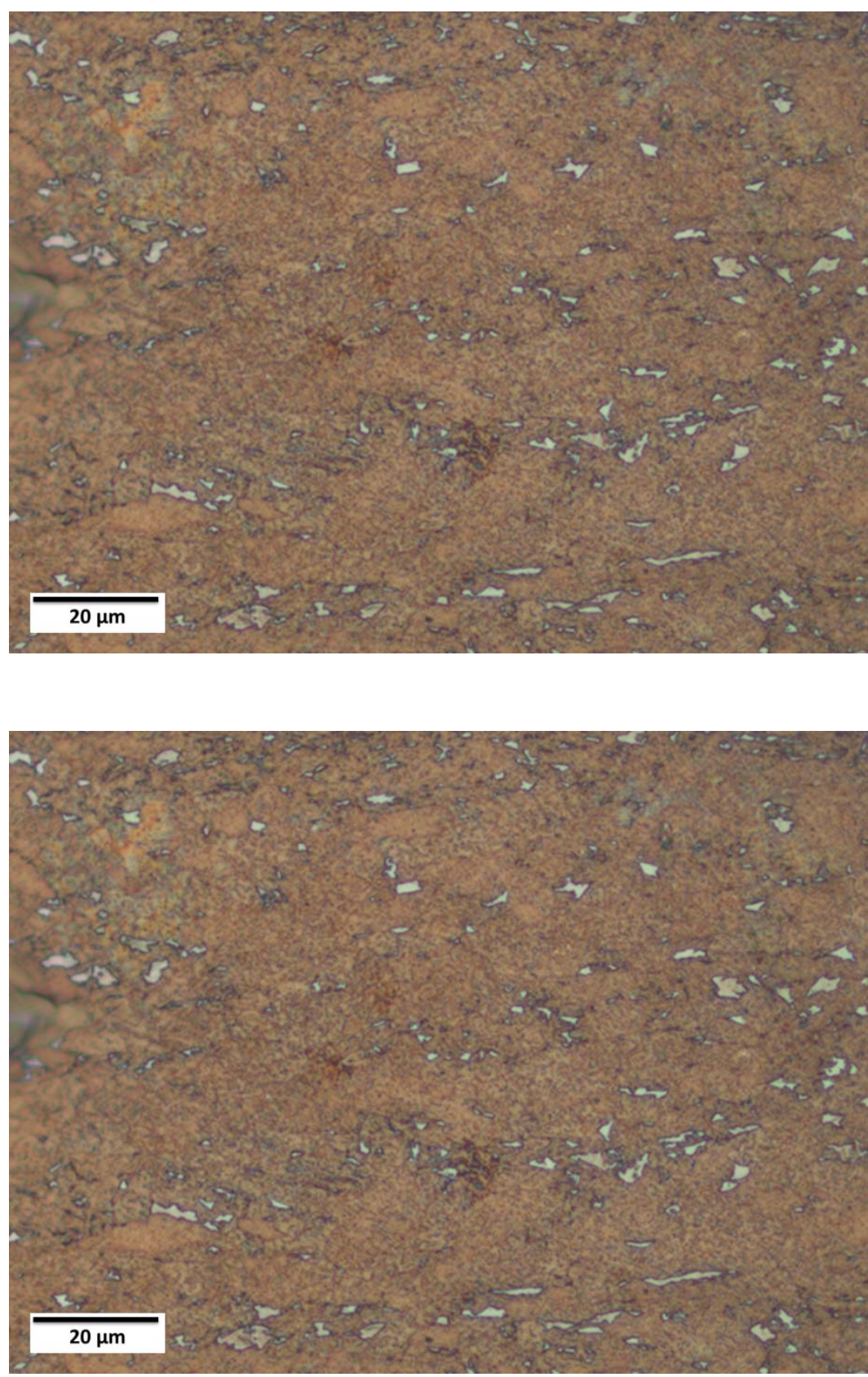

Figura 4.8 Ataque misto acrescentando um passo Lepera Modificado (Lepera Modificado: 20 s, Ikawa 2: 160 s, Lepera Modificado: 5 s). MO aumento1000X. 


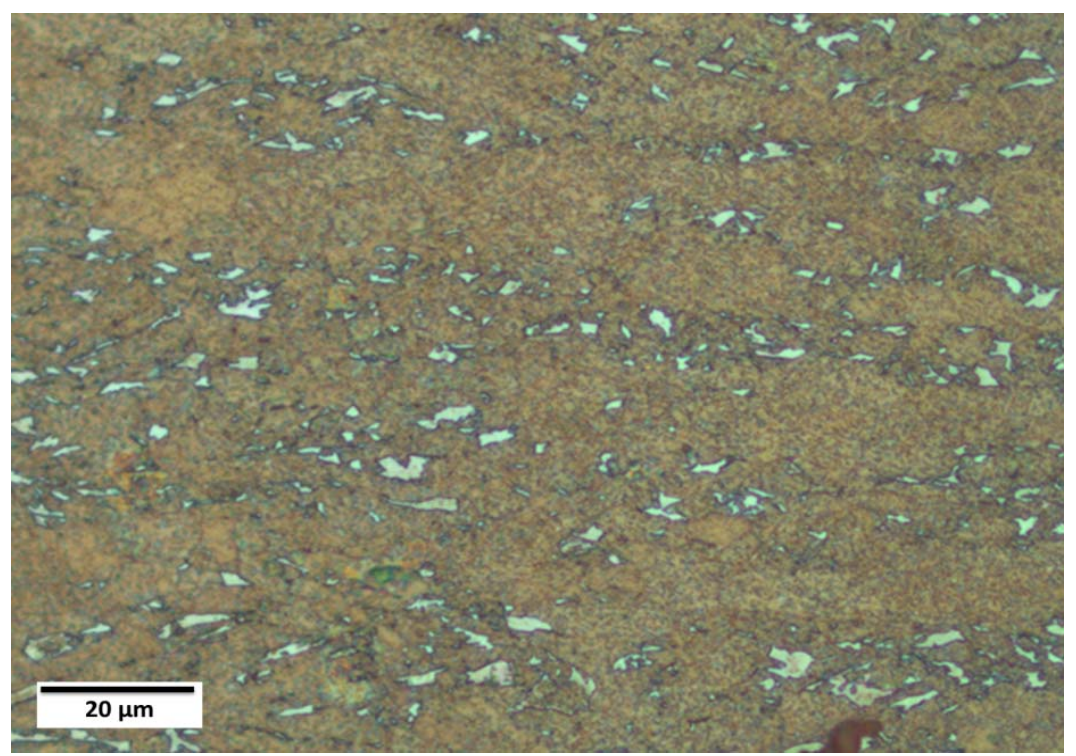

Figura 4.9 Ataque misto acrescentando um passo Lepera Modificado (Lepera Modificado: 25 s, Ikawa 2: 160 s, Lepera Modificado: 5 s). MO aumento 1000X.

Entre os métodos usados este foi o que apresentou o melhor resultado em relação à microscopia ótica. As imagens mostraram bom contraste, efeito de um passo a mais no processo do ataque Lepera modificado. $\mathrm{O}$ reagente aplicado na última etapa melhora a espessura do filme na superfície atacada, o que melhorou o contraste para a observação no microscópio ótico.

\subsection{2}

\section{Microscopia eletrônica de varredura}

\subsubsection{1}

\section{Ataque eletrolítico Ikawa}

Neste procedimento foram utilizados os seguintes parâmetros:

a) Captura de imagens nos modos SE e BSE.

Os parâmetros utilizados no ataque químico foram os mesmos para os três casos: método original Ikawa, Ikawa com variação de tempo do ataque 1, 2 e Ikawa com substituição do ataque 1 com nital 2\% (mostrados na Tabela 3.4, da Seção 3.2.1.2). 


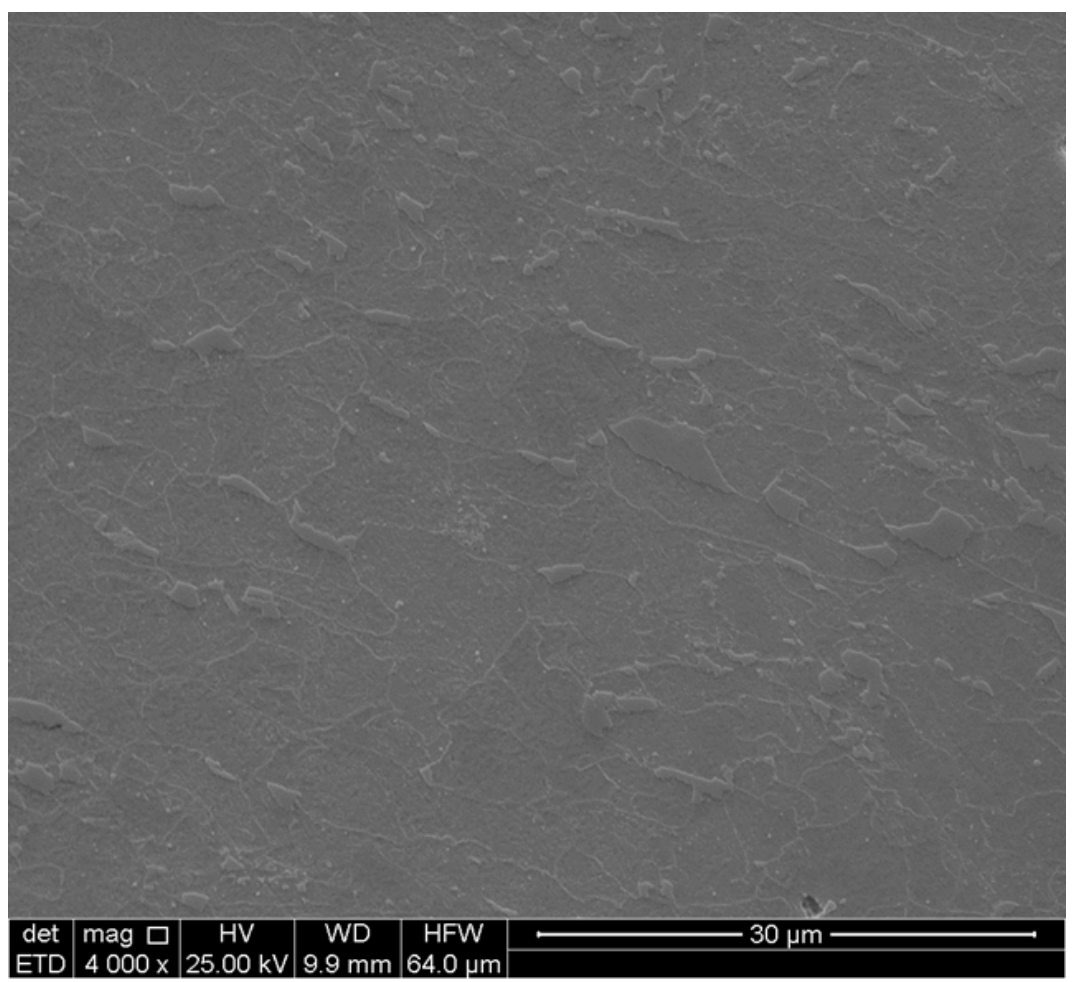

Figura 4.10 MEV (SE) Ataque 1: $3 \mathrm{~s}$. Ataque 2: $30 \mathrm{~s}$ aumento 4000X

b) Parâmetros do microscópio eletrônico de varredura:

- Tensão de aceleração $25 \mathrm{kV}$.

- Distância de trabalho de $10 \mathrm{~mm}$.

- Aumento 4000X.

O método original Ikawa (Ataque 1: $3 \mathrm{~s}$. Ataque 2: $30 \mathrm{~s}$.), não mostrou bons resultados (SE - Figura 4.10, BSE - Figura 4.11). 


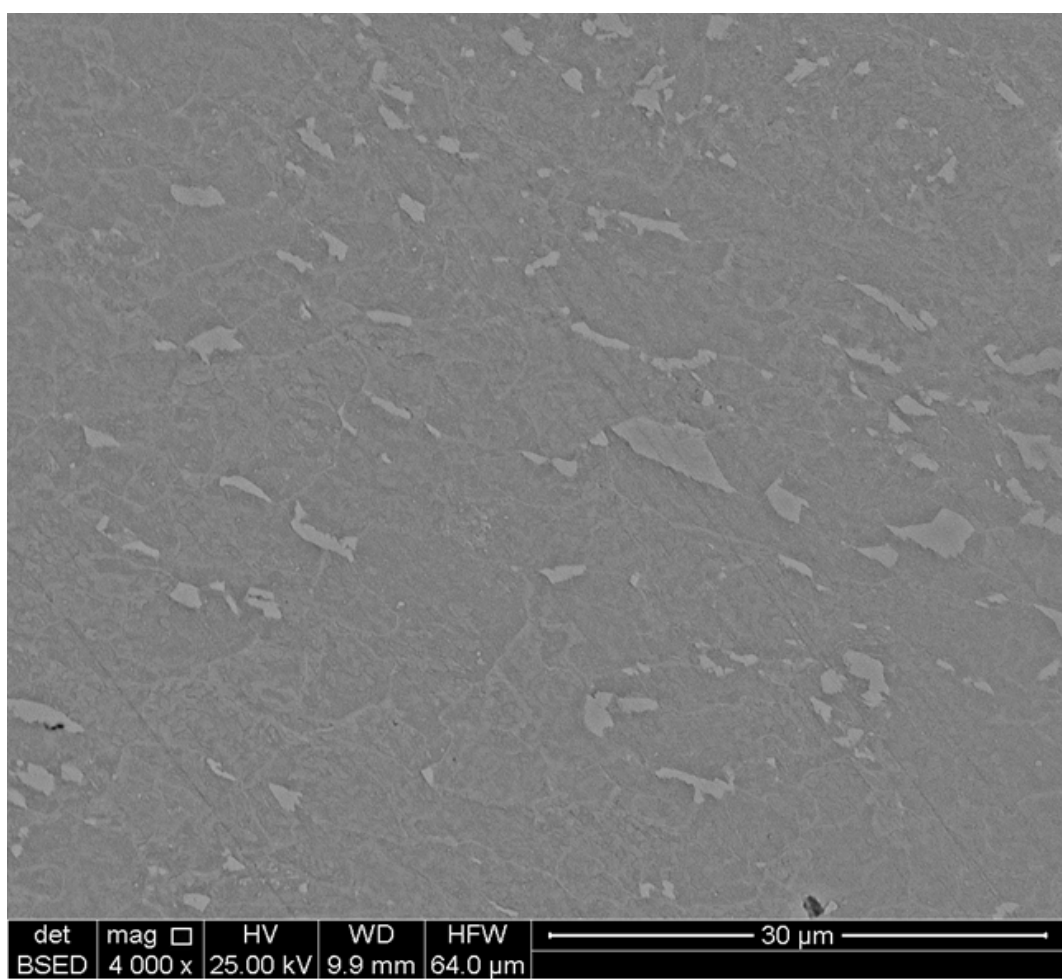

Figura 4.11 MEV (BSE) Ataque 1: $3 \mathrm{~s}$. Ataque 2: $30 \mathrm{~s}$, aumento 4000X.

Com a finalidade de buscar alternativas para melhorar o contraste, testaramse vários tempos para cada ataque (Ataque 1: $30 \mathrm{~s}$. Ataque 2: $80 \mathrm{~s}$.). Os resultados não mostraram melhora significativa nas (Figura 4.12, Figura 4.13), as imagens obtidas ainda apresentavam contraste muito baixo, tornando a etapa de PADI inviável. 


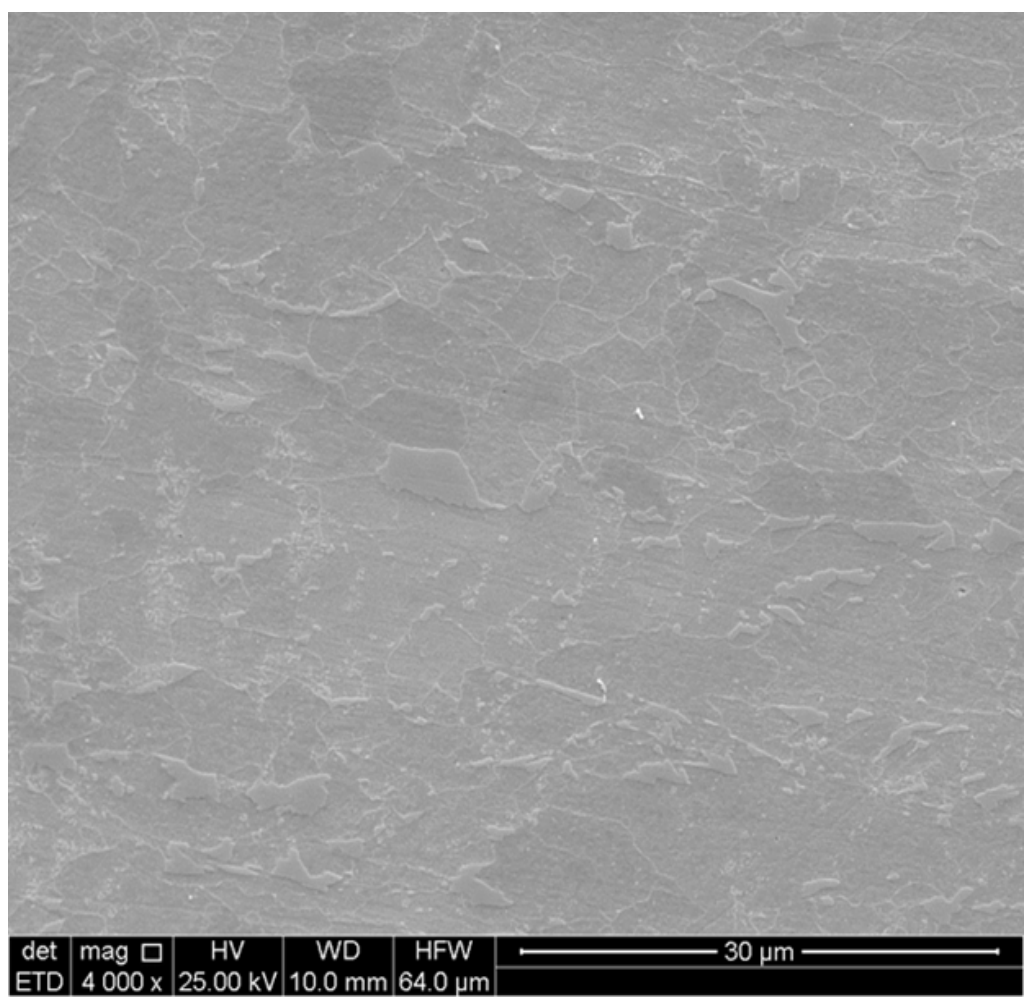

Figura 4.12 MEV (SE) Ataque 1: $30 \mathrm{~s}$. Ataque 2: $80 \mathrm{~s}$, aumento 4000X.

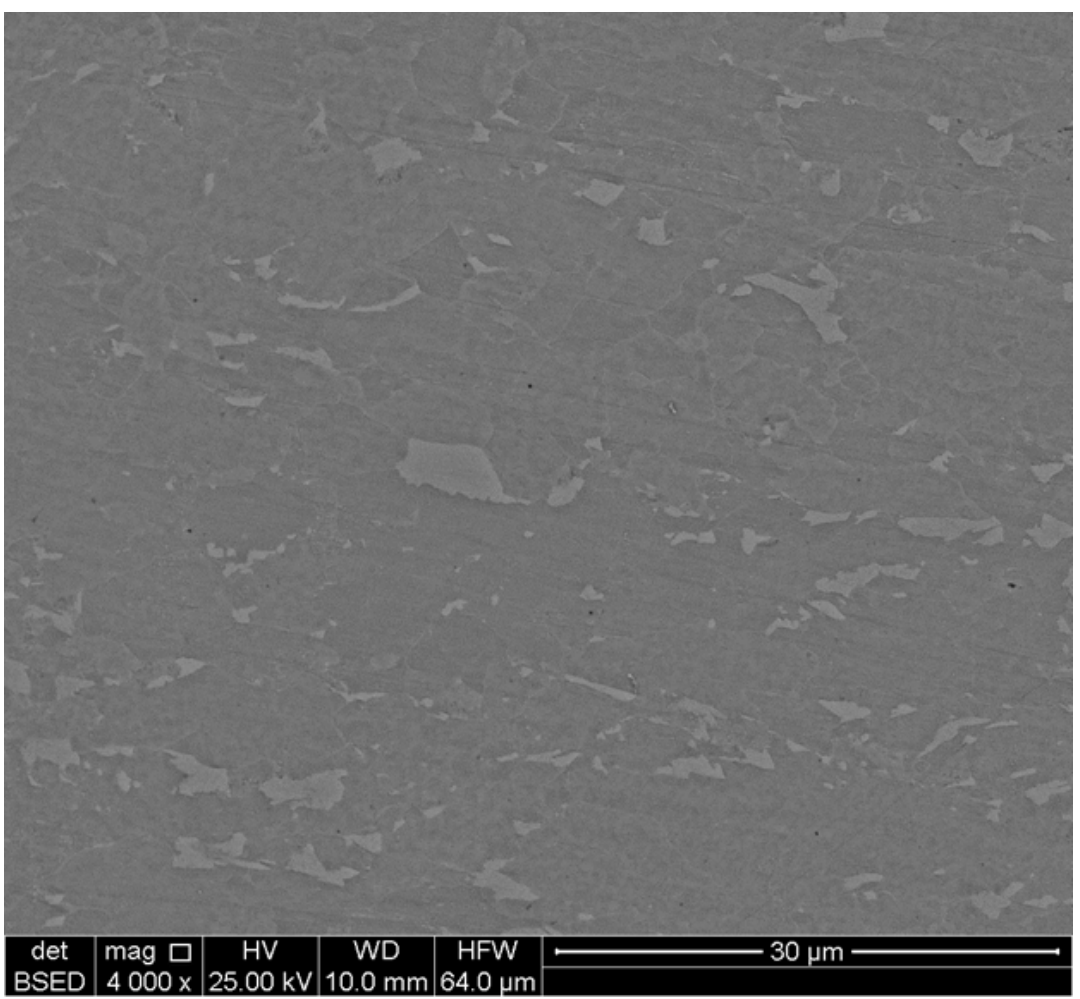

Figura 4.13 MEV (BSE) Ataque 1: $30 \mathrm{~s}$. Ataque 2: $80 \mathrm{~s}$, aumento 4000X. 
Com a finalidade de otimizar o efeito dos reagentes químicos o ataque 1 foi substituído por Nital $2 \%$, que revela os contornos de grão de maneira similar, mantendo o mesmo reagente e tempo no ataque 2 (Ataque 1: Nital 2\%, tempo de ataque $10 \mathrm{~s}$. Ataque 2: tempo de ataque $80 \mathrm{~s}, 6 \mathrm{~V}$.)

Os resultados desta substituição mostraram uma evidente melhora no contraste da imagem, Figura 4.14, com um aumento de 1000X e com os mesmos parâmetros de tensão e de distância de trabalho usados anteriormente.

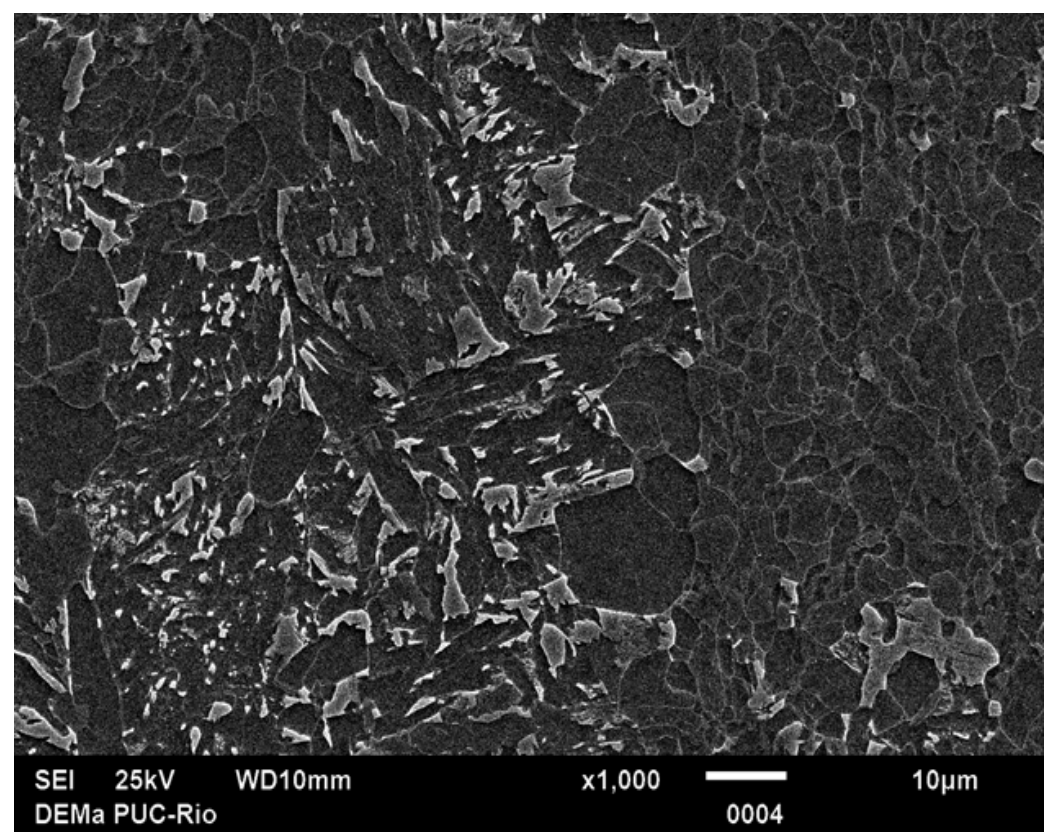

Figura 4.14 MEV (SE) Ataque 1: Nital 2\% $10 \mathrm{~s}$. Ataque 2: $80 \mathrm{~s}$, aumento 1000X.

\subsubsection{2}

\section{Ataque Misto}

Neste procedimento foram utilizados os seguintes parâmetros:

a) Captura de imagens modo eléctron secundários (SE) e modo elétron retro espalhados (BSE).

Os parâmetros utilizados no ataque químico foram os mesmos para os dois casos, são mostrados na Tabela 3.5, da seção 3.2.1.3.

b) Parâmetros do microscópio eletrônico de varredura:

- Modo de elétron secundarios

Tensão de aceleração $25 \mathrm{kV}$.

Distancia de trabalho

Aumento 1500X, 3000X 
Este procedimento resultou em melhores contraste e resolução para tempos de ataque Ikawa 2 de $160 \mathrm{~s}$ a $200 \mathrm{~s}$ com tensão de aceleração ótima de $25 \mathrm{kV}$, como mostrado nas Figura 4.17 e Figura 4.18.

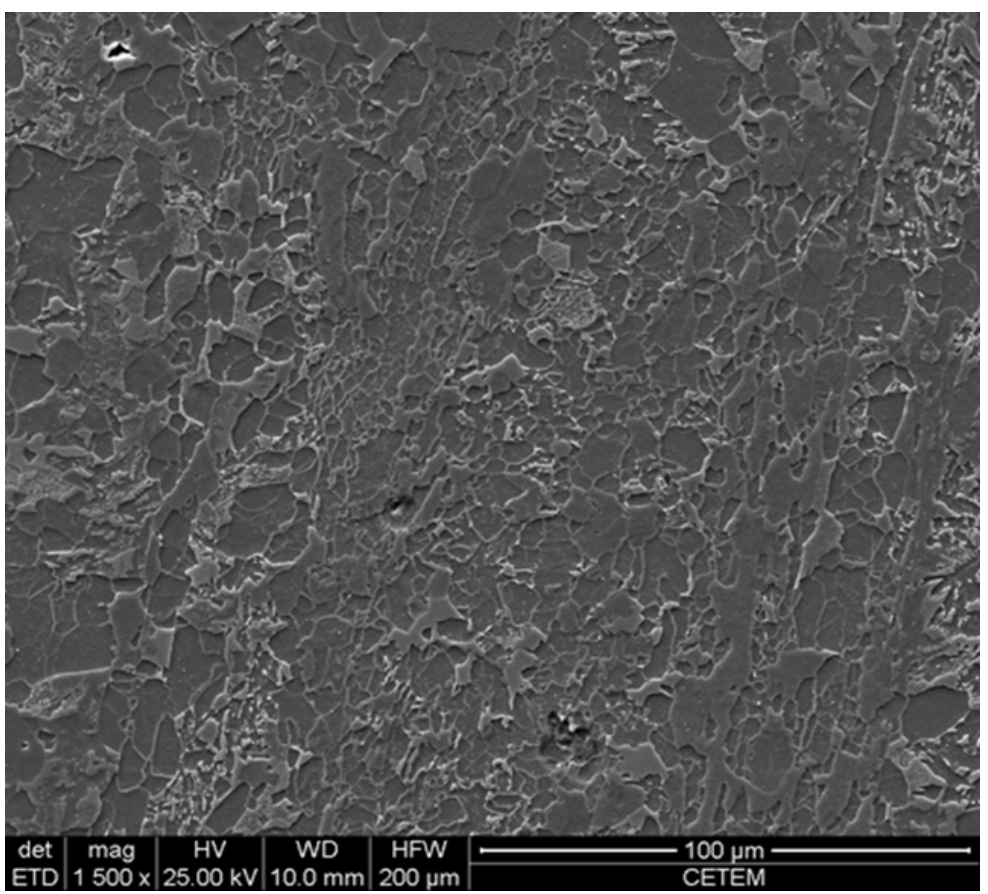

Figura 4.15 MEV (SE) Misto (1) $25 \mathrm{~s}$, (2) $80 \mathrm{~s}$, aumento 1500X.

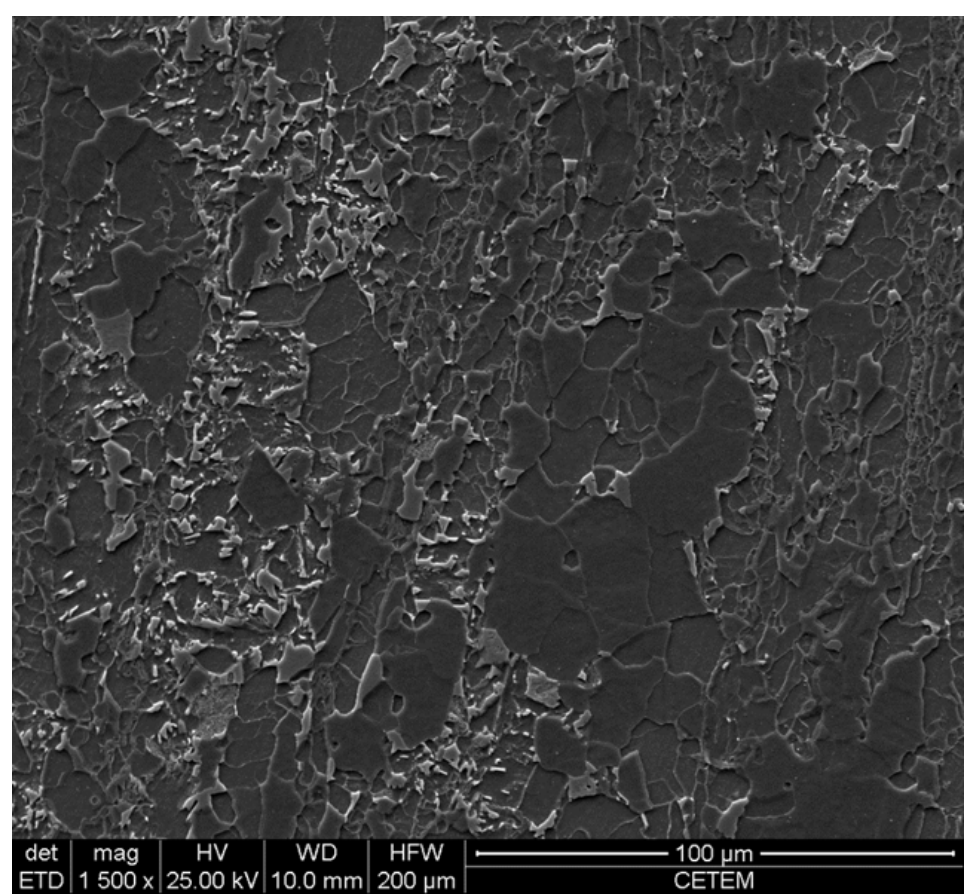

Figura 4.16 MEV (SE) Misto (1) $25 \mathrm{~s}$, (2) $120 \mathrm{~s}$, aumento 3000X. 
O mesmo não ocorreu com os tempos de ataque Ikawa 2 de $120 \mathrm{~s}$ e $140 \mathrm{~s}$, onde o contraste mostrou-se muito fraco como mostrado nas Figura 4.15 e Figura 4.16 .

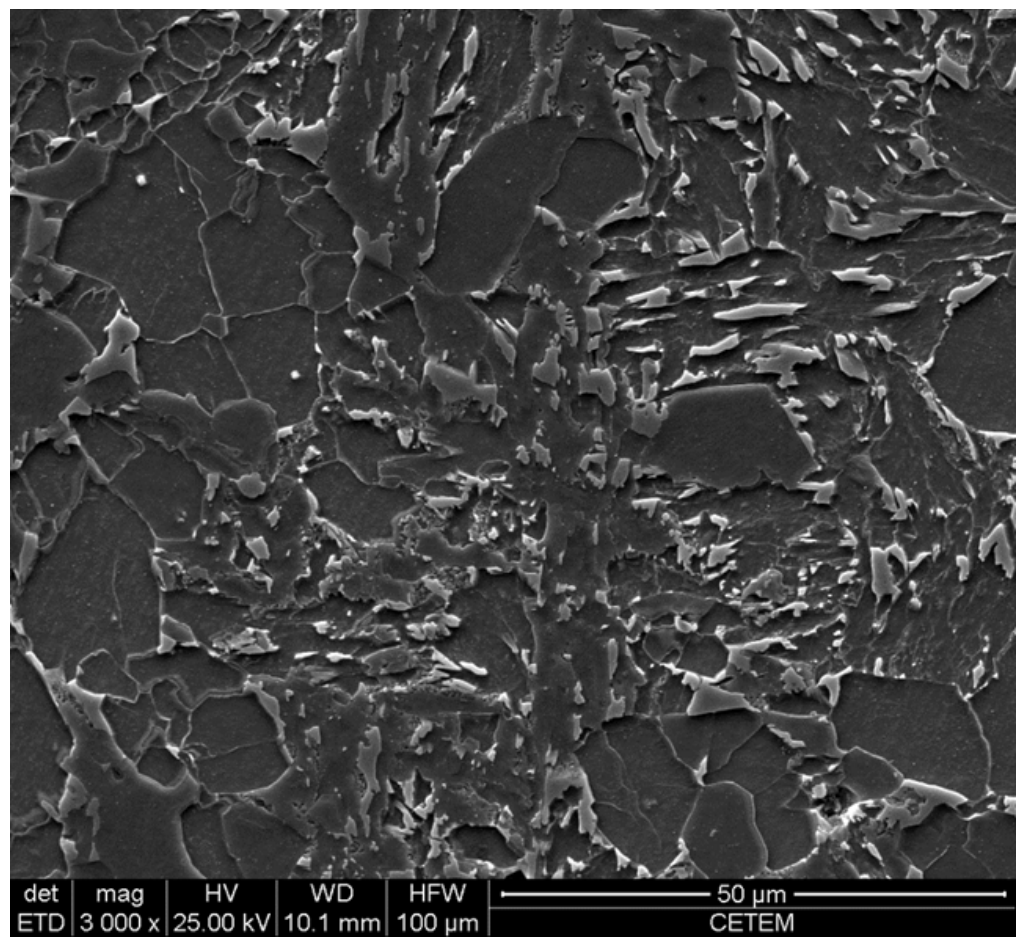

Figura 4.17 MEV (SE) Misto (1) 25 s, (2) 160 s, aumento 3000X.

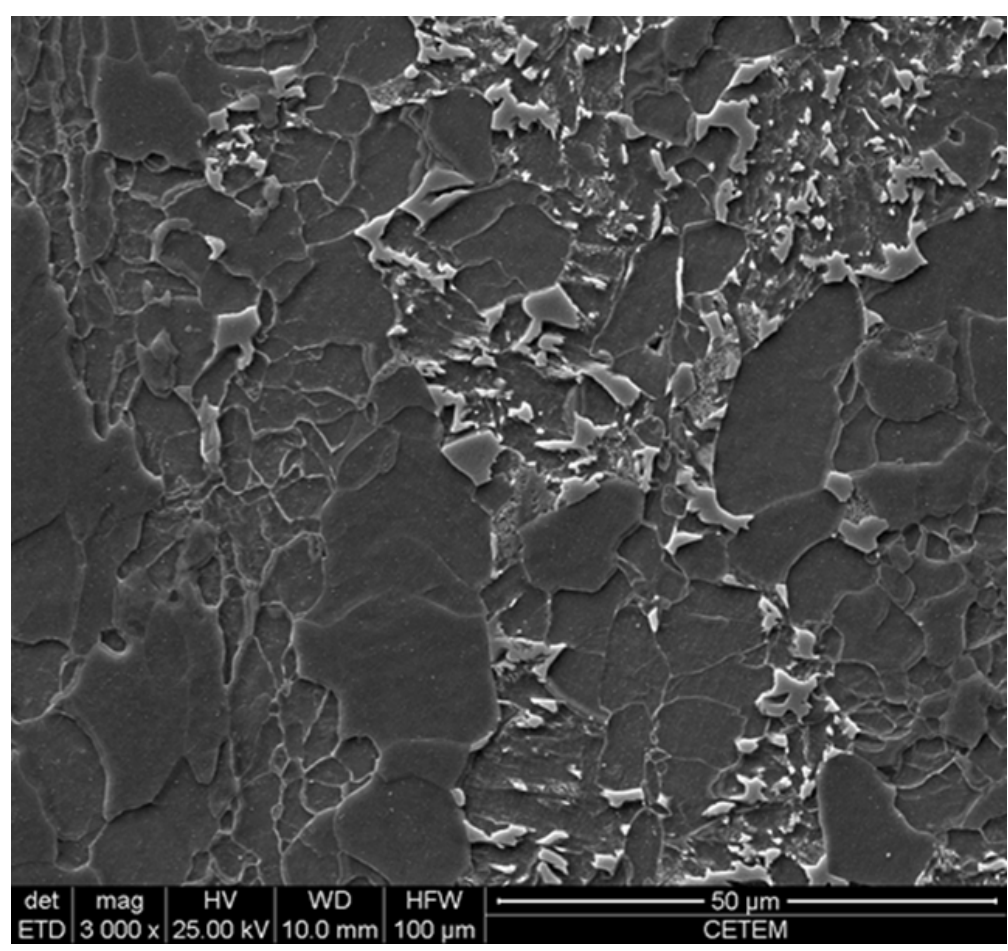

Figura 4.18 MEV (SE) Misto (1) 25 s, (2) 200 s, aumento 3000X. 
- modo elétron retro espalhados.

Tensão de aceleração 20 kV, 25 kV.

Distância do trabalho $10 \mathrm{~mm}$.

Aumento 5000X, 2000X.

Os resultados obtidos no modo de elétrons retro espalhados (BSE), com tensões de aceleração $25 \mathrm{kV}, 20 \mathrm{kV}$, não mostraram os resultados esperados, devido ao baixo contraste nas imagens. Além de isso, as condições de isolamento do equipamento não permitiram a obtenção de imagens sem ruído, Figura 4.19 e Figura 4.20.

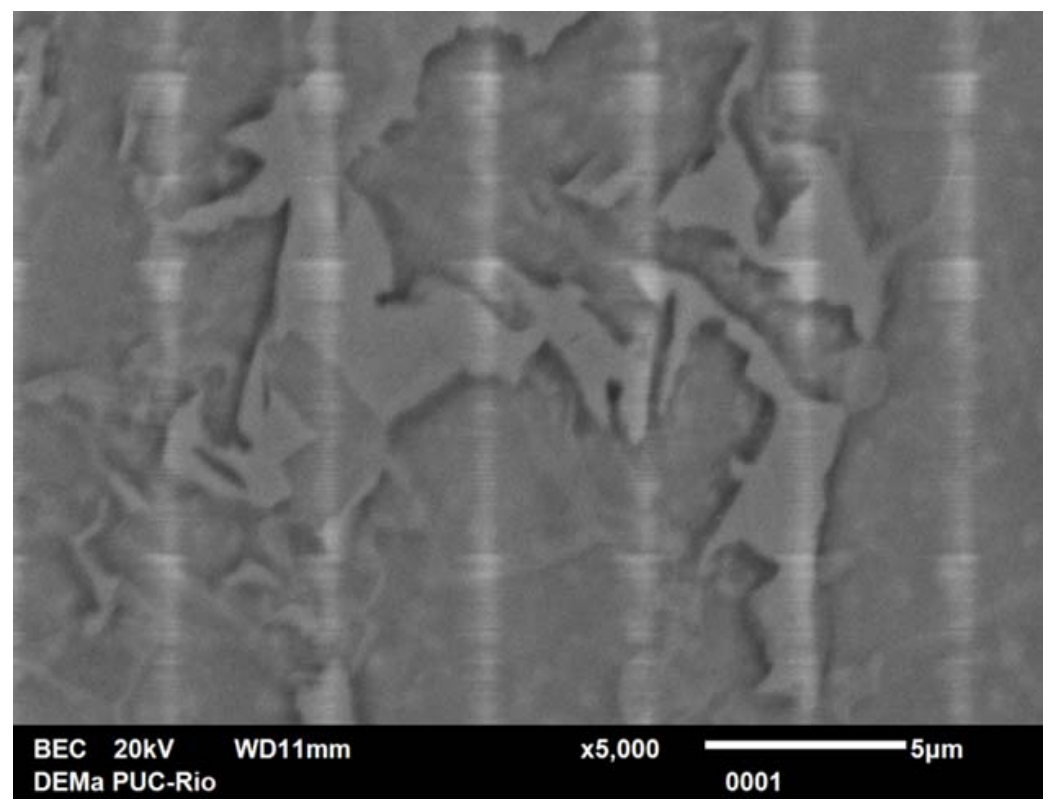

Figura 4.19 MEV (BSE) Misto (1) 25 s, (2) 200 s, 20 kV, aumento 5000X. 


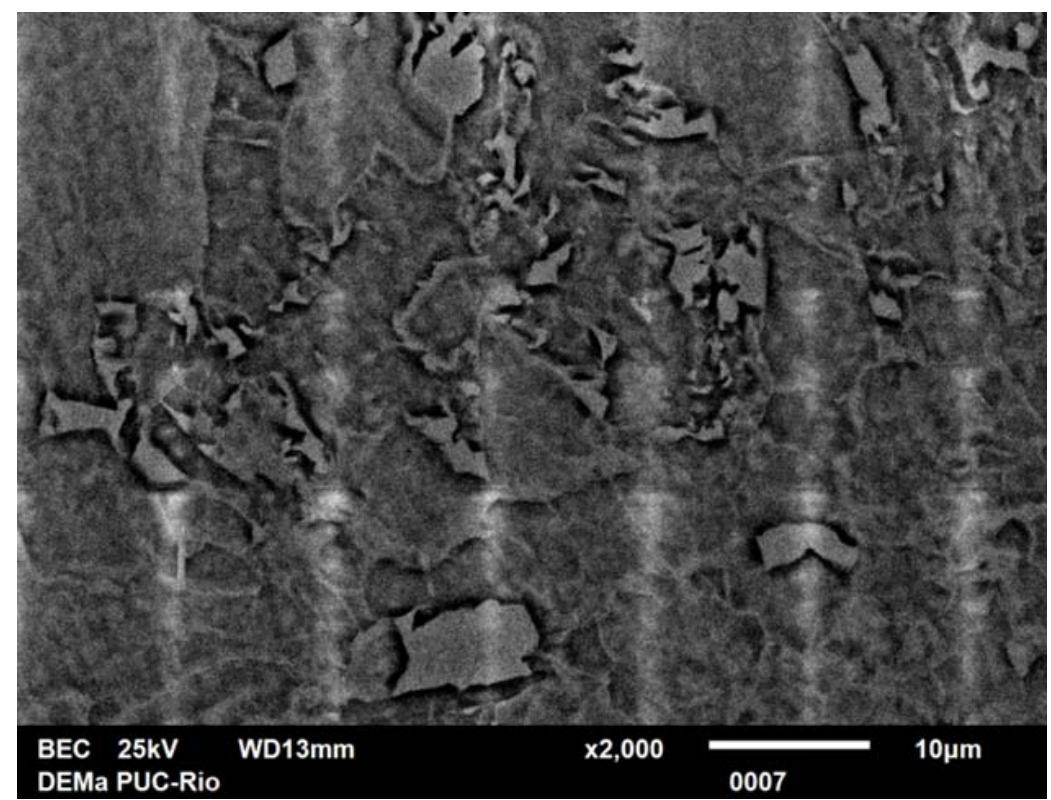

Figura 4.20 MEV (BSE) Misto (1) 25 s, (2) 200 s, 25 kV, aumento 2000X.

\subsubsection{3}

\section{Ataque misto acrescentando um passo Lepera Modificado}

Neste procedimento foram utilizados os seguintes parâmetros:

a) Captura de imagens modo eléctron retro espalhados

Os parâmetros utilizados no ataque químico são mostrados na Tabela 3.6 seção 3.2.1.4.

b) Parâmetros do microscópio eletrônico de varredura:

- Tensão de aceleração $5 \mathrm{kV}, 10 \mathrm{kV}, 15 \mathrm{kV}, 20 \mathrm{kV}$.

- Distância de trabalho de $10 \mathrm{~mm}$.

- Aumento 900X.

Os resultados de microscopia eletrônica, no modo de elétrons retro espalhados (BSE), mostraram os melhores efeitos. A tensão de aceleração foi reduzida para $5 \mathrm{kV}$, de forma reduzir a penetração do feixe de elétrons e aumentar o contraste devido à fina camada de AM, que aparece como regiões claras. Além disso, as condições de isolamento do equipamento não apresentaram ruído durante a captura das imagens, como mostrado na Figura 4.24.

As tensões de aceleração aplicadas de $20 \mathrm{kV}, 15 \mathrm{kV}, 10 \mathrm{kV}$. Mostraram baixo contraste, devido ao fato do feixe de elétrons não ter sido adequado para a 
fina camada formada sobre o AM, conforme mostrado na Figura 4.21 a Figura 4.23 .

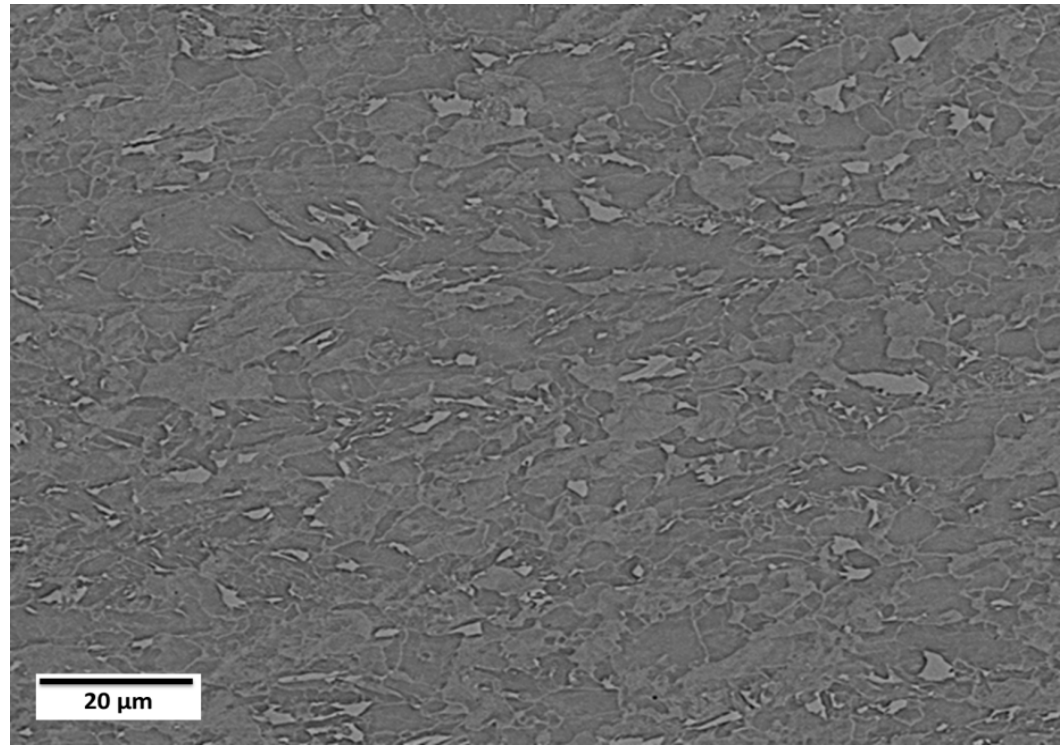

Figura 4.21 MEV(BSE), 20kV, Aumento 900X.

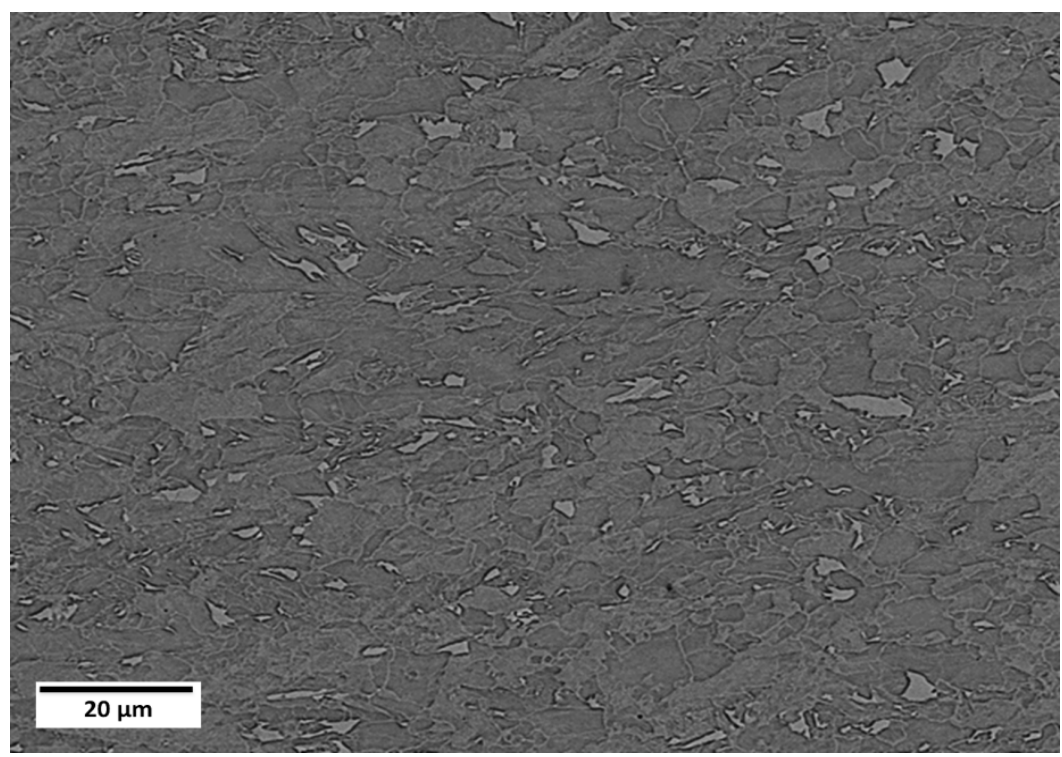

Figura 4.22 MEV(BSE), 15kV, Aumento 900X. 


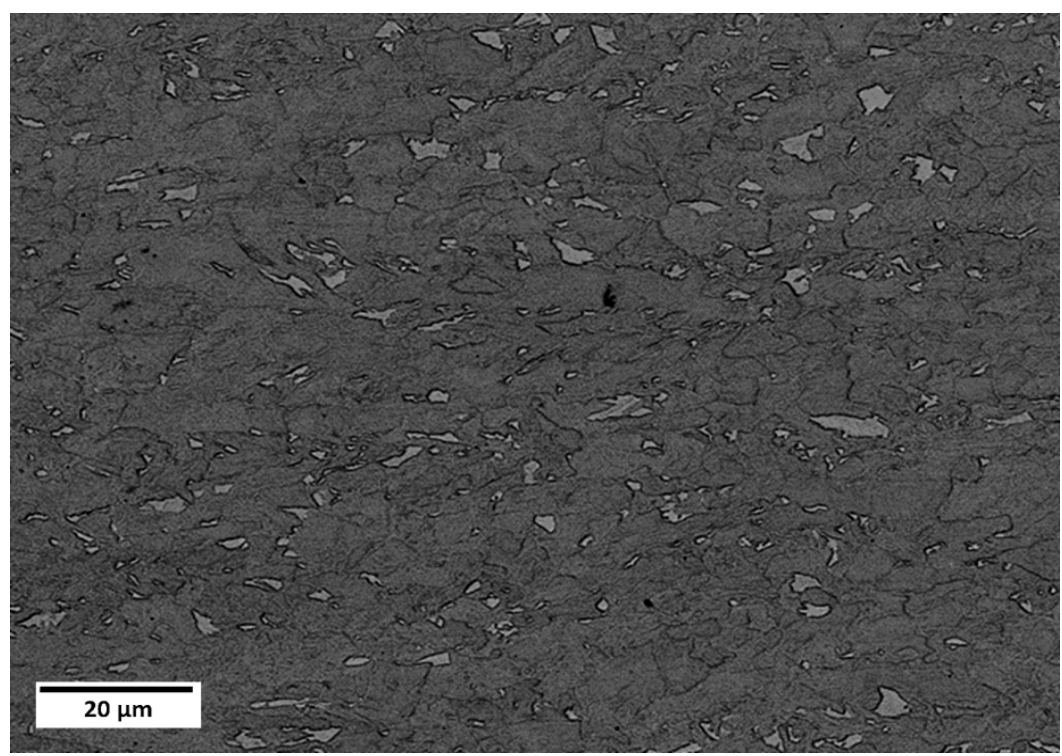

Figura 4.23 MEV(BSE), 10kV, Aumento 900X.

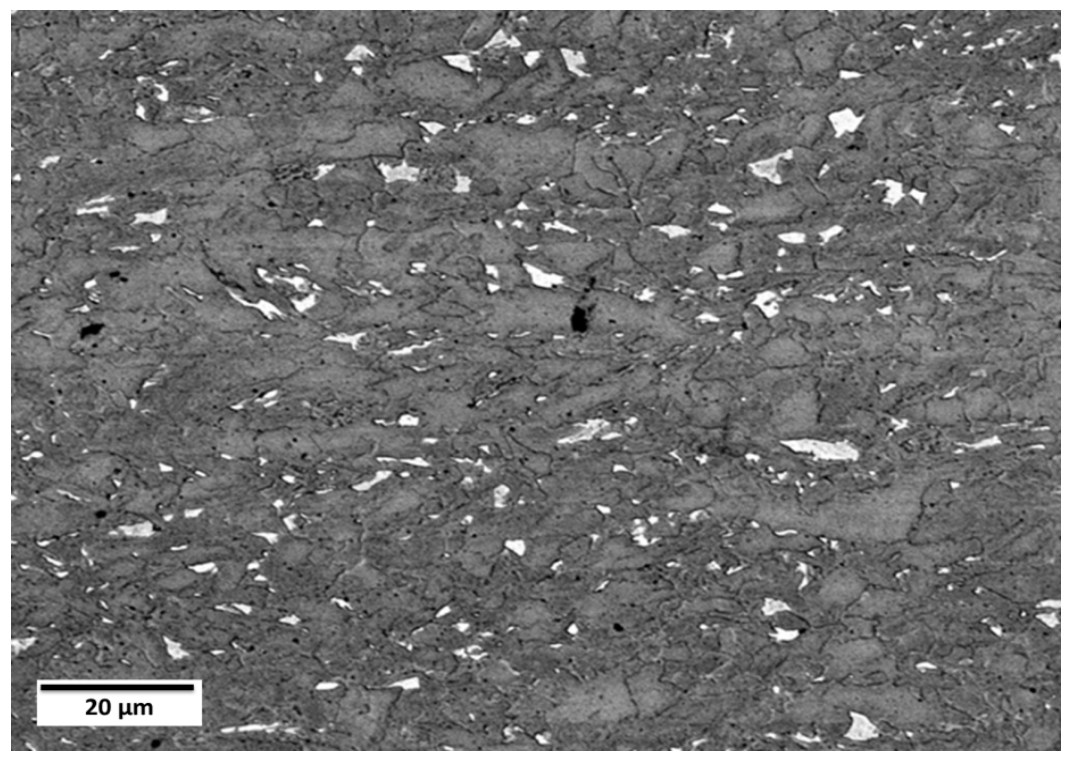

Figura 4.24 MEV(BSE), 5kV, Aumento 900X.

- Captura de imagens modo elétron secundários.

Parâmetros de ataque químico utilizados mostram-se na Tabela 3.6, seção 3.2.1.4.

Parâmetros no microscópio eletrônico de varredura:

- Tensão de aceleração 25 kV.

- Distância de trabalho $10 \mathrm{~mm}$.

- Aumento 1000X. 
O resultado na microscopia eletrônica de varredura, no modo de elétrons secundários, com os parâmetros apresentados e com tempos de ataque químico utilizado na Tabela 3.6, mostraram bom contraste. Neste, foi possível observar também a presença do microconstituinte AM. Há uma observação muito importante. Referente às bordas, pois as mesmas não estão completamente fechadas e dificultaram a quantificação do microconstituinte no processamento digital de imagens. Isso será melhor discutido na secção 4.2.2.1.

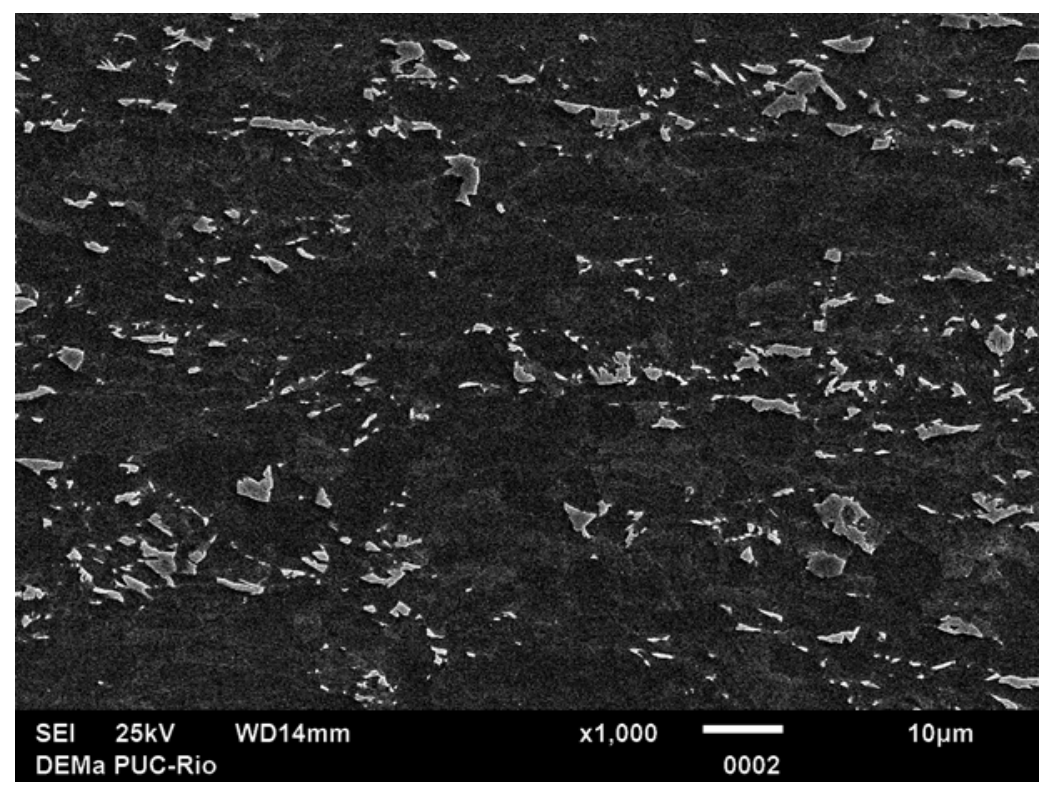

Figura 4.25 MEV(SE).

\subsection{3}

\section{Resumo de resultados qualitativos em imagens de MO}

Tabela 4.1 Resultados MO, ataque Lepera modificado.

\begin{tabular}{c|c|c|c}
\hline Ataque Químico & Pré-ataque Nital 2\% & Lepera modificado. & Observações \\
\hline \multirow{4}{*}{ Tempos ataque (s) } & 10 & 10 & Não ótimo \\
& 10 & 15 & Não ótimo \\
& 10 & 20 & Ótimo \\
& 10 & 25 & Ótimo \\
& 10 & 30 & Não ótimo \\
\hline
\end{tabular}


Tabela 4.2 Resultados MO, ataque misto.

\begin{tabular}{c|c|c|c|c}
\hline \multirow{2}{*}{ Estágios } & $\begin{array}{c}1 \\
\text { Pré-ataque } \\
\text { Nital 2\% }\end{array}$ & $\begin{array}{c}2 \\
\text { Lepera } \\
\text { modi. }\end{array}$ & $\begin{array}{c}3 \\
\text { Ikawa } \\
\text { ataque 2 }\end{array}$ & Observações \\
\cline { 2 - 5 } Tempos (s) & 10 & 20 & 160 & Ótimo \\
& 10 & 25 & 160 & Ótimo \\
\hline \multicolumn{4}{c}{ Ataque eletrolítico: Ikawa ataque 2: 6V } \\
\hline
\end{tabular}

Tabela 4.3 Resultados MO, misto acrescentando um passo Lepera modificado.

\begin{tabular}{c|c|c|c|c|c}
\hline $\begin{array}{c}\text { Estágios } \\
\text { Ataque } \\
\text { Químico }\end{array}$ & $\begin{array}{c}1 \\
\text { Pré-ataque } \\
\text { Nital 2\% }\end{array}$ & $\begin{array}{c}2 \\
\text { Lepera } \\
\text { mod. }\end{array}$ & $\begin{array}{c}3 \\
\text { Ikawa } \\
\text { ataque 2 }\end{array}$ & $\begin{array}{c}4 \\
\text { Lepera } \\
\text { mod. }\end{array}$ & Observações \\
\hline Tempos & 10 & 20 & 160 & 5 & Ótimo \\
(s) & 10 & 25 & 160 & 5 & Ótimo \\
\hline \multicolumn{7}{c}{ Ataque eletrolítico: Ikawa ataque 2: 6V } \\
\hline
\end{tabular}

\subsection{4}

\section{Resumo dos resultados qualitativos em imagens de MEV}

Tabela 4.4 Resultado do ataque Ikawa.

\begin{tabular}{|c|c|c|c|c|c|}
\hline \multicolumn{6}{|c|}{ Parâmetros de ataque químico } \\
\hline \multirow{2}{*}{ Estágios } & \multicolumn{2}{|c|}{ Ataque 1} & \multicolumn{2}{|c|}{ Ataque 2} & \multirow{2}{*}{ Observações } \\
\hline & Tempo (s) & Volts & Tempo (s) & Volts & \\
\hline $\begin{array}{l}\text { Ataque } \\
\text { Original }\end{array}$ & 3 & 3 & 30 & 6 & Não ótimo \\
\hline $\begin{array}{c}\text { Variação de } \\
\text { tempo em } \\
\text { ataque 1, } 2\end{array}$ & 30 & 3 & 80 & 6 & Não ótimo \\
\hline $\begin{array}{l}\text { Substituição } \\
\text { do ataque } 1 \\
\text { com nital 2\% }\end{array}$ & $\begin{array}{c}\text { Nital } 2 \% \\
10\end{array}$ & --- & 80 & 6 & Ótimo \\
\hline \multicolumn{6}{|c|}{ Parâmetros usados MEV } \\
\hline $\begin{array}{l}\text { Tensão de ace } \\
\text { 1000X. }\end{array}$ & ação 25 kV & istânc & de trabalhc & $0 \mathrm{~mm}$ & nento $4000 \mathrm{X}$ \\
\hline
\end{tabular}


Tabela 4.5 Resultado do ataque misto, MEV modo SE

\begin{tabular}{c|c|c|c|c}
\hline \multicolumn{5}{c}{ Parâmetros de ataque químico } \\
\hline \multirow{3}{*}{ Estágios } & 1 & $\begin{array}{c}2 \\
\text { Lepera } \\
\text { mod. }\end{array}$ & $\begin{array}{c}3 \\
\text { Ikawa ataque }\end{array}$ & Observações \\
\hline \multirow{3}{*}{ Tempos (s) } & 10 & 25 & 80 & Não ótimo \\
& 10 & 25 & 120 & Não ótimo \\
& 10 & 25 & 160 & Ótimo \\
& 10 & 25 & 200 & Ótimo
\end{tabular}

Ataque eletrolítico: Ikawa ataque 2: 6V.

Parâmetros usados MEV

Tensão de aceleração 25 kV, Distância de trabalho 10 mm, Aumento 3000X, $1500 \mathrm{X}$

Tabela 4.6 Resultado do ataque misto, MEV modo BSE

\begin{tabular}{c|c|c|c|c}
\hline \multicolumn{5}{c|}{ Parâmetros de ataque químico } \\
\hline Estágios & 1 & 2 & 3 \\
Pré-ataque & $\begin{array}{c}2 \\
\text { mod. }\end{array}$ & $\begin{array}{c}\text { Ikawa } \\
\text { ataque 2 }\end{array}$ & Observações \\
\hline Tempos (s) & 10 & 25 & 160 & $\begin{array}{c}\text { Ataque eletrolítico: Ikawa } \\
\text { ataque 2: 6V. }\end{array}$ \\
\hline
\end{tabular}

Foram os mesmos parâmetros de ataque químico para todos os casos.

Parâmetros usados MEV

\begin{tabular}{l|c|c|c|c}
\hline \multirow{3}{*}{ Parâmetros } & $\begin{array}{c}\text { Tensão de } \\
\text { Aceleração }\end{array}$ & $\begin{array}{c}\text { Distância } \\
\text { trabalho }\end{array}$ & Aumento & Observações \\
\cline { 2 - 5 } & 25 & 10 & $2000 \mathrm{X}$ & Não ótimo \\
& 20 & 10 & $5000 \mathrm{X}$ & Não ótimo \\
\hline
\end{tabular}


Tabela 4.7 Resultado ataque misto, acrescentando um passo Lepera modificado, MEV modo BSE

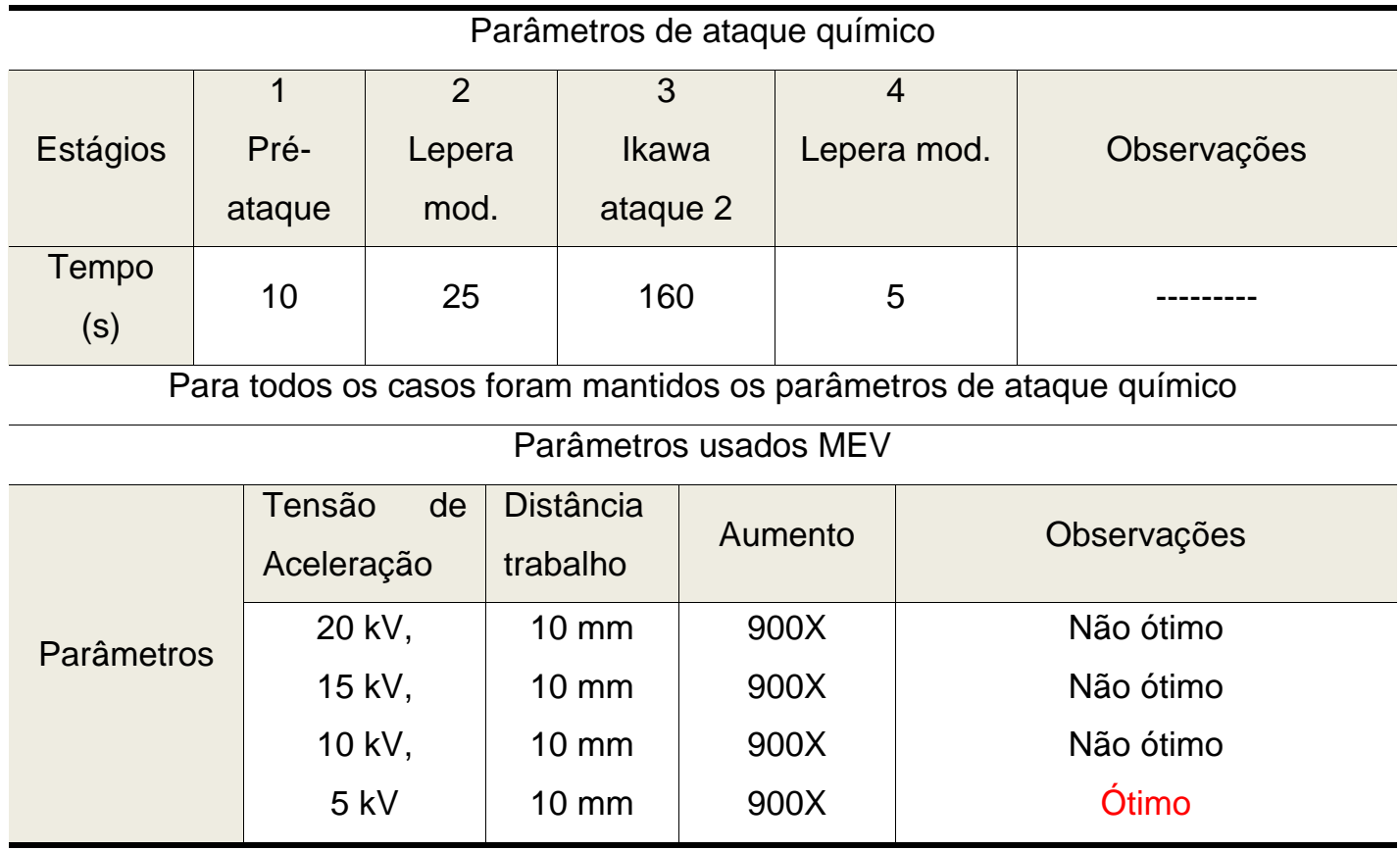

\section{2}

Processamento e análise digital de imagens

\subsection{1}

\section{Microscopia Ótica}

As imagens que apresentaram uma quantização suficiente para permitir a observação do contraste entre as fases, possibilitando sua distinção, foram as imagens de ataque químico misto, acrescentando um passo Lepera modificado, Figura 4.9. Esta imagem foi processada e analisada com funções disponíveis no software FIJI.

O primeiro passo foi observar no histograma a distribuição de intensidades dos pixels destas imagens. Nestes histogramas as intensidades relativas ao microconstituinte AM não são muito visíveis, já que a maior parte da imagem tem a tonalidade do fundo, o que gera o principal pico do histograma. Ainda assim, os pixels correspondentes à AM têm tonalidade mais alta e aparecem como um pequeno "ombro" à direita do pico central Figura 4.26. 

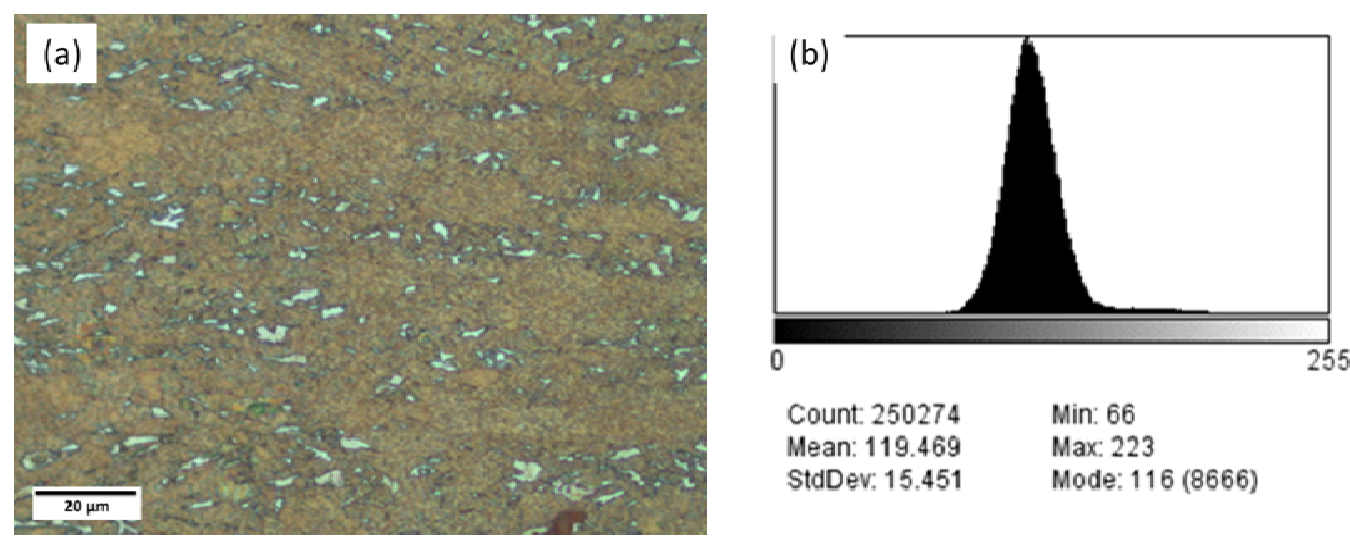

Figura 4.26 (a) MO original (método misto acrescentando um passo Lepera modificado) as regiões claras AM (b) Histograma da imagem original.

$\mathrm{Na}$ etapa de pré-processamento e realce dos detalhes de interesse, nas imagens no modo RGB (Red-Green-Blue), com 8 bits por canal, não foram aplicados este pré-processamento. Mostraram, ter tonalidades bem definidas, referentes à identificação de partículas de interesse.

Foram segmentadas por limiarização no espaço HIS (Hue, Intensity, Saturation - Matiz, Saturação Brilho), e RGB (Red, Green, Blue), mostrando as regiões de AM como partículas brancas em fundo escuro. A segmentação RGB mostrou melhor comportamento na identificação das partículas de interesse Figura 4.27 .

Depois da segmentação, observaram-se as pequenas partículas espúrias que foram segmentadas junto com o microconstituinte AM. Buscou-se, assim, eliminar este defeito analisando cuidadosamente a faixa de tamanho destas partículas espúrias, nos seguintes passos:

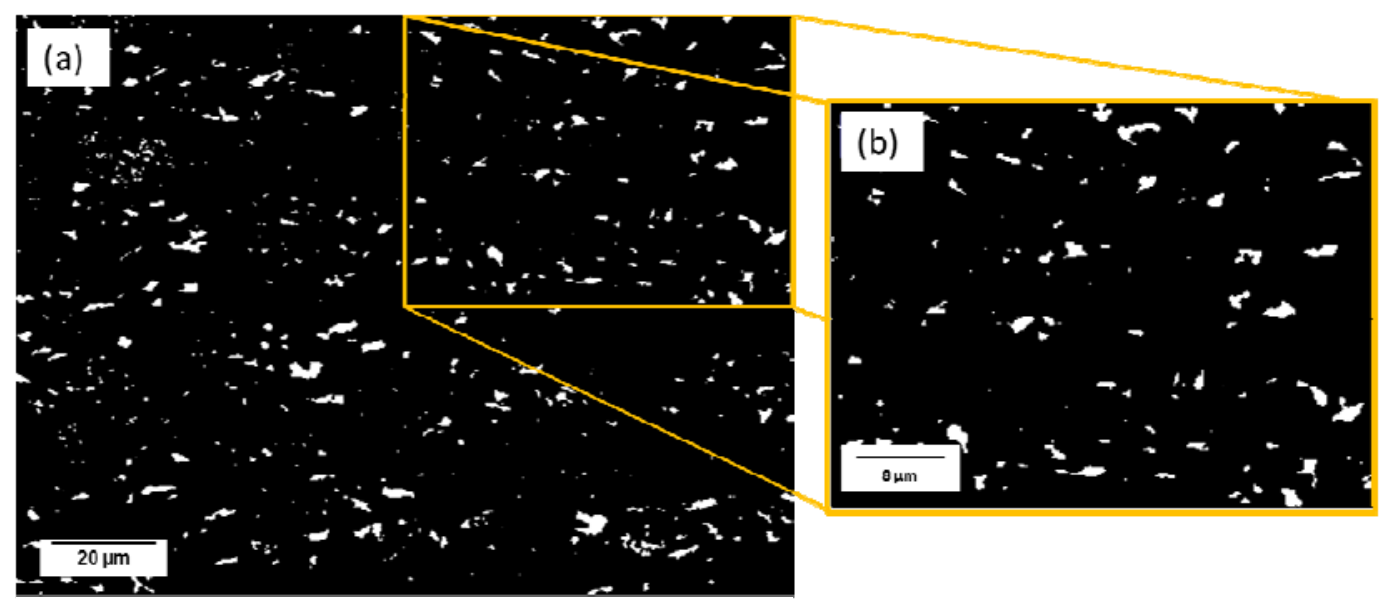

Figura 4.27 (a) MO segmentação. (b) Ampliação imagem segmentada. 
Primeiramente foi feito um processo de quantificação, considerando todos os objetos segmentados, onde se encontraram 615 objetos, que perfazem uma área de $107.585 \mu \mathrm{m}^{2}$, com uma fracção volumétrica de $3.5 \%$ (faixa de partículas 0 infinito), $\left(\mu \mathrm{m}^{2}\right)$, Tabela 4.8. Na Figura 4.28(a), observaram-se como elementos espúrios a quantificação de partículas muito pequenas.

Com a finalidade de eliminar os elementos espúrios, foi considerada a extração de atributos (faixa para as partículas do microconstituinte AM. (0.1 $\left(\mu \mathrm{m}^{2}\right)$ - infinito), Tabela 4.8. Os resultados mostraram uma redução de número de partículas, com tamanhos menores de $0.1 \mu \mathrm{m}^{2}$. Desta forma, os elementos espúrios correspondem $63.7 \%$ do total de partículas segmentadas. Na Figura 4.28 (b) mostra-se a eliminação das partículas espúrias na quantificação dos objetos de interesse.

Entretanto, a faixa de tamanho destas partículas espúrias no MO, foram eliminadas, justamente por serem partículas menores que $0,10 \mu \mathrm{m}^{2}$.

Tabela 4.8 Extração de atributos na quantificação do microconstituinte AM, no MO.

\begin{tabular}{c|c|c|c}
\hline $\begin{array}{c}\text { Faixa Partículas } \\
\left(\mu \mathrm{m}^{2}\right)\end{array}$ & $\begin{array}{c}\text { Número de } \\
\text { Partículas }\end{array}$ & $\begin{array}{c}\text { Área Total } \\
\left(\mu \mathrm{m}^{2}\right)\end{array}$ & $\begin{array}{c}\text { \% Fração } \\
\text { Volumétrica (\%) }\end{array}$ \\
\hline 0 - infinito & 615 & 107.585 & 3.5 \\
0.1 - infinito & 223 & 93.980 & 3.1 \\
\hline
\end{tabular}
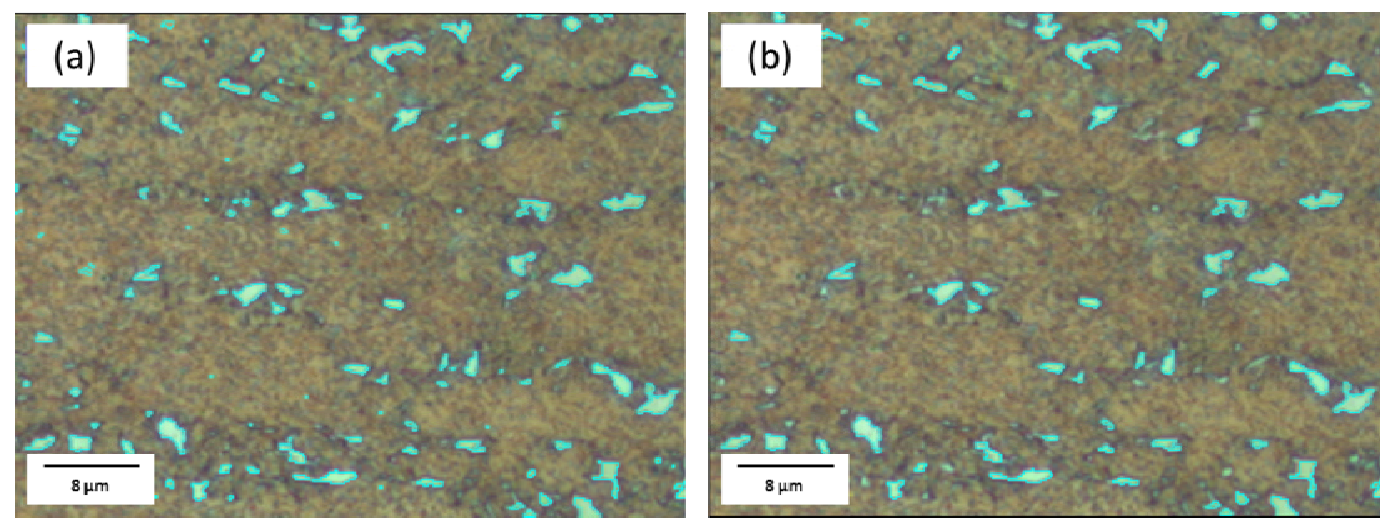

Figura 4.28 MO Bordas das imagens binárias superposta às imagens originais da Figura 4 27(b). (a) Faixa extração de atributos 0 - infinito. (b) Faixa extração de atributos 0.1infinito. 
Portanto, conclui-se: o método de ataque químico misto, acrescentando um passo Lepera Modificado, gerou uma melhora acentuada ao contraste, nas imagens de MO. E um dos resultados mais importantes do trabalho, desenvolvida para a identificação e para a quantificação do microconstituinte AustenitaMartensita (AM), por processamento digital de imagens mostrou-se viável, considerando como elementos espúrios as partículas menores que $0.1 \mu \mathrm{m}^{2}$.

\subsection{2}

\section{Microscopia eletrônica de varredura}

\subsubsection{1}

\section{Modo de elétrons secundários}

No caso das imagens de microscopia eletrônica de varredura, as imagens que apresentaram suficiente contraste, no modo de elétrons secundários, foram as imagens das Figura 4.14 (ataque químico Ikawa com substituição de reagente 1 com nital 2\%), Figura 4.17, a Figura 4.18 (com ataque químico misto) e a Figura 4.25 (com ataque químico misto, acrescentando-se um passo lepera modificado).

$\mathrm{Na}$ etapa do pré-processamento, houve o realce dos detalhes de interesse, de modo a facilitar a sua visualização para a segmentação. Observou-se que as imagens apresentavam um tipo de defeito comum e crítico para a quantificação do microconstituinte AM, através do processamento digital de imagens:

O microconstituinte AM não tem as bordas claras e inteiras nas imagens. As zonas sombreadas ficaram localizadas em zonas com bordas não definidas. Estas se mostraram também como efeito da posição do detector de elétrons secundários e dificultaram a quantificação dos mesmos, como se mostra na Figura 4.29(b), imagem ampliada.

Uma alternativa para a solução de completar as bordas do microconstituinte foi a possibilidade de, depois da captura da primeira imagem, girar a amostra em $180^{\circ}$ e obter a captura da segunda imagem, onde as zonas sombreadas na primeira imagem, mudaram a bordas claras, por efeito da posição do detector de elétrons secundários, como se mostra na Figura 4.30, com ajuda das ferramentas de análise e do processamento digital são possíveis de serem preenchidas. Assim as bordas 
do microconstituinte AM, sobrepõem-se às imagens obtidas, facilitando a quantificação da fase AM.

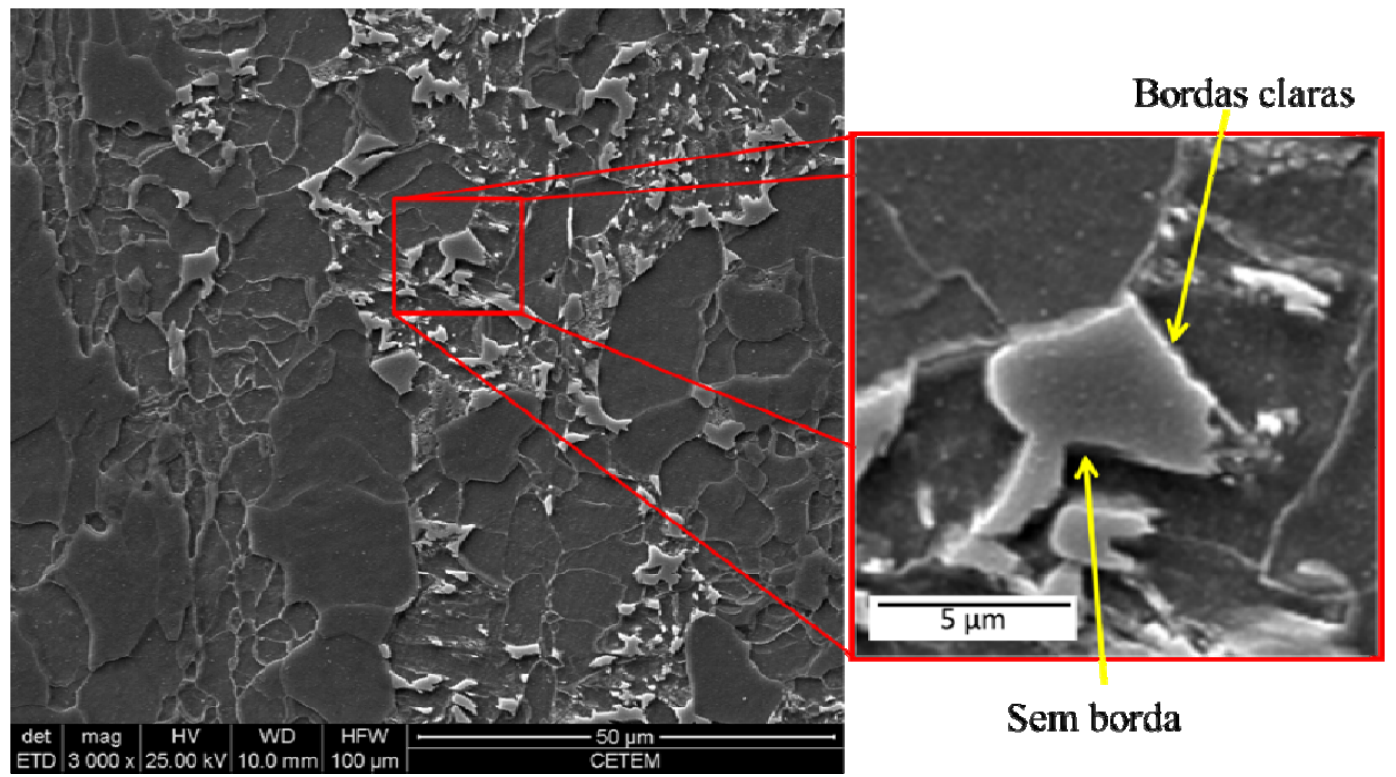

Figura 4.29 MEV (SE) Defeito das bordas do microconstituinte AM incompletas.

Bordas claras

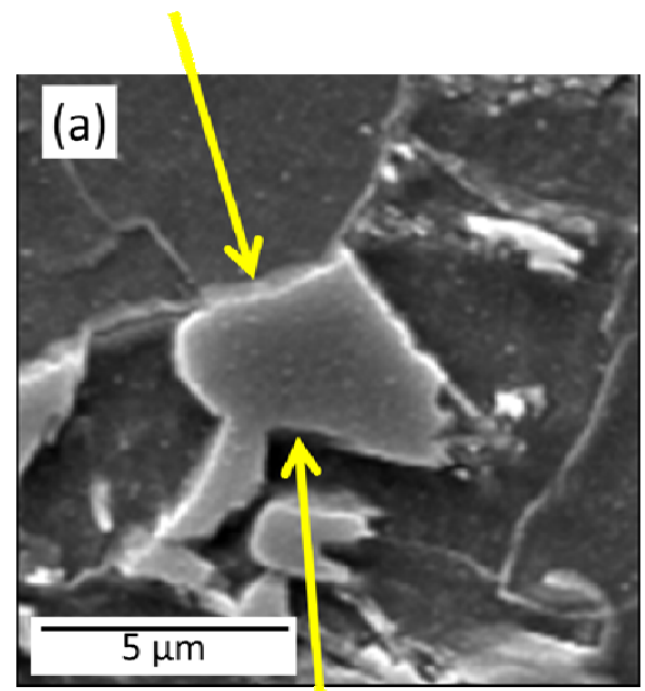

Sem bordas
Sem bordas

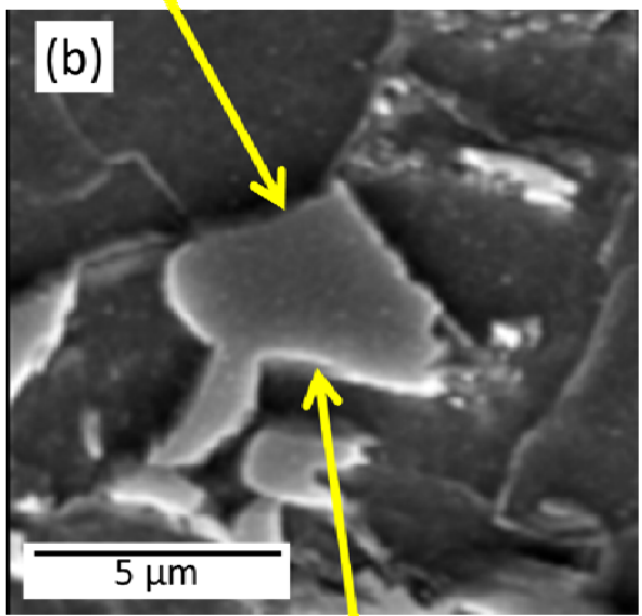

Bordas claras

Figura 4.30 MEV (SE) (a)Imagem posição inicial (b) Imagem com amostra girada $180^{\circ}$

As imagens foram alinhadas para corrigir as diferenças de ampliação, translação, rotação e eventuais distorções. Para isto foi utilizada a função SIFT 
(Scale Invariant Feature Transform) que realiza alinhamento automático entre imagens, como se mostra na Figura 4.31.
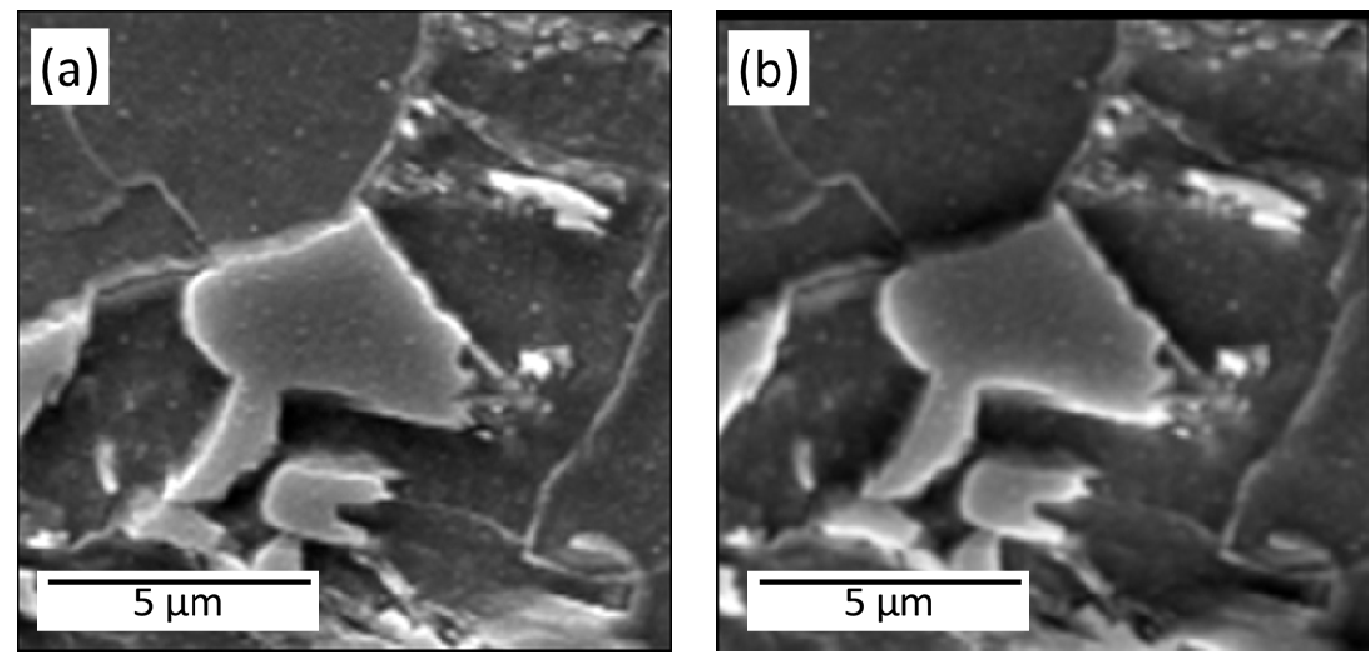

Figura 4.31 Alinhamento automático de imagens, utilização função SIFT (Scale Invariant Feature Transform).

È admissível notar que foi possível obter campos idênticos. As duas imagens foram segmentadas individualmente por limiarização simples de intensidade. A Figura 4.32, (a e b), mostram as regiões incompletas de AM, como partículas brancas, em fundo escuro.
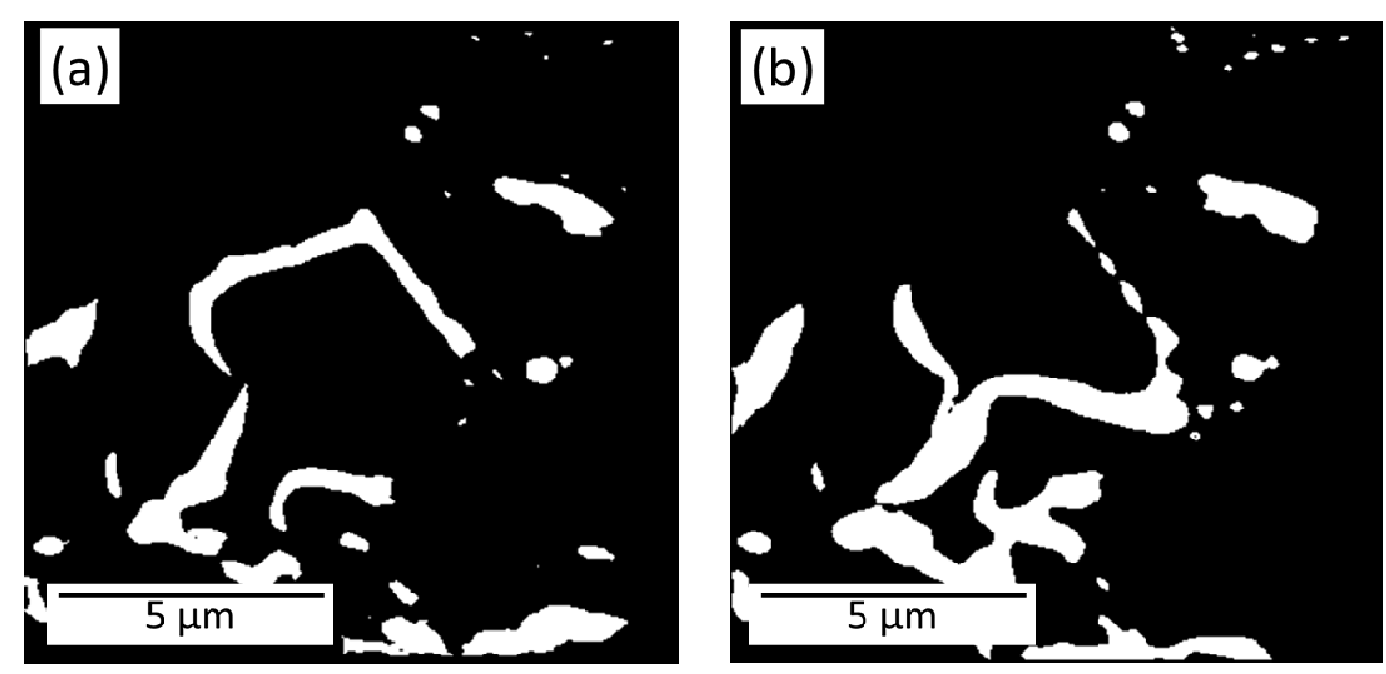

Figura 4.32 Segmentação (a) Imagem posição inicial da amostra (b) Imagem com giro de $180^{\circ}$ da amostra.

O resultado da segmentação não foi adequado, sendo necessária uma etapa de pós-processamento, com o uso de operações lógicas pontuais de combinação 
das duas imagens que envolvem uma imagem binária de entrada, para gerar uma imagem de saída, como se mostra na Figura 4.33(a) e no posterior preenchimento de área das bordas completas, como se mostra na Figura 4.33(b).
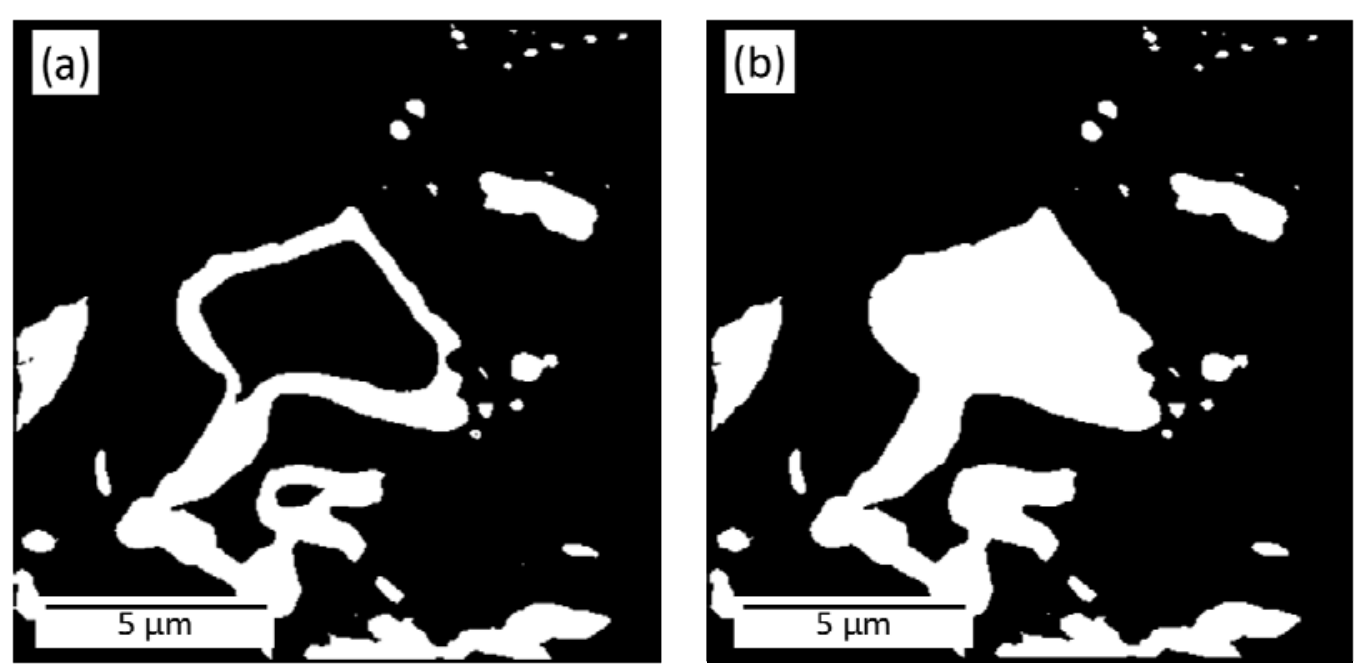

Figura 4.33 (a) combinação das imagens da Figura 4 32, (b) Preenchimento de área do microconstituinte AM.

$\mathrm{Na}$ etapa da extração de atributos e de análise, na qual os objetos da imagem são identificados às medidas de campo, para calcular a fração volumétrica do microconstituinte AM, os resultados mostraram um valor de \%Fração Volumétrica $\mathrm{AM}=8.47$.

Os dados mostraram diferenças expressivas entre a imagem original, Figura 4.34(a), e a imagem segmentada, Figura 4.34(b). Ali as partículas do microconstituinte AM foram sobredimensionadas em alguns casos e subdimensionadas em outros. Além disso, a imagem segmentada mostra partículas segmentadas que não correspondem ao microconstituinte $\mathrm{AM}$, justificando que o método de processamento digital de imagens aplicado não foi viável devido à dificuldade em obter as bordas completas das partículas do microconstituinte. 

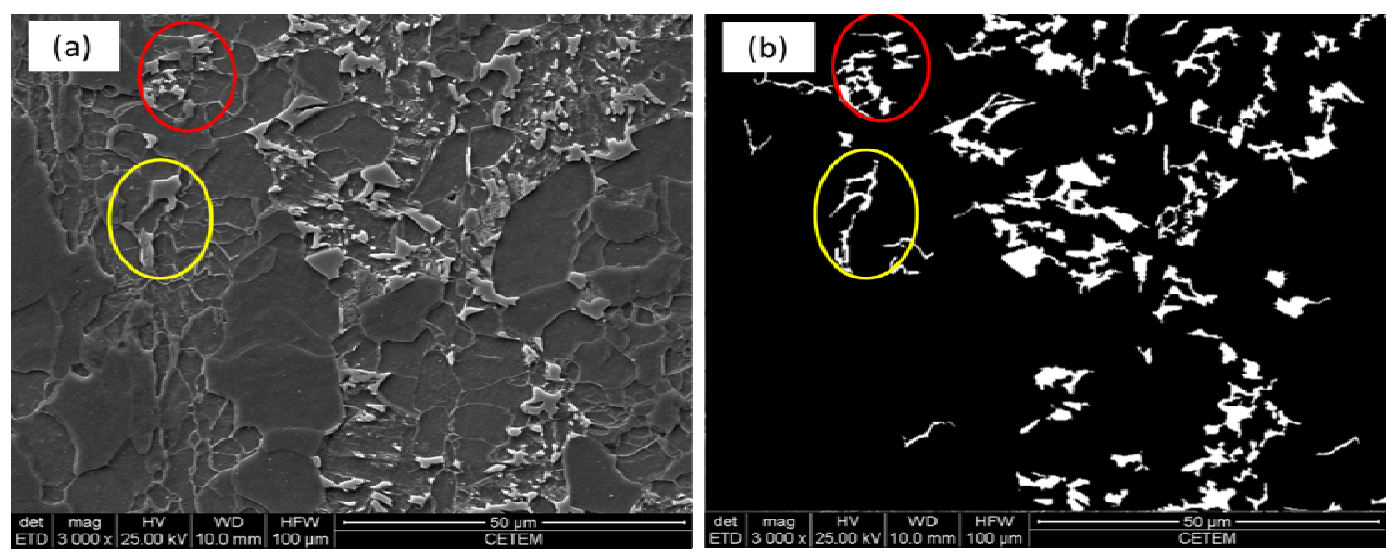

Figura 4.34 (a) Imagem Original, (b) Imagem segmentada e quantificação de atributos.

\subsubsection{2}

\section{Modo de elétrons retroespalhados}

As imagens que apresentaram suficiente contraste no modo de elétrons retro espalhados foram as imagens da Figura 4.24 (ataque químico misto, acrescentando um passo Lepera modificado). Com a redução tensão de aceleração do feixe de elétrons à $5 \mathrm{kV}$, a fina camada de $\mathrm{AM}$ aparece como regiões claras.

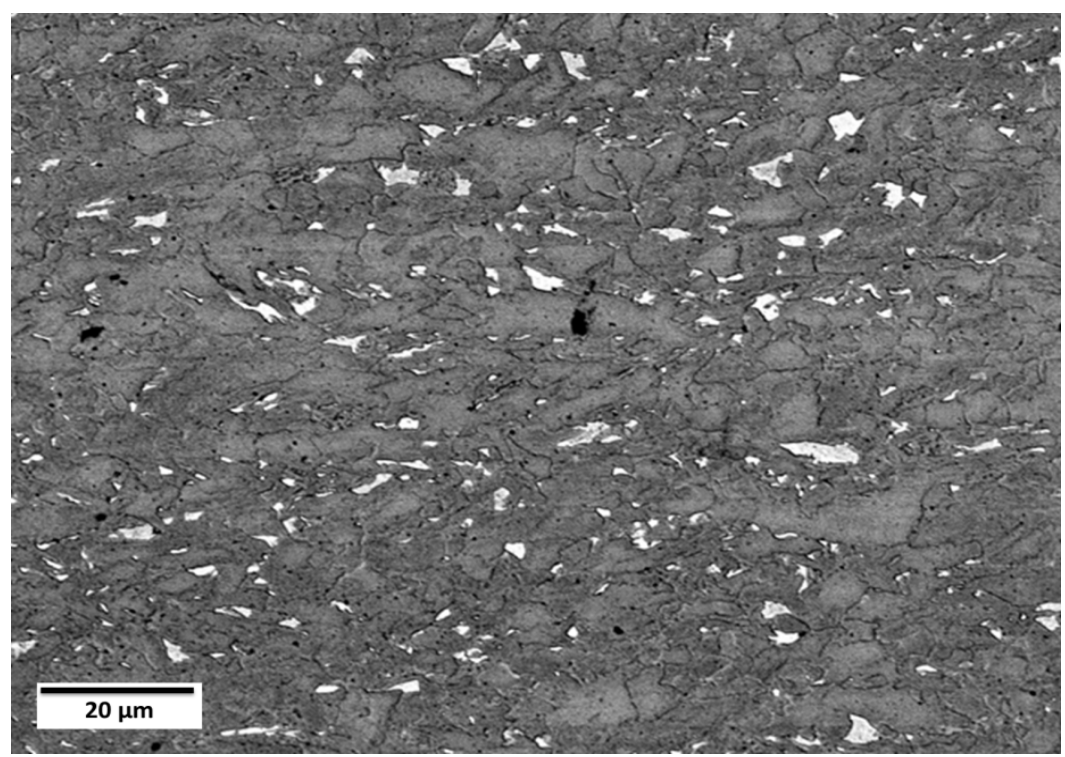

Figura 4.35 Imagem Original MEV (BSE). Tensão 5 kV.

$\mathrm{Na}$ etapa de pré-processamento e de realce detalhes de interesse, foi aplicado o filtro sigma conforme explicado na seção 2.6.2, para reduzir o ruído preservando os detalhes da imagem, como se mostra na Figura 4.36(b). 


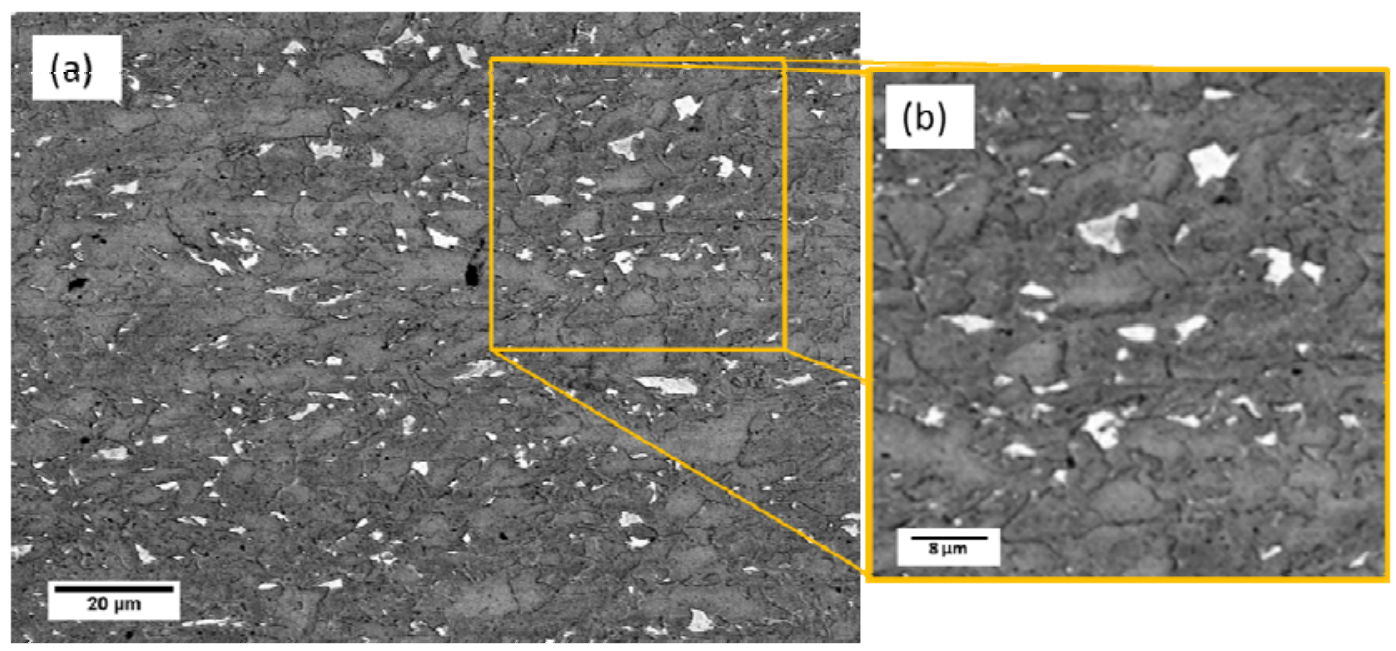

Figura 4.36 (a) MEV (BSE) Imagem original (b) Imagem ampliada com redução de ruído.

A segmentação feita apresenta repartições bem definidas na imagem em regiões e distingue estas regiões como objetos independentes. O resultado é uma imagem binária, onde os objetos são regiões contíguas de pixels brancos em um fundo preto, como se mostram na Figura 4.37.
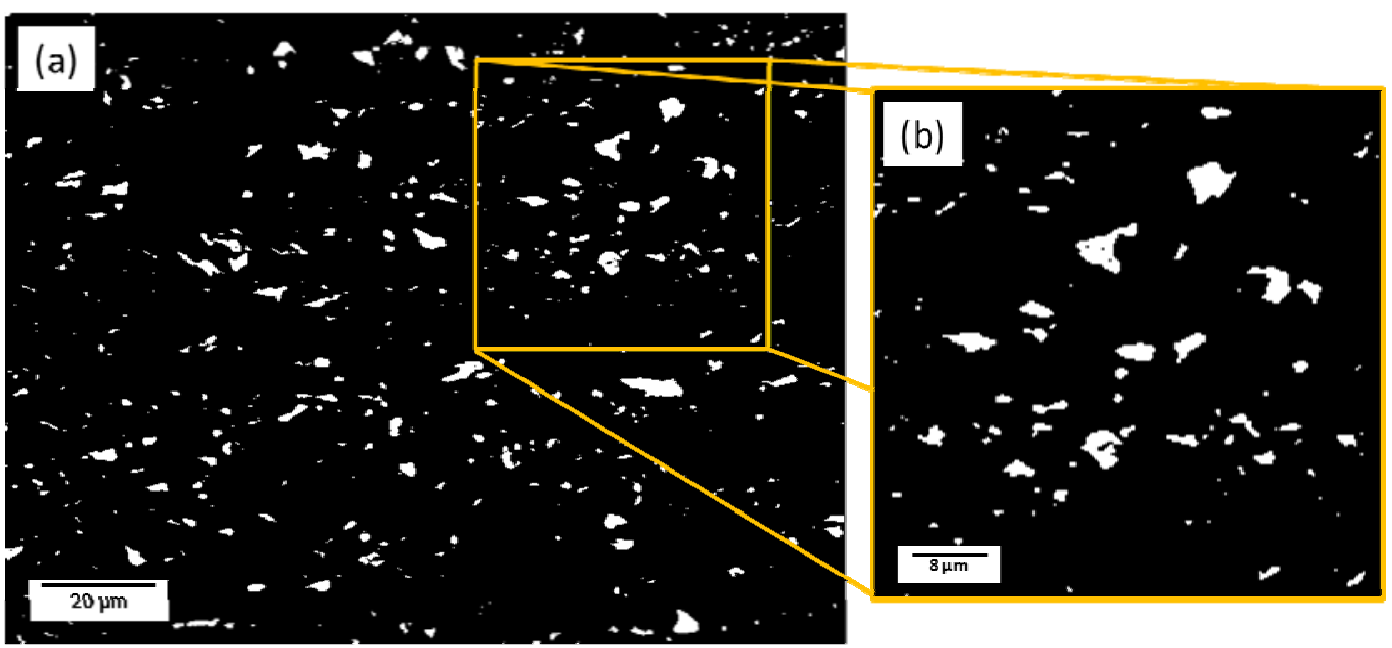

Figura 4.37 (a) MEV (BSE) Imagem segmentada (b) Imagem ampliada da segmentação.

Depois da segmentação, observou-se que pequenas partículas espúrias foram segmentadas junto com o microconstituinte AM. Assim, antes de realizar qualquer medida, buscou-se eliminar este defeito, analisando cuidadosamente a faixa de tamanho destas partículas espúrias.

No primeiro caso, consideraram-se todos os objetos resultado da segmentação, onde se encontraram 3288 objetos, perfazendo uma área de 0.878 $u^{2}$, em fracção volumétrica de $4.6 \%$, como se mostra na Tabela 4.9. Resultado: 
estes dados não correspondem, realmente, aos objetos do microconstituinte AM e foram considerados objetos espúrios na quantificação, como mostra a Figura 4.38.

No segundo caso, se testou, considerando partículas pequenas as menores que $0.20 \mu \mathrm{m}^{2}$ como objetos espúrios e os resultados mostraram que $86.5 \%$ do total das partículas correspondem à tamanhos menores que $0.20 \mu \mathrm{m}^{2}$ e se apresentam como elementos espúrios. Pode-se notar, ainda, que existem partículas espúrias com tamanhos maiores que $0.20 \mu \mathrm{m}^{2}$, como se mostra na Figura 4.38(b).

$\mathrm{Na}$ terceira etapa mostra-se, considerando partículas menores que $0.40 \mu \mathrm{m}^{2}$ como elementos espúrios, se testou os resultados que não mostravam mudança abrupta. Foram consideradas, nesta faixa, 155 partículas como elementos espúrios, que correspondiam a uma diferença na fração volumétrica de $0.3 \%$, em relação ao teste anterior à tamanhos menores que $0.20 \mu \mathrm{m}^{2}$. Também foi possível observar que as partículas de AM nesta faixa, estavam sendo consideradas como elementos espúrios e, contrariamente, ainda existiam partículas espúrias que não foram consideradas, como se mostra na Figura 4.38(c).

Finalmente, foram testadas, como última alternativa, as partículas menores que $0.60 \mu \mathrm{m}^{2}$, como elementos espúrios. Os resultados mostraram que, nesta faixa, existem 62 partículas entre elementos espúrios e partículas de AM, Figura 4.38(d).

Conclui-se a faixa mais representativa de tamanho de partículas espúrias correspondem a partículas menores que $0,40 \mu \mathrm{m}^{2}$. 

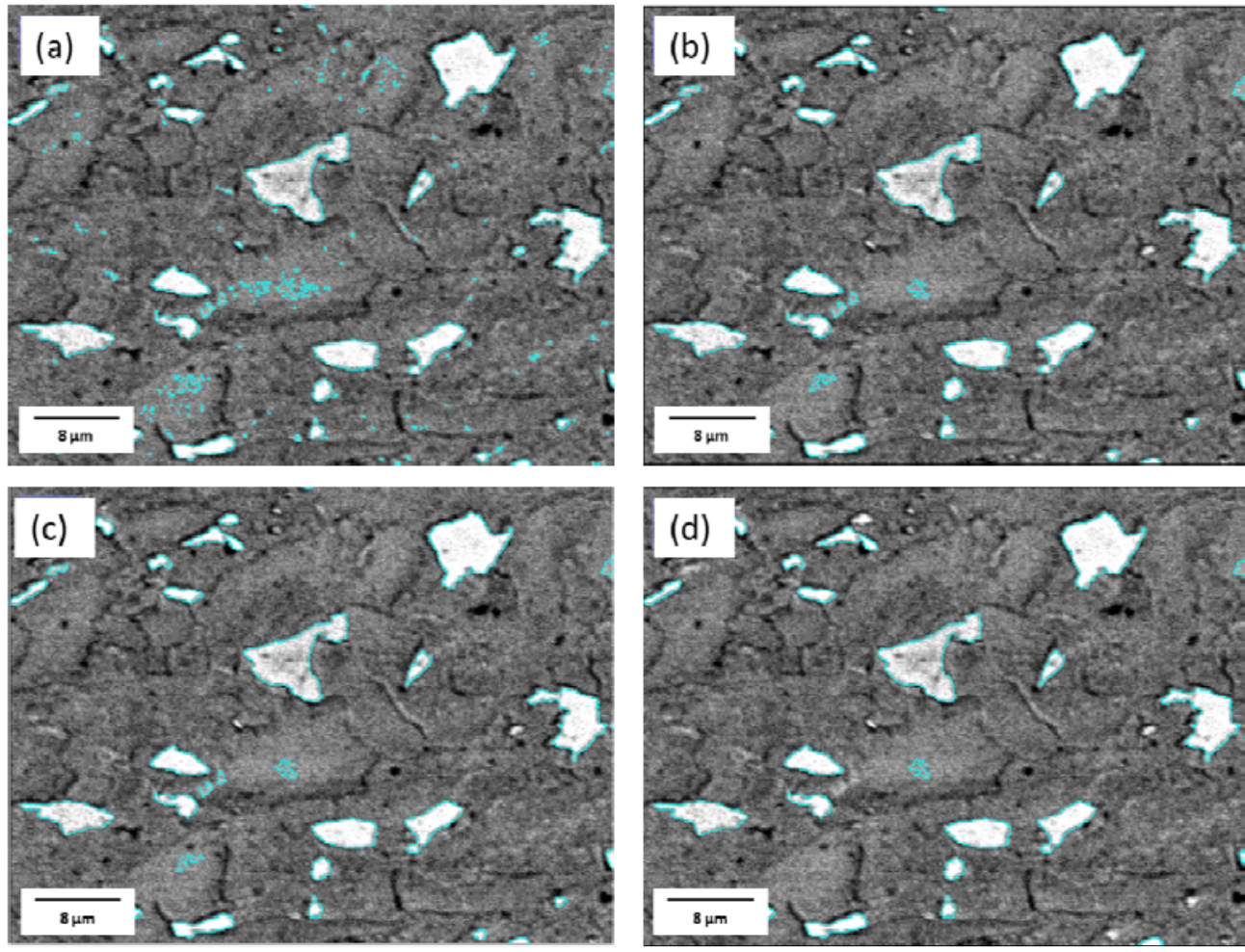

Figura 4.38 MEV (BSE) Bordas das imagens binárias superposta às imagens originais (a) Faixa extração de atributos 0 - infinito. (b) Faixa extração de atributos 0.2 - infinito. (c) Faixa extração de atributos 0.4 - infinito. (d) Faixa extração de atributos 0.6 - infinito.

Tabela 4.9 Resultados MEV(BSE), pós-processamento e extração de atributos

\begin{tabular}{c|c|c|c}
\hline $\begin{array}{c}\text { Faixa Partículas } \\
\left(\mu \mathrm{m}^{2}\right)\end{array}$ & $\begin{array}{c}\text { Número de } \\
\text { Partículas }\end{array}$ & $\begin{array}{c}\text { Área Total } \\
\left(\mu \mathrm{m}^{2}\right)\end{array}$ & $\begin{array}{c}\text { \% Fração } \\
\text { Volumétrica (\%) }\end{array}$ \\
\hline 0-infinto & 3288 & 0.878 & 4.6 \\
0.2-infinito & 450 & 0.777 & 4.1 \\
0.4-infinito & 305 & 0.723 & 3.8 \\
0.6-infinito & 243 & 0.685 & 3.6 \\
\hline
\end{tabular}

Portanto, conclui-se: o método de ataque químico misto, acrescentando um passo Lepera Modificado, no microscópio eletrônico de varredura, no modo elétrons retro espalhados (BSE) mostrou diferença expressiva de contraste entre o microconstituinte AM e as demais fases, com tensão de aceleração reduzida para 5 kV. Portanto, a quantificação do microconstituinte Austenita-Martensita (AM), por processamento digital de imagens foi viável, considerando como elementos espúrios as partículas menores que $0.4 \mu \mathrm{m}^{2}$. 


\section{3}

\section{Quantificação da Fase AM - MO e MEV}

\subsection{1}

\section{Procedimento de Registro para Microscopia Co-localizada}

Este procedimento visa visualizar campos iguais nos dois microscópios, MO e MEV, e a comparar ambas as técnicas, conforme a secção 2.5.2.

As imagens que apresentaram melhor contraste e melhor resolução em ambos os microscópios e a possibilidade de quantificação do microconstituinte Austenita-Martensita (AM), por processamento digital de imagens, foram as de ataque Misto, acrescentando um passo Lepera Modificado.

Para comparar as imagens de MO e MEV, marcas de referência foram utilizadas para identificar campos similares nos dois microscópios, seção 3.2.3.2. Foram capturadas imagens de 30 campos, no MO e de 30 campos no MEV, modo BSE, usando os procedimentos mostrados na seção 2.5.1.2. As imagens foram alinhadas para corrigir as diferenças de ampliação, translação, rotação e eventuais distorções. Para isto foi utilizada a função SIFT (Scale Invariant Feature Transform) que realiza alinhamento automático entre imagens, seção 2.6.2.1.

A Figura 4.39 e a Figura 4.40 mostram imagens de MO e MEV de um dos campos, após o alinhamento e o recorte de um sub-campo equivalente. Nota-se que foi possível obter campos idênticos, os quais permitem uma comparação quantitativa da fração de AM obtida nos dois casos.

O mesmo procedimento foi repetido para todas as imagens. 


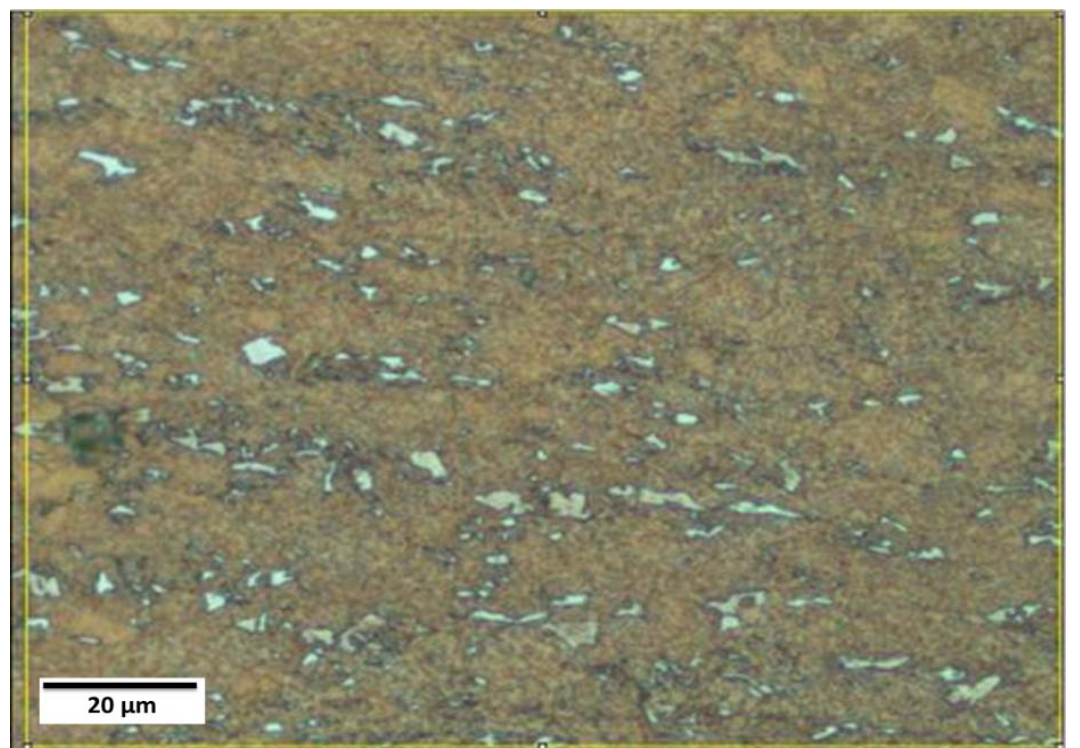

Figura 4.39 Alinhamento de imagem MO com respeito à imagem MEV (BSE), aumento 1000X.

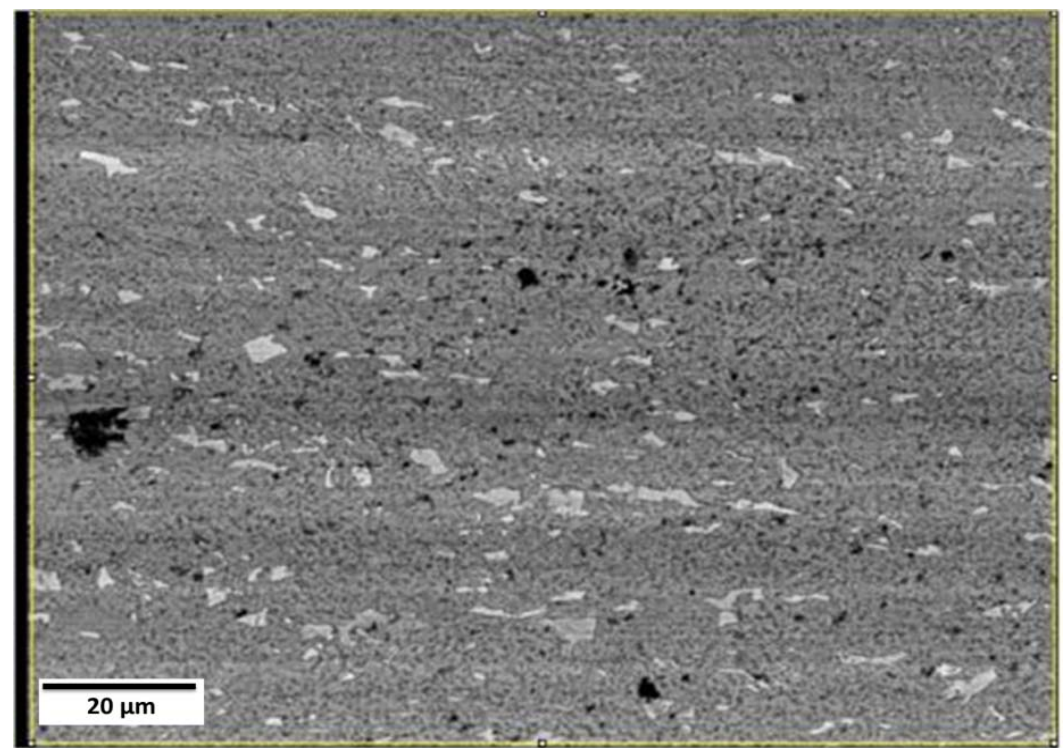

Figura 4.40 Alinhamento de imagem MEV(BSE) com respeito à imagem MO, aumento $900 \mathrm{X}$

\subsubsection{1}

\section{Quantificação do microconstituinte AM em imagens de MO}

As imagens de MO foram segmentadas usando os procedimentos da seção 4.2.1 selecionando os limiares ótimos para cada caso. A Figura 4.41 mostra o resultado de uma segmentação, com as regiões selecionadas marcadas em vermelho. A Figura 4.42 mostra os histogramas dos canais RGB para 
limiarização. Na Figura 4.43 mostra-se o resultado da limiarização, com as regiões de AM como partículas brancas em fundo escuro.

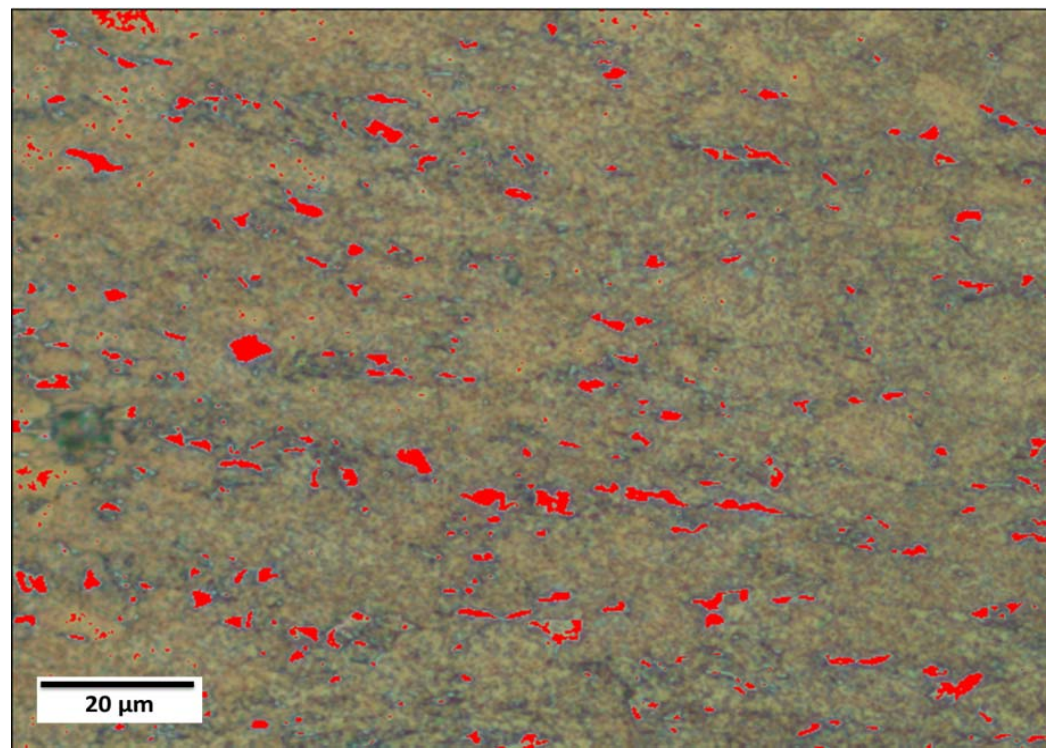

Figura 4.41 Seleção de Limiarização no espaço RGB (Red=87, Green=129, Blue=133), Imagens MO.

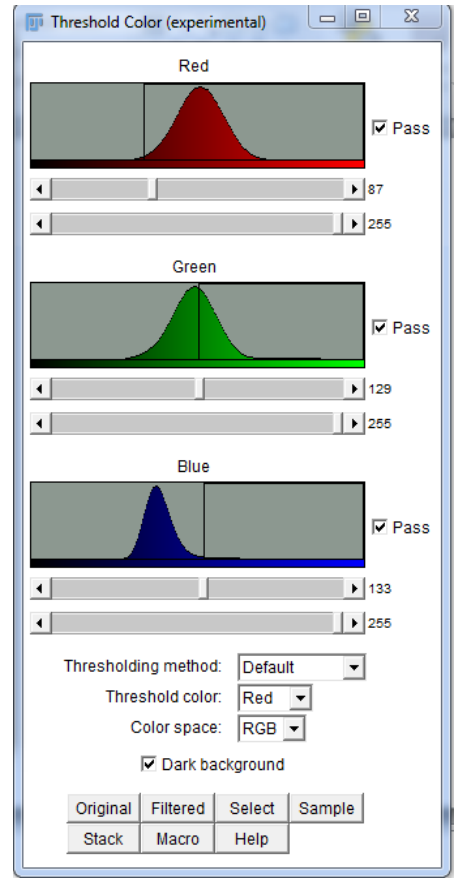

Figura 4.42 Histogramas para limiarização no espaço RGB (Red=87, Green=129, Blue=133), Imagens MO. Imagem Figura 4.41. 


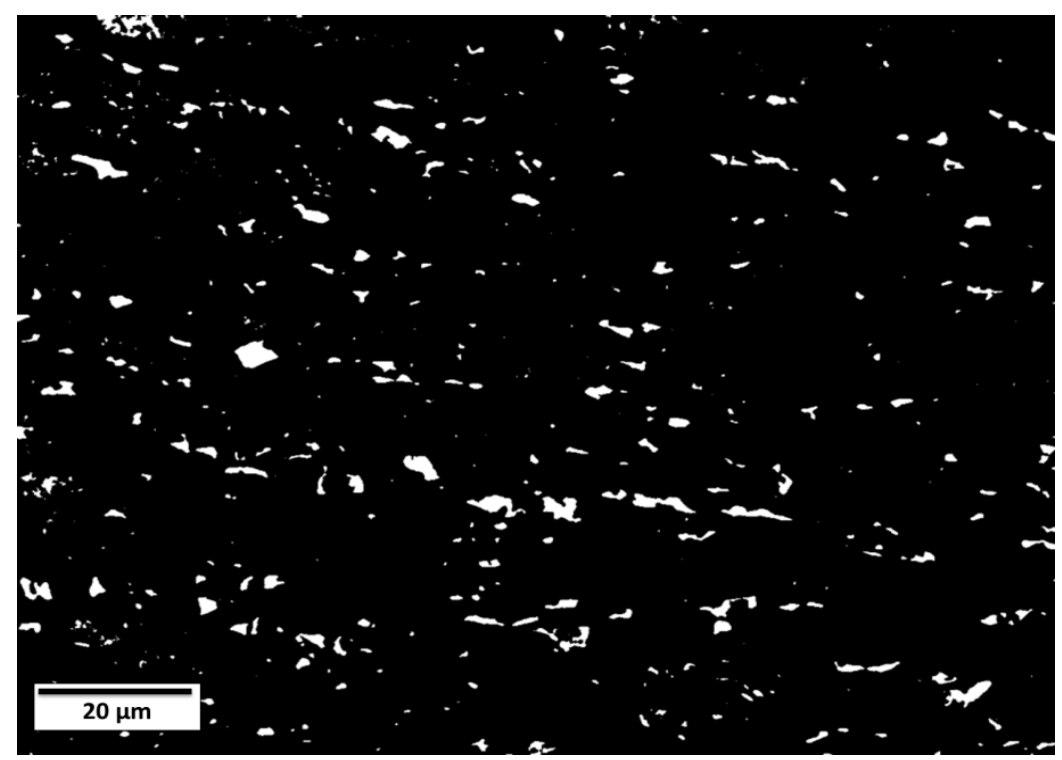

Figura 4.43 Limiarização no espaço espaço RGB (Red=87, Green=129, Blue=133), Imagens MO.

Na Figura 4.44 mostra-se o comportamento dos limiares RGB para as 30 imagens MO. Os canais R e G mostraram comportamento muito estável, mas o canal B tem comportamento mais variável, definindo as tonalidades na identificação de partículas do microconstituinte AM.

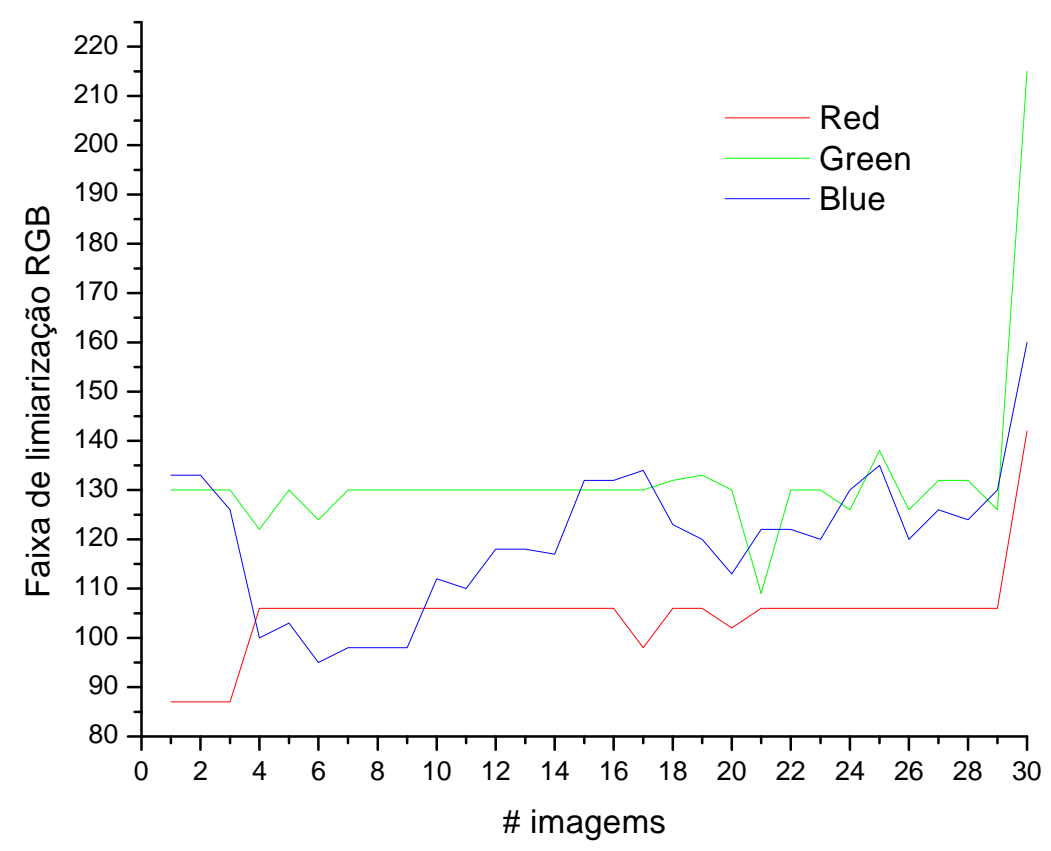

Figura 4.44 Comportamento dos tons de corte RGB em imagens MO. 
Na Figura 4.45 é apresentado o comportamento da quantidade de partículas segmentadas antes (linha preta) e depois (linha vermelha) da eliminação de partículas espúrias detalhada na seção 4.2.1. Nota-se que, sem esta eliminação a quantidade total de partículas varia fortemente entre os diversos campos, com um mínimo de 416, máximo de 2187 e média de 968 partículas, Tabela 4.10.

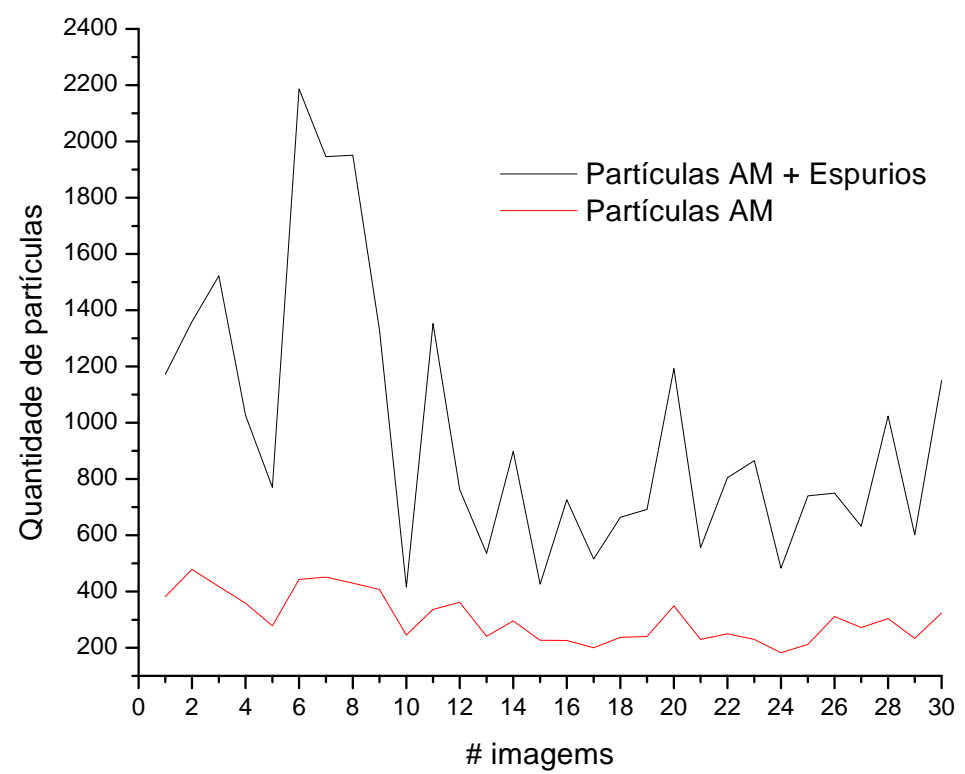

Figura 4.45 Comparação de quantidade de partículas AM + partículas espúrias em imagens MO.

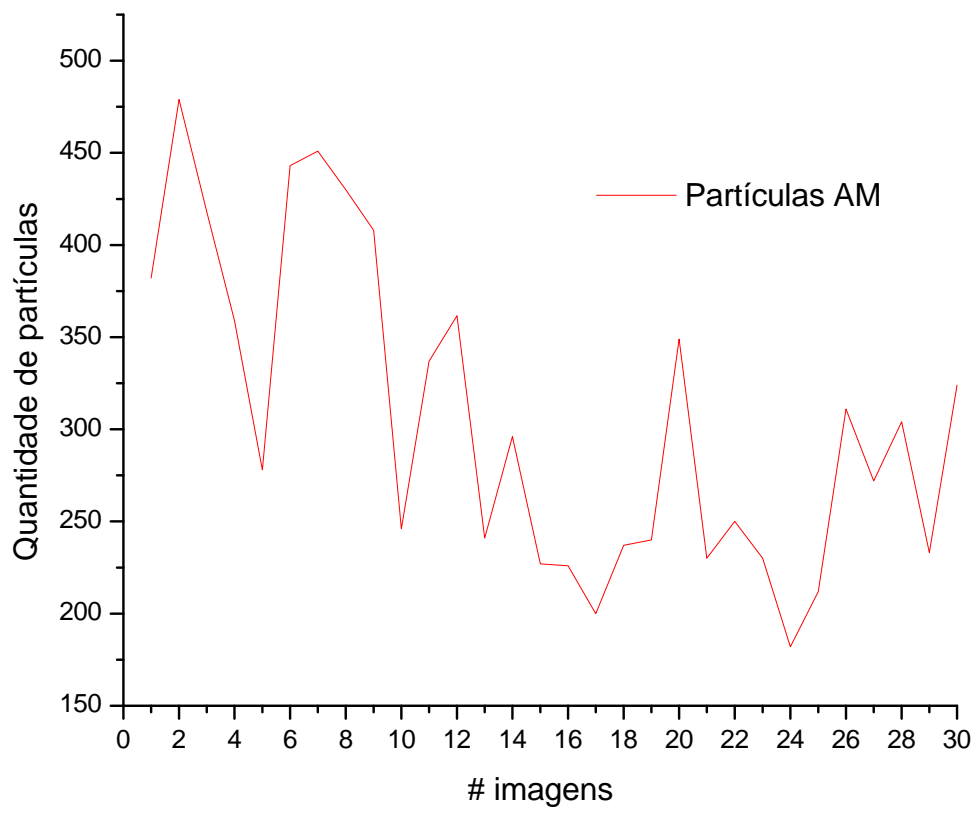

Figura 4.46 Ampliação do gráfico da quantidade de partículas de AM em imagens de MO 
Eliminando as partículas espúrias (geradas por defeitos de aquisição e processamento de imagens) esta variação é fortemente reduzida, entre 182 e 479 partículas e média de 305, ilustrada no gráfico ampliado da Figura 4.46. A Tabela 4.10 resume alguns destes valores estatísticos.

Tabela 4.10 Extração de atributos na quantificação do microconstituinte AM em MO.

\begin{tabular}{|c|c|c|c|c|c|c|}
\hline \multirow{2}{*}{$\begin{array}{l}\text { Faixa de } \\
\text { Partículas } \\
\quad\left(\mu \mathrm{m}^{2}\right)\end{array}$} & \multirow{2}{*}{$\begin{array}{l}\text { Quantidade } \\
\text { de imagens }\end{array}$} & \multicolumn{2}{|c|}{$\begin{array}{c}\text { Quantidade de } \\
\text { Partículas }\end{array}$} & \multicolumn{2}{|c|}{$\begin{array}{c}\text { Fração } \\
\text { Volumétrica (\%) }\end{array}$} & \multirow{2}{*}{ Observações } \\
\hline & & Média & $\begin{array}{l}\text { Desvio } \\
\text { Padrão }\end{array}$ & Média & $\begin{array}{l}\text { Desvio } \\
\text { Padrão }\end{array}$ & \\
\hline 0-infinito & 30 & 968.5 & 468.71 & 2.8 & 0.72 & $\begin{array}{c}\text { AM + } \\
\text { Espúrios }\end{array}$ \\
\hline 0.1-infinito & 30 & 305.2 & 85.09 & 2.7 & 0.68 & AM \\
\hline
\end{tabular}

As variações do número de partículas, no entanto, não têm efeito tão relevante sobre a fração volumétrica do AM. Isto pode ser avaliado na Tabela 4.10 e visualizado pelo gráfico da Figura 4.47. Na verdade, a grande maioria das partículas espúrias é pequena, e sua eliminação implica em uma pequena redução da fração volumétrica, de 2,8\% para 2,7\%, na média dos 30 campos.

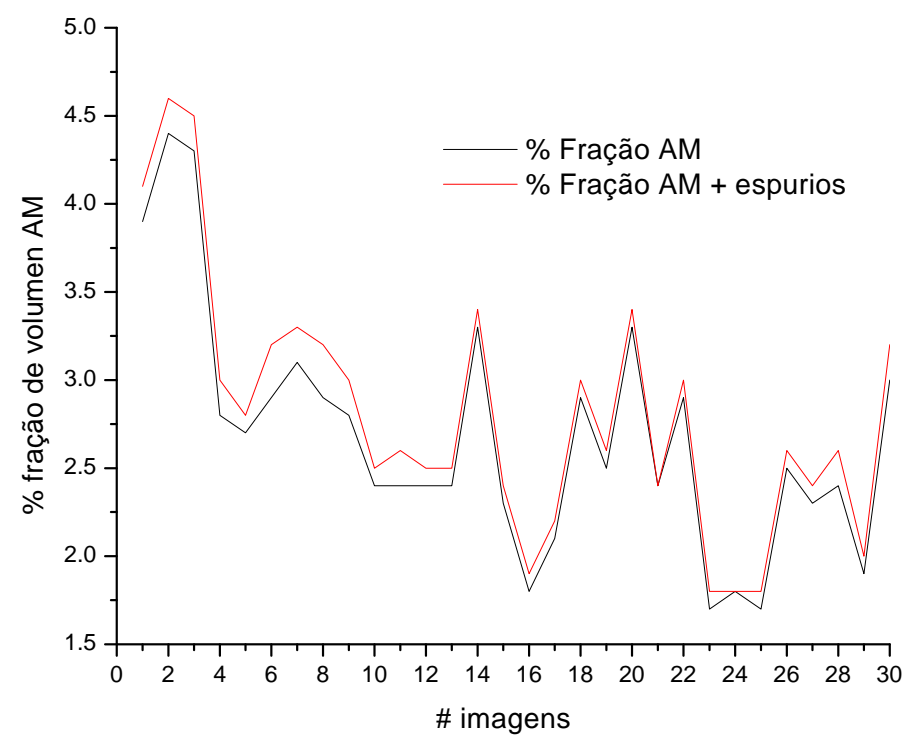

Figura 4.47 Variação da fração volumétrica de AM mantendo ou eliminando partículas espúrias pequenas em imagens MO. 
4.3.1.2

\section{Quantificação do microconstituinte AM em imagens de MEV}

As imagens MEV (BSE) foram segmentadas usando os procedimentos apresentados anteriormente, selecionando o limiar ótimo para cada campo. A Figura 4.48 mostra uns campos típicos, com os pixels selecionados marcados em vermelho.

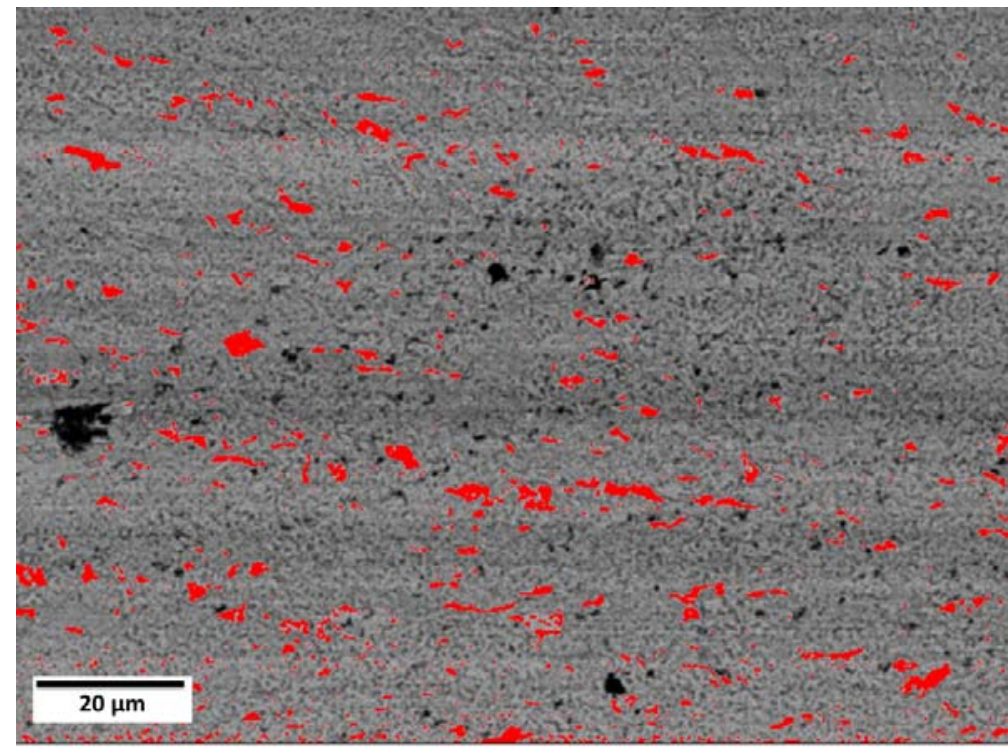

Figura 4.48 Seleção limiarização binaria imagem MEV(BSE) os pixels selecionados marcados em vermelho mostra o microconstituinte AM.

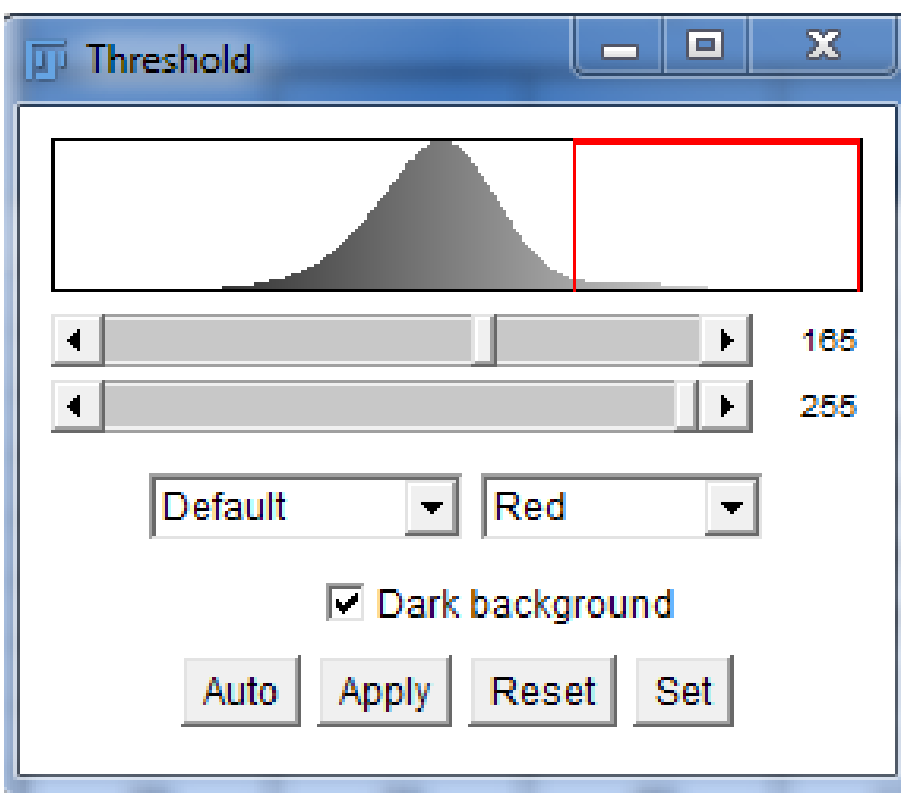

Figura 4.49 Histograma limiarização binaria imagem MEV(BSE). Limiar=165. 
A Figura 4.50 mostra-se o resultado da limiarização, com as regiões de AM como partículas brancas em fundo escuro.

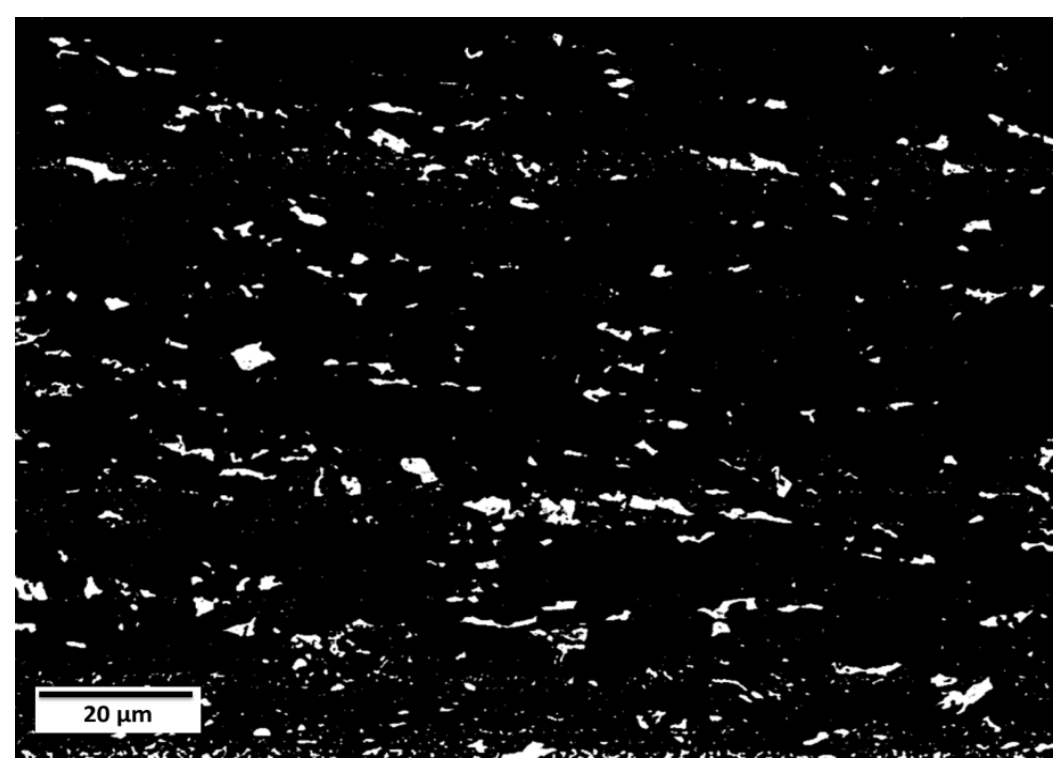

Figura 4.50 Limiarização binaria imagem MEV(BSE). Limiar=165.

A Figura 4.51 mostra a variação do limiar tonal para as 30 imagens analisadas, com tom mínimo de 160 e máximo de 215.

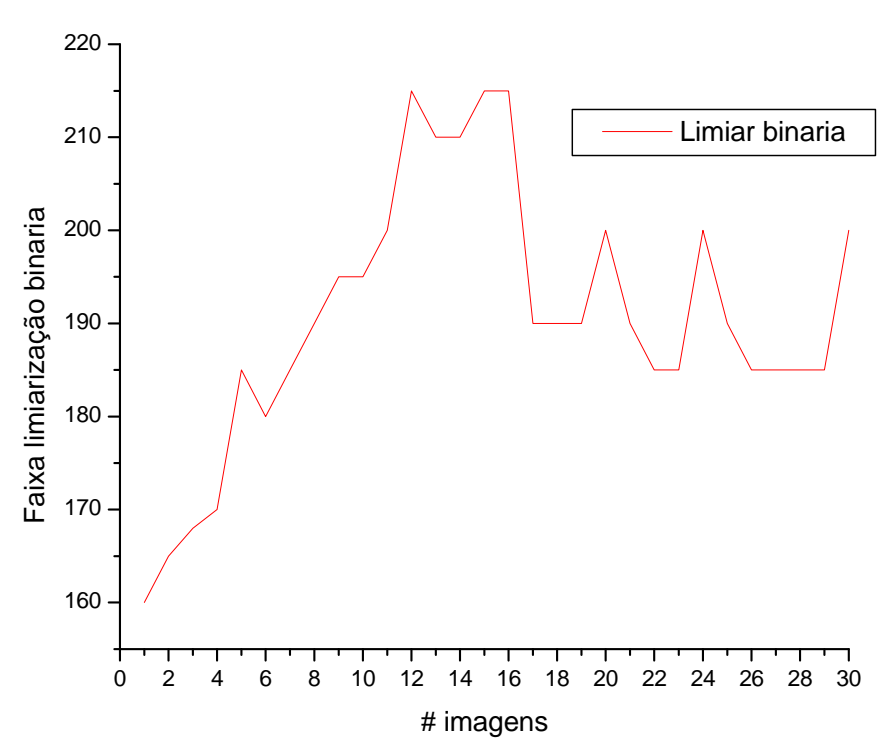

Figura 4.51 Comportamento faixa de limiarização em imagens binarias MEV. 
A mesma análise do impacto de partículas espúrias, apresentada na seção anterior para MO, foi realizada para as 30 imagens obtidas com MEV-BSE. O comportamento da quantidade de partículas é apresentado na Figura 4.52. Como as imagens de MEV apresentam mais ruído, ainda que tenham sido filtradas no processamento digital, a quantidade de partículas espúrias ainda é bastante expressiva em alguns campos. A média dos 30 campos, incluindo todas as partículas segmentadas, é de 863 partículas. Eliminando partículas menores do que $0,4 \mu \mathrm{m}^{2}$, esta média cai para 235 partículas.

A Figura 4.53 mostra uma visão ampliada do gráfico da Figura 4.52, com a variação apenas das partículas consideradas AM de fato. A Tabela 4.11 apresenta algumas estatísticas relevantes. É possível notar que, após a eliminação de partículas espúrias, o comportamento é muito mais estável.

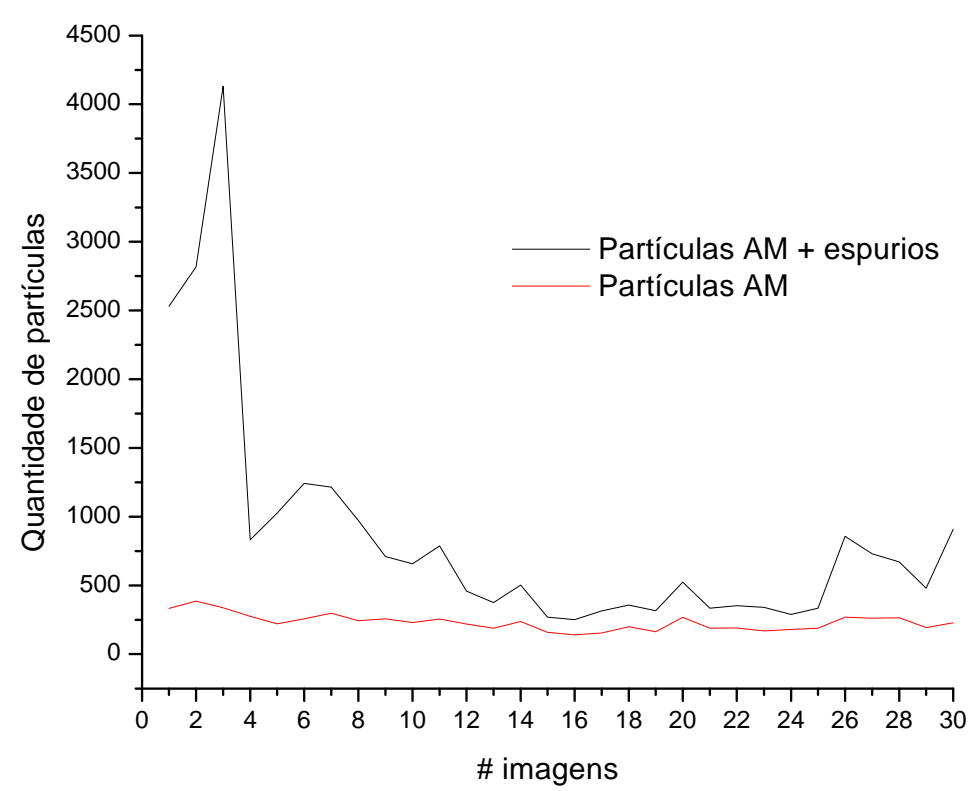

Figura 4.52 Comportamento de partículas de AM + elementos espúrios em imagens MEV. 


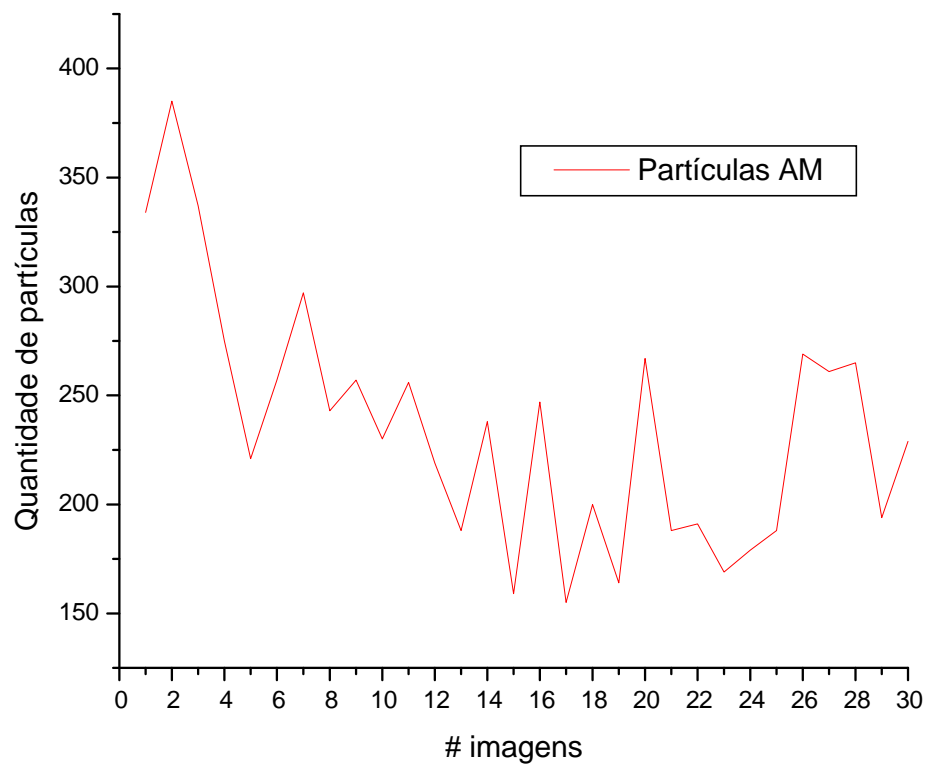

Figura 4.53 Ampliação do gráfico da quantidade de partículas de AM em imagens de MEV

Tabela 4.11 Extração de atributos na quantificação do microconstituinte AM em MEV.

\begin{tabular}{c|c|cc|cc|c}
\hline \multirow{2}{*}{$\begin{array}{c}\text { Faixa } \\
\text { Partículas } \\
\left(\mu \mathrm{m}^{2}\right)\end{array}$} & $\begin{array}{c}\text { Quantidade } \\
\text { de imagens }\end{array}$ & $\begin{array}{c}\text { Quantidade de } \\
\text { Partículas }\end{array}$ & \multicolumn{2}{|c|}{$\begin{array}{c}\text { Fração } \\
\text { Volumétrica AM } \\
(\%)\end{array}$} & \multirow{2}{*}{ Observações } \\
\cline { 3 - 5 } & & Média & $\begin{array}{c}\text { Desvio } \\
\text { Padrão }\end{array}$ & Média & $\begin{array}{c}\text { Desvio } \\
\text { Padrão }\end{array}$ & \\
\hline 0-infinito & 30 & 863 & 855 & 3,7 & 0,81 & AM + Espúrios \\
0.4-infinito & 30 & 235 & 56 & 3,3 & 0,60 & AM \\
\hline
\end{tabular}

A Figura 4.54 mostra o comportamento da fração volumétrica de AM com e sem partículas espúrias. Ainda que menos expressivas do que para o número de partículas, ainda existem campos com variações relevantes. $\mathrm{O}$ valor médio cai de $3,7 \%$ para $3,3 \%$ após a eliminação das partículas espúrias. 


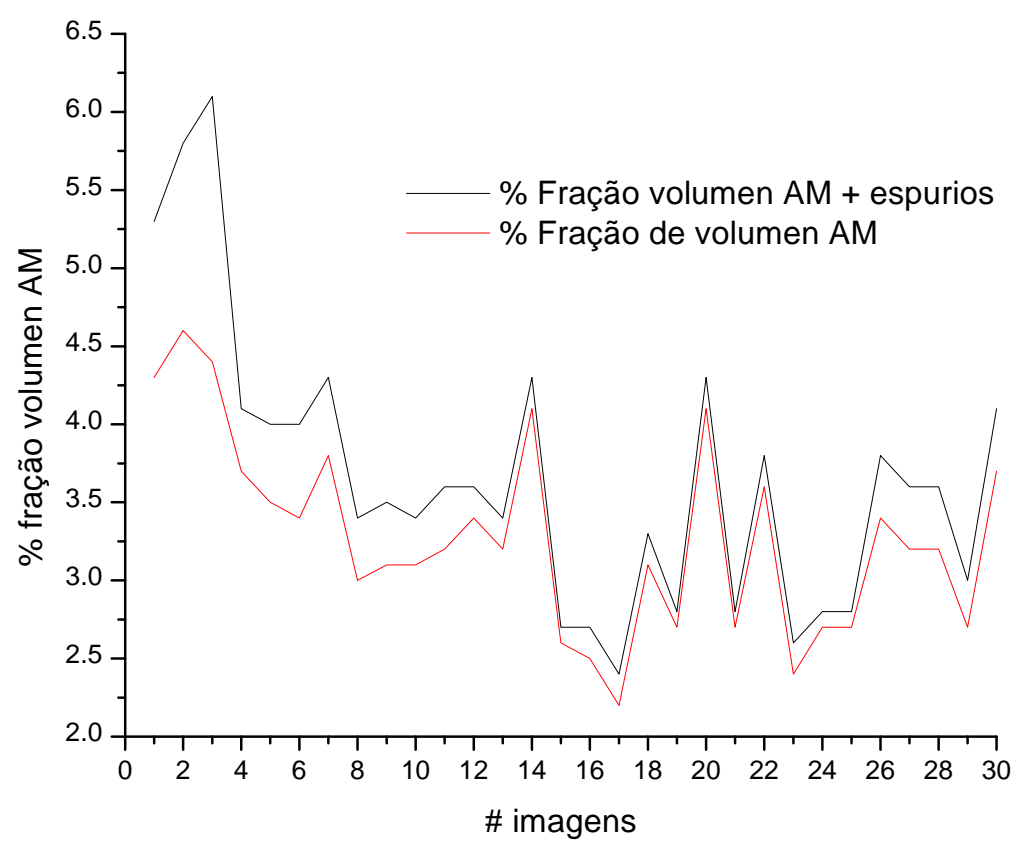

Figura 4.54 Comportamento \% fração AM em imagens MEV.

\subsubsection{3}

\section{Análise da Quantificação Co-localizada do microconstituinte AM}

Como já comentado, o procedimento de Microscopia co-localizada permite comparar campos idênticos obtidos nos dois microscópios. Assim, as imagens dos 30 campos co-localizados foram processadas e analisadas, comparando os valores de quantidade de partículas e fração volumétrica de AM, após a eliminação de partículas espúrias.

A Figura 4.55 mostra a comparação do número de partículas nas imagens de MO e MEV. O número de partículas nas imagens de MO é consistentemente maior do que nas imagens de MEV. Isto talvez possa ser explicado pela sensibilidade de segmentação colorida das imagens de MO, que depende dos limiares de 3 canais de cor. Assim, pixels espúrios podem ter cor similar a partículas do AM e são assim incluídos na segmentação. 


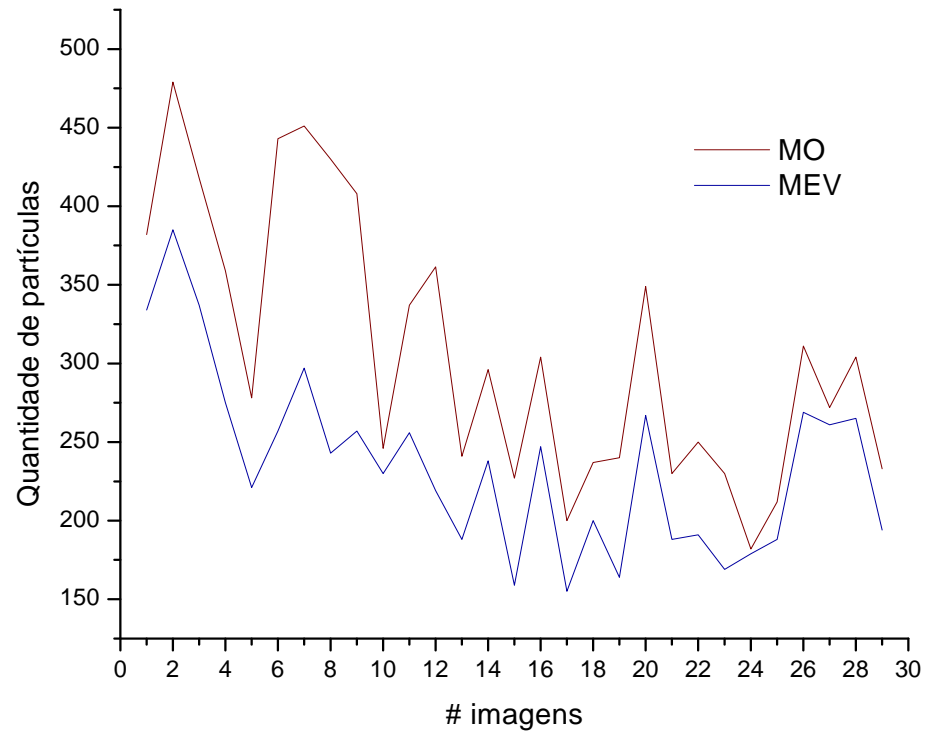

Figura 4.55 Comparação de quantidade de partículas em imagens MO-MEV.

Ao comparar os valores de fração volumétrica, Figura 4.56, um comportamento diferente fica evidente. Neste caso, o MEV fornece valores sistematicamente maiores do que o MO, ainda que uma faixa maior de tamanho tenha sido utilizada na eliminação de partículas espúrias no $\operatorname{MEV~}\left(0,4 \mu \mathrm{m}^{2}\right.$ versus $0,1 \mu \mathrm{m}^{2}$ ). O valor médio para os 30 campos é de 3,3\% para imagens de MEV e de 2,7\% para imagens de MO, uma diferença de 18\%. A Tabela 4.12 resume estes dados.

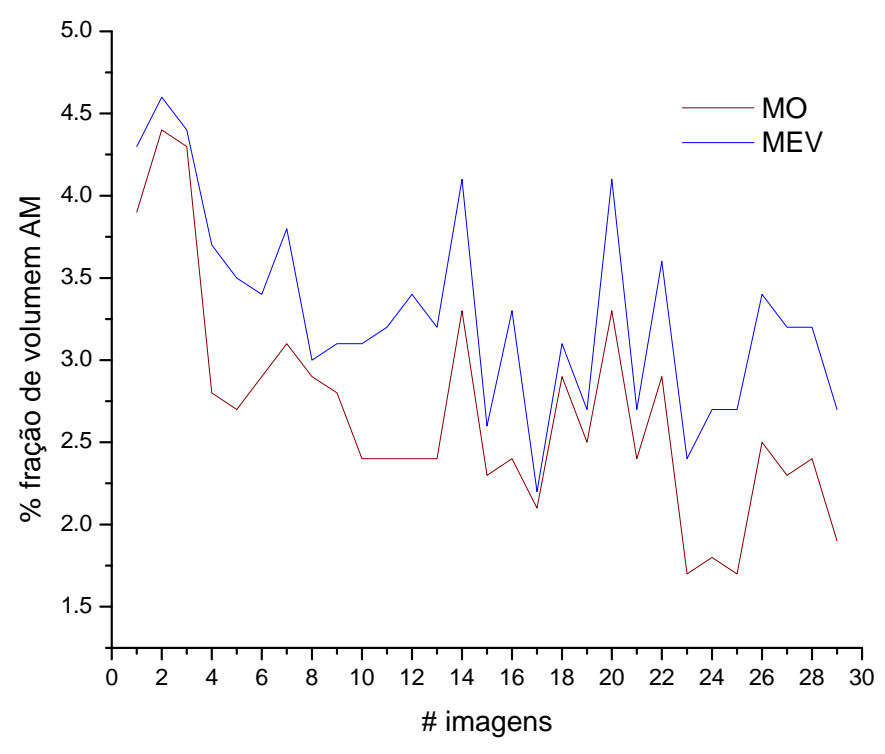

Figura 4.56 Comparação de \% fração de volumem AM em imagens MO-MEV. 
Tabela 4.12 Resultados de Analise da Quantificação Co-localizada do microconstituinte AM. (MO - MEV).

\begin{tabular}{c|c|cc|cc|c}
\hline $\begin{array}{c}\text { Faixa } \\
\text { Partículas } \\
\left(\mu \mathrm{m}^{2}\right)\end{array}$ & $\begin{array}{c}\text { Quantidade } \\
\text { de imagens }\end{array}$ & \multicolumn{2}{|c|}{ Quantidade } & \multicolumn{2}{|c|}{$\begin{array}{c}\text { \% fração } \\
\text { Partículas (Média) }\end{array}$} & \multicolumn{2}{c|}{$\begin{array}{c}\text { Volumétrica AM } \\
\text { (Média) }\end{array}$} & Observações \\
\hline 0-infinito & \multirow{2}{*}{ MO } & MEV & MO & MEV & \\
0.1-infinito & 30 & 305 & ----- & 2.7 & ----- & AM (Próprio) \\
0.4-infinito & & & 235 & & 3.3 & \\
\hline
\end{tabular}

Em outras palavras, o número de partículas medidas em MO é muito maior, mas estas ocupam fração de volume menor, indicando que as partículas foram subdimensionadas. Isto pode ser entendido analisando as imagens co-localizadas MO e MEV da Figura 4.57 e da Figura 4.58, respectivamente.

Nestas figuras, as partículas efetivamente medidas aparecem coloridas em azul claro e numeradas. As partículas eliminadas pelo filtro de tamanho aparecem como pequenos pontos vermelhos. As versões ampliadas destas imagens mostram as partículas espúrias circundadas com círculos amarelos. Já os círculos vermelhos demarcam regiões idênticas das duas imagens permitindo avaliar a detecção de partículas de AM. Fica evidente que nas imagens de MO as partículas são reduzidas em sua área e fragmentadas em partículas menores. Isto explica o comportamento da quantidade de partículas, muito maior no caso de $\mathrm{MO}$, mas levando a uma fração de volumétrica menor do que no caso de MEV. 

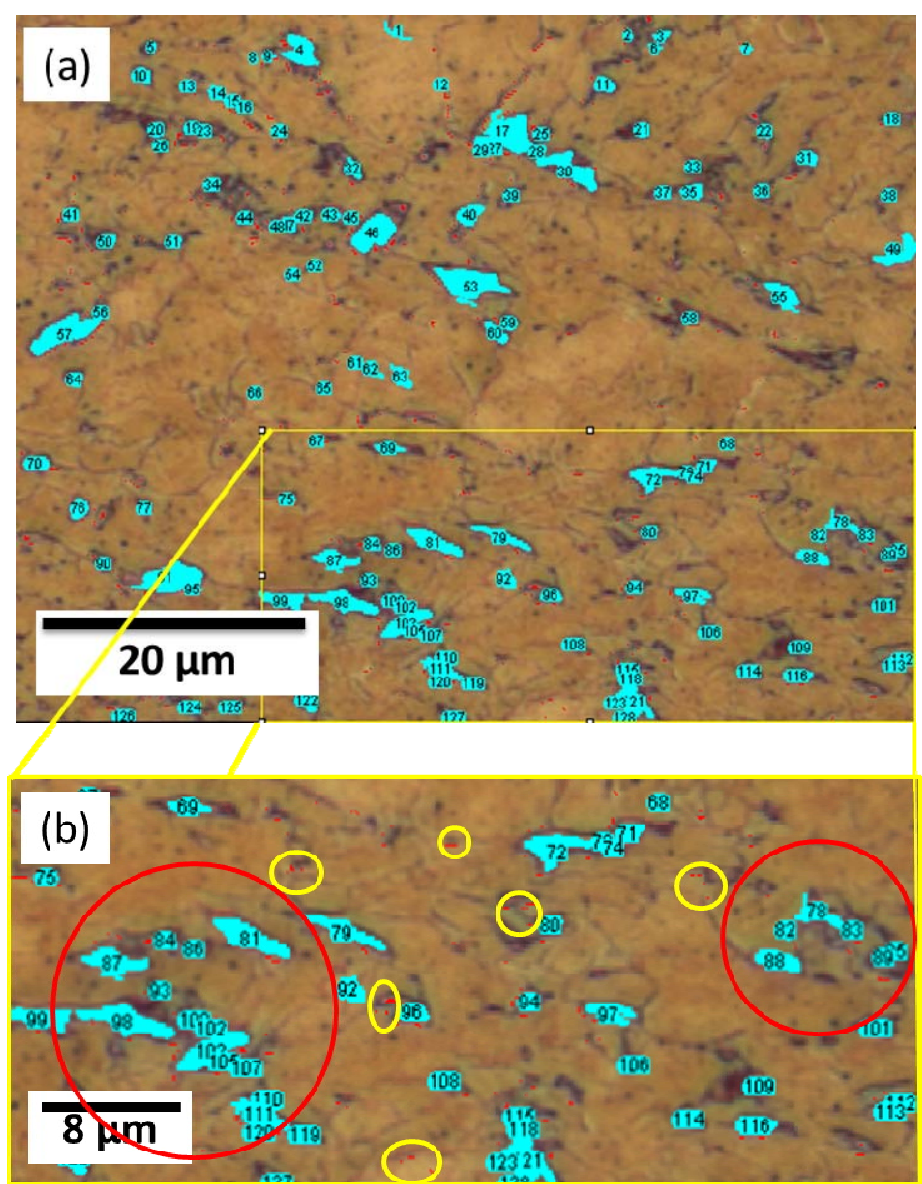

Figura 4.57 (a) Bordas das imagens binárias superpostas na imagem original MO. (b) Visão ampliada do retângulo amarelo em (a). Partículas vermelhas não foram medidas. Compare a quantidade de partículas dentro dos círculos vermelhos com a Figura 4.58b. 


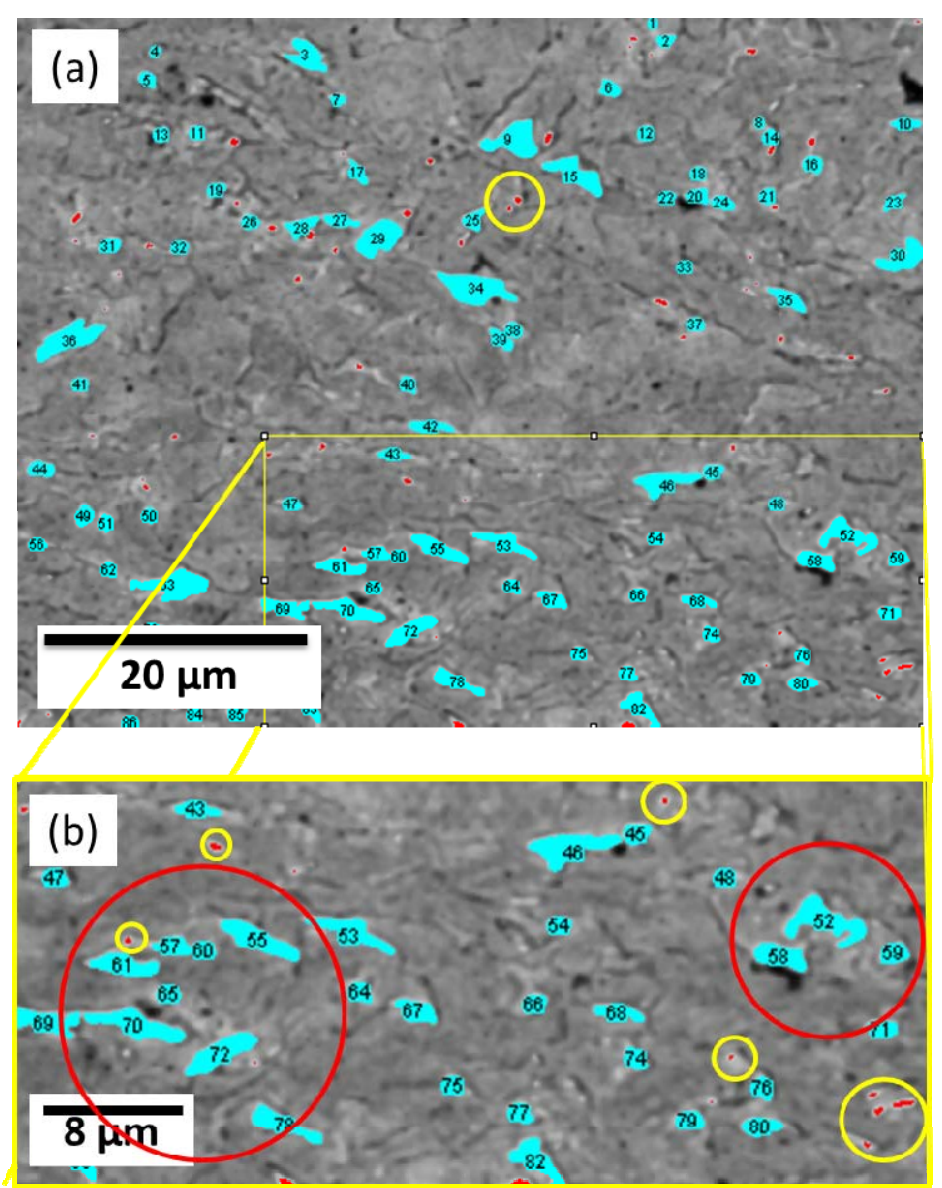

Figura 4.58 (a) Bordas das imagens binarias superpostas na imagem original MEV(BSE) (b) Visão ampliada do retângulo amarelo em (a). Partículas vermelhas não foram medidas. Compare a quantidade de partículas dentro dos círculos vermelhos com a Figura 4.57b. 


\section{Conclusões}

Foi desenvolvida uma metodologia adequada para identificação e quantificação do microconstituinte Austenita-Martensita (AM) em aços de alta resistência baixa liga (ABRL). Esta metodologia utiliza ataque químico específico para otimizar o contraste do AM, tanto em MO quanto em MEV. Rotinas de Análise Digital de Imagens foram desenvolvidas para quantificar automaticamente o microconstituinte. A microscopia co-localizada foi utilizada, com sucesso, para comparar os resultados dos dois tipos de microscópio.

Especificamente

- A metodologia proposta de ataque químico misto, acrescentando um passo Lepera modificado, gerou uma melhora acentuada do contraste em imagens de MO e de MEV no modo BSE.

- Em imagens MEV(BSE) obteve-se aumento de contraste trabalhando com tensão de aceleração reduzida para $5 \mathrm{kV}$.

- Com a técnica de microscopia co-localizada foi possível comparar as imagens de campos idênticos, obtidos por MO e MEV, tanto qualitativa, quanto quantitativamente. $\mathrm{O}$ uso da função SIFT (Scale Invariant Feature Transform) que realiza alinhamento automático entre imagens foi essencial para obter os mesmos campos MO e MEV.

- Os resultados de microscopia co-localizada da quantificação de 30 imagens mostraram fração de volume do microconstituinte AM no MEV(BSE) sempre superior a MO. Ficou evidente que as imagens de MO apresentam resolução pior do que as imagens de MEV no mesmo aumento, o problema e a formação da imagem. Isto implicou em medidas subestimadas da fração de volume de AM. 


\section{Referências bibliográficas}

[1] Gorni, Augusto Antonio, Dolabela da Silveira, José Herbert e de Sousa Reis, Jackson Soares. Metalurgia dos Aços Microligados Usados na Fabricação de Tubos Soldados com Grande Diâmetro. 2009. 5, pp. 52-63.

[2] Davis, C. L. e King, J. E. Effect of Cooling Rate on Intercritically Reheated Microstructure and Toughness in High Strength Low Steel. January de 1993. Vol. Vol.9, pp. pp. 8-15. Materials Science and Tecnology.

[3] Yakubtsov, I. A., Poruks, P. e Boyd, J. D. Microstructure and mechanical properties of bainitic low carbon high strength plate steels. Materials Science and Engineering A 480 (2008) 109-116.

[4] Almeida Halfeld Vieira, Adriana. Avaliação Microestrutural de Aços da Classe API5LX80 Submetidos a Diferentes Ciclos Térmicos. 2007. Dissertação (Mestrado) - Pontifícia Universidade Católica do Rio de Janeiro.

[5] Rodrigo de Lima Lessa, Cleber. Soldagem FHPP - Processo e Metalurgia nas Transformações das Fases de um Aço C-Mn. Dissertação (Mestrado) Universidade Federal do Rio Grande do Sul, 2011.

[6] da Costa e Silva, André Luiz V. e Mei, Paulo Roberto. Aços e Ligas Especiais. Editora Blucher Ltda. 3a edição- 2010 - Brasil.

[7] Hillenbrand, H. G. e Heckmann, C. J. X80 Line Pipe for LargeDiameter High Strength Pipelines.

[8] Gray, J. M. e Fazakerley, W. J. 37th Annual Conf. of Metallur - gists, AB, Canada. 1998. pp. 1-31. August 16-19, CIM, Canada.

[9] Hillenbrand, H. G. e Kalwa, C. High Strength Line Pipe for Project Cost Reduction. Jan./Feb. de 2002. World Pipelines, Vol. 2 No. 1.

[10] Grimpe, F., et al., et al. Development, Production and Application of heavy Plates in Grades Up to X120. 1st International Conference Super-High Strength Steels - November 2-4, 2005, Rome, Italy .

[11] Bott, Ivani de Souza. Tendencias e Inovações em Aços. Agosto de 2008. Associação Brasilera de Metalurgia e Materiais. 
[12] LiYing, LI, et al., et al. Embritlement and toughening in CGHAZ of ASTM4130 stell. Science China, August 2011 Vol.54 No.8: 1447-1454..

[13] Okada, H., et al., et al. Metallographic investigation of M-A constituent Deterioration and improvement of HAZ toughness in 780 and 980 MPa class HSLA steels welded with high heat inputs (2nd report). Welding International, Volume 8, Issue 11, 1994, 886-892..

[14] Matsuda, F. Li, et al., et al. An Investigation on the bahaviour of the A-M Constituent in Simulated HAZ of HSLA Steels. 1991. Vol. Vol. 29, No 910, pp. 307 - 313. Welding in the World.

[15] GHASEMI BANADKOUKI, S.S. e DUNNE, D. P. Formation of Ferritic Products during Continuous Cooling of a Cu-bearing HSLA Steel. ISIJ International, Vol. 46 (2006), No. 5, pp. 759-768.

[16] Biss, V. e Cryderman, R.L. Martensite and Retained Austenite in Hot-Rolled Low-Carbon Bainitic Steels. 2267-2276, 1971, Vol. 2..

[17] Ikawa, Hiroshi, Oshige, Hiroaki e Tanoue, Toyoaki. Effect of Martensite-Austenite Constituent on HAZ Toughness of a High Strength Steel. Transactions of the Japan Welding Society, Vol. 11, No 2, October 1980.

[18] Bott, Ivani de Souza, et al., et al. High-Strength Steel Development for Pipelines: A Brazilian Perspective. Metallurgical and Material Transactions. Vol. 36A, p443-454, February 2005.

[19] Lepera, F. S. Improved Etchnique for the Determination of Percent Martensite in High-Strength Dual-Phase Steels. Metallography 12: 263-268 (1979).

[20] Alé, R. M., Revello, J. M.A. e Charlier, J. A Metallographic Technique for Detecting Martensite-Austenite Constituents in the Weld HeatAffected Zone of a Micro-alloyed Steel. Elsevier Science Inc., 1996 Materials Characterization 37:89-93. Materials Characterization 37:89-93 - Elsevier Science., 1996.

[21] Elisei, C.C.A., et al., et al. Utilização de Metalografia Colorida na Identificação dos Microconstituintes de um Açõ Microligado. 17 CBECIMat Congresso Brasilero de Engenharia e Ciência dos Materiais, 15 a 19 de Novembro de 2006, Foz do Iguaçu, PR, Brasil.. 
[22] Pereira, M. S., Garcia, P. E.L. e Hashimoto, T. M. Metallographic Procedure to Microstructural Characterization of a Multiphase Steel Applied to Pipelines Industry by Optical Microscopy. Microscopy Society of America 2002.

[23] de Araujo Silva, Rafael. Correlação entre parâmetros de curvamento por indução de tubo API X80 e propriedades mecânicas e microestruturais. Dissertação de Mestrado - Pontificia Universidade Católica do Rio de Janeiro 2009.

[24] Paciornik, Sidnei e Henrique de Pinho Mauricio, Marcos. Digital Imaging. Department of Materials Science and Metallurgy - Catholic University of Rio de Janeiro.

[25] Paciornik, Sidnei. Microscopia Quantitativa. MET 2433. Notas de aula. DCMM/PUC-Rio. Disponível em: <http://www.dcmm.pucrio.br/cursos/micquant/>. Acesso em: 05 ago. 2012 ..

[26] Cesar, Álvarez Iglesias Julio. Uma Metologia para Caracterização de Sinter de Minério de Ferro: Microscopia Digital e Analise de Imagens. 2008. Dissertação (Mestrado) - Pontificia Universidade Catolica do Rio de Janeiro..

[27] Gomes, O. F. M. Microscopia Co-Localizada: Novas Possibilidades na Caracterização de Minérios. 2007. p. 103p. Tese de Doutorado - Departamento de Ciência dos Materiais e Metalurgia - Pontificia Universidade Catolica do Rio de Janeiro..

[28] Glasbey, C. A. e Martin, N. J. Multimodal microscopy by digital image processing. Journal of Microscopy, v. 181, n. 3, p. 255-237, 1996..

[29] Jones, M. P. Applied mineralogy: a quantitative approach. London (UK): Graham and Trotman Ltd., 1987.

[30] Soto, O. A. J., et al., et al. Native Copper Analysis through Digital Microscopy. In Applied Mineralogy: Developments in Science Technology, v.2, p. 1043-1046. International Congress on Applied Mineralogy (ICAM 2004), Aguas de Lindóia, 2004.

[31] Russ, J. C. The Image Processing Handbook. 5th ed. CRC Boca Raton, 2006..

[32] Paciornik, S. Processamento Digital de Imagens. Notas de aula 2012DEMA- PUC-Rio, www.dema.puc-rio.br/cursos/ipdi/index.html .

[33] Mikolajczyk, K. e Schimid, C. Scale \& Affine Invariant Interest Point Detectors. International Journal of Computer Vision 60(1), 63-86, 2004. 
[34] Lowe, D. G. Distinctive Image Features from Scale-Invariant Keypoints. International Journal of Computer Vision, 2004.

[35] Assis da Silva, Francisco. Georreferenciamiento automatico de placas de sinalização com imagens obtidas com um sistema movel de mapeamento. Tese de Doutorado: Departamento de Engenharia Eletrica: Universidade de Sâo Paulo. 2012.

[36] Gonzalez, R. C. e Woods, R. E. Digital Image Processing. Ed. 2. Upper Saddle River (NJ, USA): Prentice-Hall, $2002 .$.

[37] Amar , K. D., Speer, J. G. e Matlock, D. K. Color Tint - Etching for Multiphase Steels. Advanced materials \& Processes - February 2003..

[38] Colpaert, Hubertus e da Costa e Silva, André Luiz V. Metalografia dos Produtos Siderúrgicos Comuns. Editora Edgard Blucher Ltda. 4a edição 2008 São Paulo - Brasil.

[39] Anazawa, R. M., et al., et al. Efeitos dos tratamentos intercriticos e isotermicos sobre as propriedades mecânicas e a microstrutura no aço $300 \mathrm{M}$. Revista Brasiliera de aplicações de Vácuo, v. 25, n2, 93 - 97, 2006.

[40] Ferreira, Tiago e Rasband, Wayme. ImageJ User Guide IJ $1.45 \mathrm{~m}$. December 2011.

[41] Siciliano, F. Materiais para gasodutos aços de alta resistência para dutos de transporte de gás e petróleo- tendencias atuais. Metalurgia e Materiais, v. 64, p.208-211.maio de 2008. 


\section{Apêndice}

\section{Apêndice 1}

Sequência de Alinhamento de Imagens: uso de software FIJI

\section{Microscopia co-localizada - Imagens MEV-MO}

1. Carga imagem MO

2. Carga imagem MEV

3. Cria um stack (imagen/stack/image to stack), que vai conter MO, MEV (opção keep sourse imagens para preservar a MO colorida).

a. Use titles as labels.

b. Keep sourse images.

c. Ok.

4. Navega no stack para mostrar MO

5. Usar plugins/registration/linear stack alignment with sift/align stack:

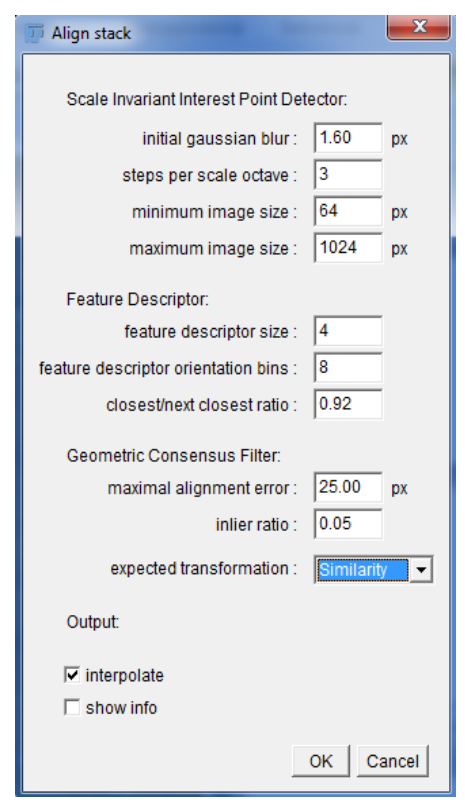

6. Usa a ferramenta de seleção retangular para definir uma ROI equivalente sobre as duas camadas do stack, usando a imagem de MEV, girada como referencia.

7. Separa as imagens MO e MEV com imagem/stack/stack to imagem.

8. Recupera ROI retangular com CRT $+\mathrm{SHITF}+\mathrm{E}$, executando em cada imagem. O mais importante executar sobre MO (colorida) e MEV (já alinhado) 


\section{Apêndice 2}

Programa 1: Uso software FIJI

1 //Macro analise imagens e quantificação do microconstituinte AM no MEV co-localizada

2 imagens=newArray("001MEV","002MEV","003MEV"," 004MEV","005MEV","006MEV","007MEV","008MEV", "009MEV","010MEV","011MEV","012MEV","013MEV", "014MEV","015MEV","016MEV","017MEV","018MEV", "019MEV","020MEV","021MEV","022MEV","023MEV", "024MEV","025MEV","026MEV","027MEV","028MEV", "029MEV","030MEV");

$3 \quad / /$ bucle para analise 30 imagens

4 for $(\mathrm{i}=0 ; \mathrm{i}<30 ; \mathrm{i}++)\{$

$5 \quad$ //endereço das imagens

6 direccion $=$ "C: $\backslash \backslash$ tessis de mestrado $\backslash$ Imagens $\backslash$ imagens Finales $\backslash \backslash M E V(c)$ Co-Localizada - copia $\backslash "$;

7 direccionfinal $=$ direccion + imagens $[\mathrm{i}]+$ ".tif";

$8 \quad$ write(direccionfinal);

9 open(direccionfinal);

10 newname = imagens [i]+".tif";

11 title $=$ "title="+newname ;

12 run("Duplicate...", title);

13 // redução de ruido - aplicação filtro sigma

14 run("Sigma Filter Plus", "radius=2 use=2 minimum=0.2 outlier");

15 // Etapa de segmentação

16 setAutoThreshold("Default dark");

17 / /run("Threshold..."); seleção do limiar ótimo

18 setThreshold(170, 255);

19 run("Convert to Mask");

20 // Escala de medição unit="um"

21 run("Set Scale...", "distance=1280 known=141.9 pixel=1 unit=um");

22 run("Set Measurements...", "area perimeter area_fraction display redirect=["+newname+"] decimal=3"); 
23 //Quantificação: tamanho de partículas (size $=0.0$ - Infinity),(size $=$ 0.40 - infinity);

24 run("Analyze Particles...", "size=0.0-Infinity circularity $=0.00-1.00$ show=Nothing display include summarize add");

25 roiManager("Show All with labels");

26 roiManager("Show All"); 


\section{Apêndice 3}

Programa 2: Uso software FIJI

1 //Macro analise imagens e quantificação do microconstituinte AM no MO co-localizada

2 imagenes=newArray("001MO","002MO","003MO","004MO", "005MO","006MO","007MO","008MO","009MO","010MO", "011MO","012MO","013MO","014MO","015MO","016MO", "017MO","018MO","019MO","020MO","021MO","022MO", "023MO","024MO","025MO","026MO","027MO","028MO", "029MO","030MO");

$3 \quad / /$ bucle para analise 30 imagens

4 for $(\mathrm{x}=0 ; \mathrm{x}<30 ; \mathrm{x}++)\{$

$5 \quad$ //endereço das imagens

direccion $=$ "C: $\backslash \backslash$ tessis de mestrado\IImagens $\backslash$ imagens Finales $\backslash \backslash M O(c)$ Co-Localizada - copia $\backslash "$;

7 direccionfinal $=$ direccion + imagenes $[\mathrm{x}]+$ ".tif";

$8 \quad$ write(direccionfinal);

$9 \quad$ open(direccionfinal);

10 newname $=$ imagenes $[\mathrm{x}]+$ ".tif";

11 newname $=$ imagenes $[\mathrm{x}]+"-\mathrm{n}+\mathrm{x}+1+$ ".tif";

12 title $=$ "title $=$ "+newname ;

13 run("Duplicate...", title);

14 //Etapa de segmetação colorida RBG

15 run("Color Threshold...");

16 // Color Thresholder 1.46r

17 // Autogenerated macro, single images only!

$18 \min =$ newArray $(3)$;

$19 \max =$ newArray(3);

20 filter=newArray(3);

$21 \quad \mathrm{a}=\operatorname{getTitle}()$;

22 run("RGB Stack");

23 run("Convert Stack to Images");

24 selectWindow("Red"); 


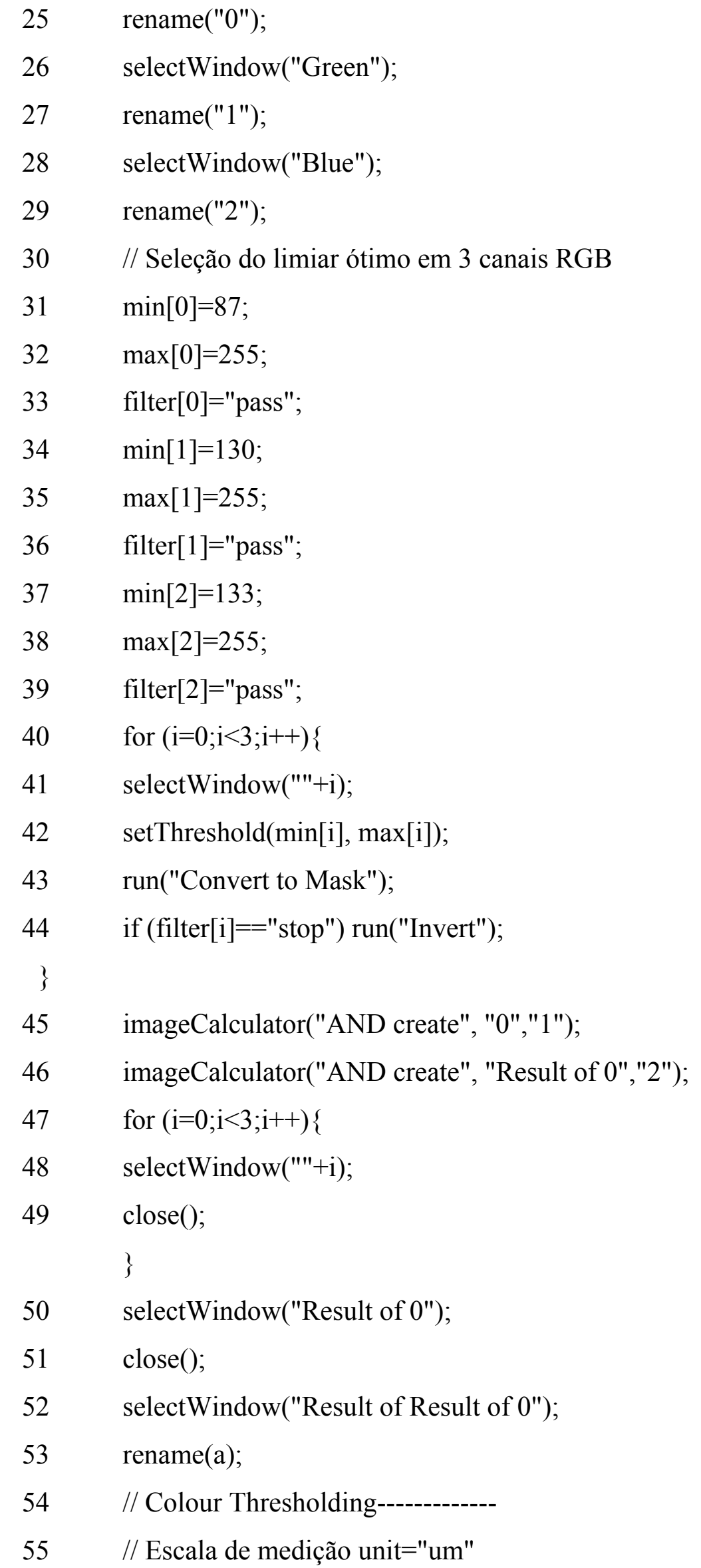


56 run("Set Scale...", "distance=1280 known=141.9 pixel=1 unit=UM");

57 run("Set Measurements...", "area perimeter area_fraction display redirect $=["+$ newname $+"]$ decimal=3");

58 //Quantificação: tamanho de partículas (size = 0.0- Infinity),(size = 0.40 - infinity);

59 run("Analyze Particles...", "size=0.0-Infinity circularity $=0.00-1.00$ show $=[$ Overlay Masks] display include summarize add");

60 roiManager("Show All with labels");

61 roiManager("Show All"); \} 